STATE OF OHIO

DEPARTMENT OF NATURAL RESOURCES

DIVISION OF GEOLOGICAL SURVEY Horace R. Collins, Chief

Report of Investigations No. 113

\title{
CHEMICAL COMPOSITION, STRATIGRAPHY, AND
}

\section{DEPOSITIONAL ENVIRONMENTS OF THE BLACK RIVER GROUP}

\section{(MIDDLE ORDOVICLAN), SOUTHWESTERN OHIO}

by

David A. Stith 


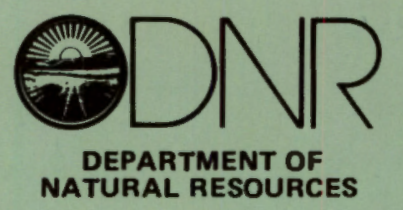

\title{
SCIENTIFIC AND TECHNICAL STAFF OF THE DIVISION OF GEOLOGICAL SURVEY
}

\author{
ADMINISTRATION \\ Horace R. Collins, MS, State Geologist and Division Chief \\ Richard A. Struble, PhD, Geologist and Assistant Chief \\ William J. Buschman, Jr., BS, Administrative Geologist \\ Barbara J. Adams, Office Manager
}

\section{REGIONAL GEOLOGY}

Robert G. Van Horn, MS, Geologist and Section Head

Richard W. Carlton, PhD, Geologist

Douglas L. Crowell, MS, Geologist

Richard M. DeLong, MS, Geologist

Michael C. Hansen, MS, Geologist

David A. Hodges, MS, Geologist

Dennis N. Hull, MS, Geologist

Michele L. Risser, BA, Geologist

Clark L. Scheerens, MS, Geologist

Joel D. Vormelker, MS, Geologist

Vanessa Tolliver, BS, Laboratory Technician

\section{GEOCHEMISTRY LABORATORY}

David A. Stith, MS, Geologist and Section Head

George Botoman, MS, Geologist

Norman F. Knapp, PhD, Chemist

Steven F. Kullman, BS, Laboratory Technician

\section{LAKE ERIE}

Charles H. Carter, PhD, Geologist and Section Head

Jonathan A. Fuller, MS, Geologist

Donald E. Guy, Jr., BA, Geologist

Carl L. Hopfinger, MS, Geology Technicien

Dale L. Liebenthal, Research Vessel Operator

Marlene S. Longer, Typist

\section{SUBSURFACE GEOLOGY}

Ftank L. Majchszak, MS, Geologist and Section Head

J. Scott Dailey, BA, Geologist

John D. Gray, MS, Geologist

Floyd M. Honeycutt, MS, Geologist

Richard H. Kingsbury, Jr., MS, Geologist

Michael T. Abele, AAS, Geology Technician

Martin L. Bretz, BA, Geology Technician

John C. Hadley, BGS, Geology Technician

Nina Hawranick, BS, Environmental Technician

David A. Nicklaus, BS, Geology Technician

Jerry M. Parks, BS, Geology Technician

James Wooten, Geology Technician

Garry E. Yates, Environmental Technician

Angelena M. Bailey, Secretary

Brenda L. Rinderle, Office Machine Operator

\section{TECHNICAL PUBLICATIONS}

Cartography

Philip J. Celnar, BFA, Cartography Supervisor

James A. Brown, Cartographer

Leonard M. Guckenheimer, BA, Cartographer

Victor J. Saylor, BA, Cartographer

Robert L. Stewart, Cartographer

Photocopy Composition Jean M. Lesher, Printing Technicion

Technical Editing

Merrianne Hackathorn, MS, Geologist/Editor

Sue Ellen Shear, BA, Geologist/Editor

\section{PUBLIC SERVICE}

Madge R. Fitak, BS, Geologist and Supervisor

Michael S. Temple, BS, Geologist

Inalee E. Johnson, Public Inquiries Assistant

Beverly A. Leffler, Public Inquiries Assistant

Rose Lehman, Technical Typist

Billie Wilder, Clerical Specialist 
STATE OF OHIO

DEPARTMENT OF NATURAL RESOURCES

DIVISION OF GEOLOGICAL SURVEY

Horace R. Collins, Chief

Report of Investigations No. 113

CHEMICAL COMPOSITION, STRATIGRAPHY, AND

DEPOSITIONAL ENVIRONMENTS OF THE BLACK RIVER GROUP

(MIDDLE ORDOVICIAN), SOUTHWESTERN OHIO

by

David A. Stith 


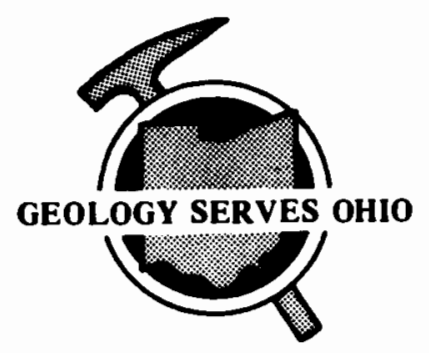




\section{CONTENTS}

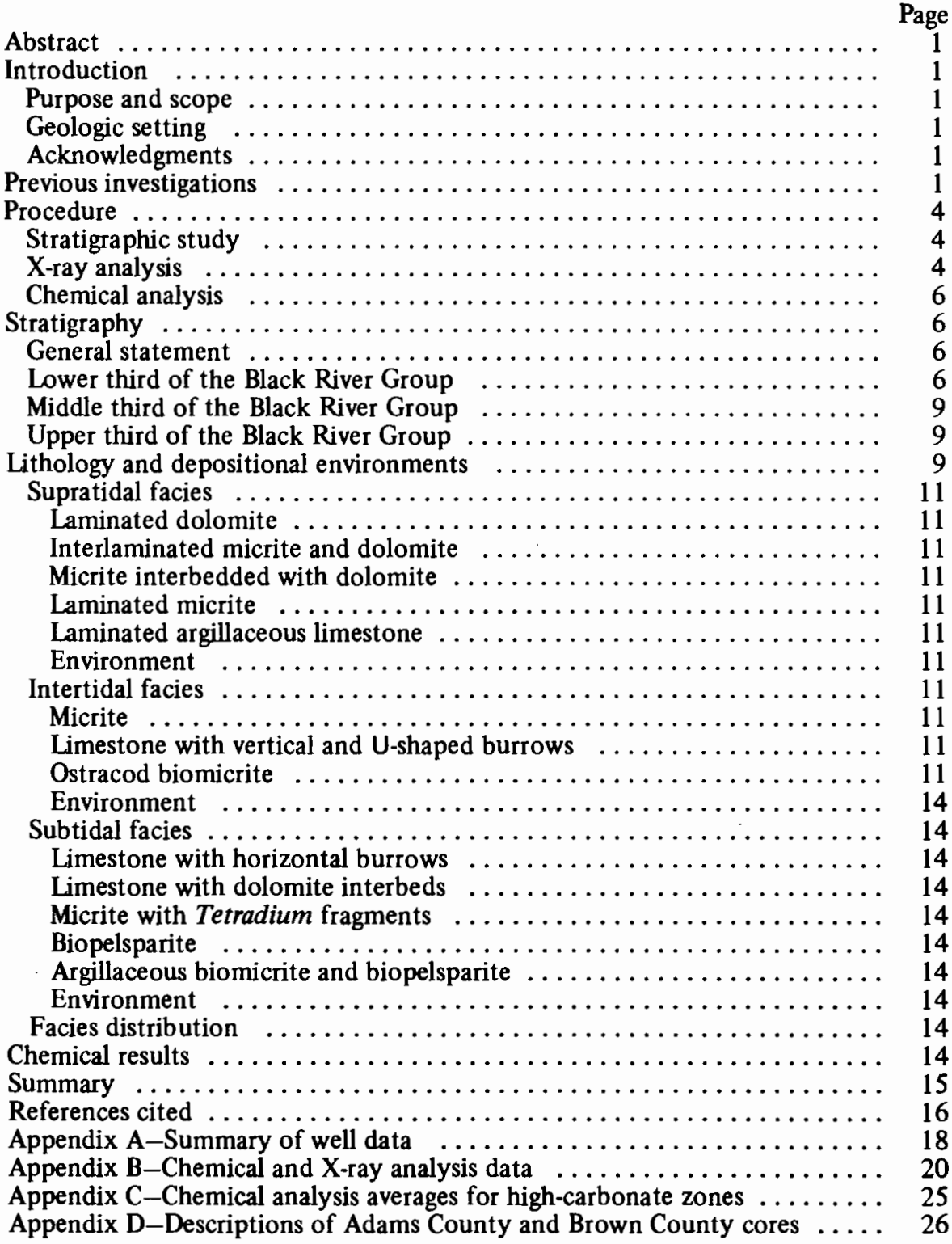

\section{FIGURES}

1. Study area and well locations $\ldots \ldots \ldots \ldots \ldots \ldots \ldots \ldots \ldots \ldots \ldots \ldots$

2. Comparison of gamma ray-neutron logs of basal Black River Group-Knox Dolomite section of Calvert (1962), Carpenter (1965), and this study . .

3. Thickness of Carntown unit

4. Thickness of rock between marker bed $a$ and top of the Carntown

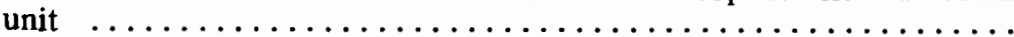

5. Elevation of top of the Carntown unit $\ldots \ldots \ldots \ldots \ldots \ldots \ldots$

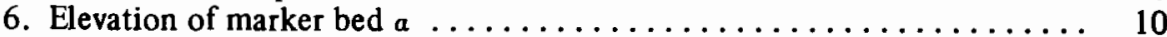

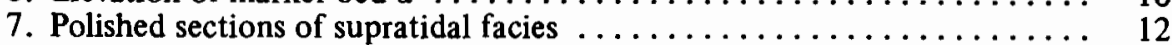

8. Polished sections of intertidal and subtidal facies $\ldots \ldots \ldots \ldots \ldots \ldots$ 


\section{CONTENTS}

\section{TABLES}

2. Depth to top of Carntown unit in Ohio wells $\ldots \ldots \ldots \ldots \ldots \ldots \ldots \ldots \ldots \ldots \ldots$

3. Character of marker beds, upper part of the Black River Group . . . . . . . . . 9

4. Gamma-ray neutron logs showing apparent very low dolomite rock in the

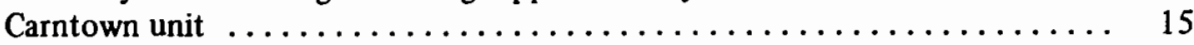

\section{PLATES}

1. Geophysical-log cross section of the Black River Group from Union County, Indiana, to Fayette County, Ohio . ...................... In pocket

2. Geophysical-log and core cross section of the Black River Group from Boone County, Kentucky, to Adams County, Ohio ................... In pocket

3. Environmental interpretations of Adams County and Brown County cores .. In pocket 


\title{
CHEMICAL COMPOSITION, STRATIGRAPHY, AND DEPOSITIONAL ENVIRONMENTS OF THE BLACK RIVER GROUP (MIDDLE ORDOVICIAN), SOUTHWESTERN OHIO
}

\section{by \\ David A. Stith}

\begin{abstract}
The chemical composition and stratigraphy of the Black River Group in southwestem Ohio were studied. Chemical analyses were done on two cores of the Black River in Adams and Brown Counties, Ohio. These studies show that substantial reserves of high-carbonate rock $(96$ to $98+$ percent $\mathrm{CaCO}_{3}$ plus $\mathrm{MgCO}_{3}$ ) are present in the Black River at depths of less than 800 feet, in proximity to Cincinnati and the Ohio River.

Stratigraphic studies show that the Black River Group has eight marker beds in its middle and upper portions and three distinct lithologic units in its lower portion; these marker beds and units are present throughout southwestern Ohio. The Black River Group correlates well with the High Bridge Group of Kentucky. Depositional environments of the Black River are very similar to those of the High Bridge and to present-day tidal flats in the Bahamas.
\end{abstract}

\section{INTRODUCTION}

\section{PURPOSE AND SCOPE}

Surface deposits of high-purity carbonate rock are scarce in southwestern Ohio. Although mining is generally more expensive than quarrying, the lack of surface deposits requires the consideration of possible subsurface sources. The most likely subsurface source of carbonate rock in southwestern Ohio is the Black River Group (Middle Ordovician). The Black River correlative, the High Bridge Group, is quarried in central Kentucky and is mined near Carntown and Maysville, Kentucky, along the Ohio River.

This report presents the results of an investigation of the stratigraphy of the Black River Group in southwestern Ohio and of a chemical study of Black River high-carbonate zones. Forty-one geophysical logs and three cores from Ohio were examined along with several logs from adjacent parts of Indiana and Kentucky (fig. 1; Appendix A). The interpretation of the geophysical logs was done in conjunction with examination of drill cuttings from most of the wells and with a detailed lithologic study of the three cores. Mineralogy was determined by X-ray diffraction studies (Appendix B) on cores from Adams and Brown Counties, Ohio. Detailed chemical analyses (Appendixes B, C) were done on probable high-carbonate zones indicated by the X-ray study of the two cores. Rock with greater than 95 percent $\mathrm{CaCO}_{3}$ is termed high calcium, and rock with greater than 95 percent total carbonates, $\mathrm{CaCO}_{3}$ plus $\mathrm{MgCO}_{3}$, is termed high carbonate.

\section{GEOLOGIC SETTING}

The Black River Group in Ohio is overlain by the Trenton Limestone and underlain by the Wells Creek Formation. In Indiana the correlative units, in ascending order, are the Chazyan, the Black River Limestone, and the Trenton Limestone (pl. 1) (L. E. Becker, written commun., 1976). In Kentucky the correlative of the Black River is the High Bridge Group, overlain by the Lexington Limestone and underlain by the Wells Creek Dolomite. The High Bridge Group is composed of, in ascending order, the Camp Nelson Limestone, the Oregon Formation, and the Tyrone Limestone (pl. 2) (Dever, 1974).

Because this study began as a chemical study of the Black River Group and is restricted to southwestem Ohio, formal subdivision of the group is not proposed. On an informal basis the Black River has three distinct units in the lower portion and eight distinctive marker beds that extend across the entire study area (pls. 1,2). These units are, in ascending order, the lower argillaceous unit, the Carntown unit, the upper argillaceous unit, and marker beds II, I, b, a, $\Delta, \gamma, \beta$, and $a$.

\section{ACKNOWLEDGMENTS}

The author would like to express his appreciation for discussions of the Black River Group and its correlatives to L. E. Becker of the Indiana Geological Survey, G. R. Dever, Jr., of the Kentucky Geological Survey, W. C. Sweet of the Department of Geology and Mineralogy, Ohio State University, and Max Warner formerly of MCQ Industries, Inc., Columbus, Ohio. Sulfur and phosphorus analyses were done by the author. Major and minor element chemical analyses were done in part by the author and in part by E. Lorraine Thomas.

\section{PREVIOUS INVESTIGATIONS}

Calvert (1962) gives an extensive review of the development of sub-Trenton terminology in Ohio. He correlates the 


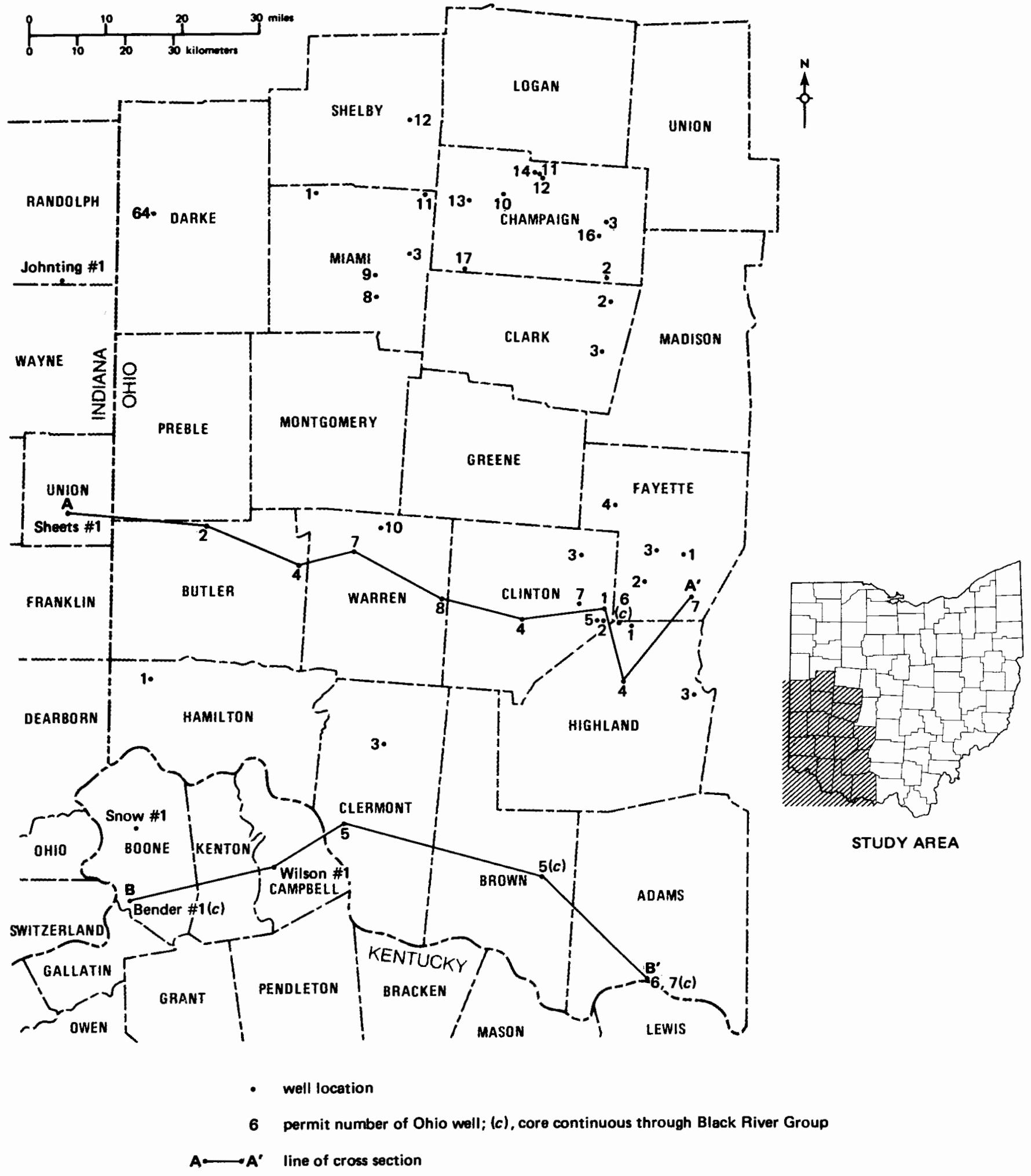

FIGURE 1.-Study area and well locations. Lines of cross sections in plate 1 (A-A') and plate 2 (B-B') also shown. 


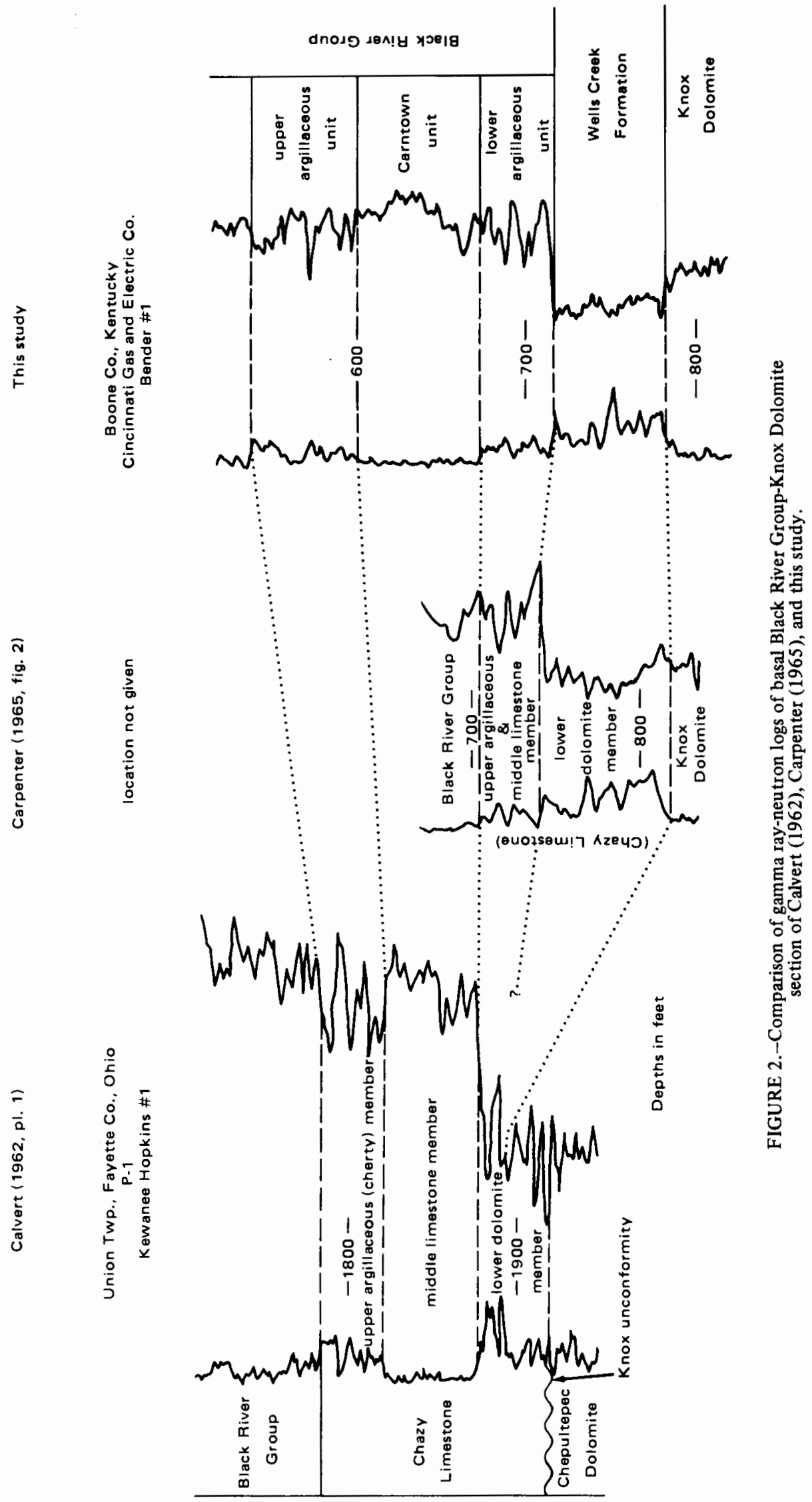


sub-Trenton rocks of Ohio with the outcrop in western Virginia by means of geophysical logs and commercial sample descriptions. Unfortunately, the one gamma rayneutron $\log$ he illustrates from southwestern Ohio is from a well, the Kewanee Hopkins \#1, drilled on a high point of the Knox unconformity. All the stratigraphic section normally present from the basal Black River Group to the Knox Dolomite is absent in this well. Use of Calvert's log as a type illustration gives an erroneous picture of the stratigraphy between the Carntown unit as defined in this study (fig. 2) and the Knox in southwestern Ohio and adjacent Indiana and Kentucky. The problem is further compounded by Calvert's use of Virginia outcrop lithologies for text descriptions of Chazy Limestone members and by his incorrect location of the top of the Knox in the Kewanee Hopkins \#1 well. No chert was found in the upper argillaceous unit, and the top of the Knox Dolomite is at 1,893 feet on the gamma ray-neutron $\log$ of the Kewanee Hopkins \#1, not at 1,920 feet as Calvert indicates (fig. 2).

Huff (1963) studied the mineralogy of the Middle Ordovician bentonites in southwestern Ohio and northcentral Kentucky but made no stratigraphic correlations.

Carpenter (1965) studied the lower dolomite member of the Chazy Limestone in northern Kentucky and adjacent Ohio and Indiana. He apparently misinterpreted Calvert's work because of the missing section in Calvert's illustration. Carpenter assigns the upper argillaceous and middle limestone members of the Chazy to the upper part of the section (lower argillaceous unit, this study) generally present in northern Kentucky and southwestern Ohio (fig. 2) but which is missing from Calvert's illustration. The lower dolomite member is assigned to the lower part of the section (Wells Creek Formation) normally found in this region (fig. 2). The units that Calvert assigned to the upper and middle Chazy are referred to as the Black River Group by Carpenter.

Levine (1971), in an article describing a new lime plant at the Carntown, Kentucky, mine, reports a typical chemical composition for the 34 feet of limestone being mined in the lower part of the Black River Group. This analysis shows a high-calcium limestone, 95.1 percent $\mathrm{CaCO}_{3}$ and 3.8 percent $\mathrm{MgCO}_{3}$. The mine is in Calvert's middle Chazy Limestone (Max Warner, oral commun., 1972), the Carntown unit of this study.

Votaw (1972) studied the conodonts of the type Black River Group and correlative strata from New York to Iowa and from Ontario to Tennessee. He gives an extensive summary of the development of Black River terminology for the eastern midcontinent. There are discrepancies among Votaw's text, tables, and figures, and he ignores lithology in at least one core (Mason County, Kentucky). Nevertheless, his data for the Mason County core, which is near Brown County, Ohio, indicate that all the rock from the base of the Lexington Limestone down at least to the top of the Wells Creek Formation is Black Riveran in age (W. C. Sweet, oral commun., 1977).

Dever (1974) lists core descriptions and foot-by-foot chemical analyses of the portion of a core from basal Lexington Limestone to upper Knox Group from southwestern Boone County, Kentucky (fig. I). He reports several zones of high-carbonate rock in this core, particularly in the lower part of the Camp Nelson Limestone.

Cressman and Noger (1976) studied in detail the surface exposures of the High Bridge Group in central Kentucky.
Their study shows that the Tyrone, Oregon, and uppermost Camp Nelson Formations were deposited in extensive tidal-flat environments similar to present-day Bahamas and Florida Bay environments.

\section{PROCEDURE}

\section{STRATIGRAPHIC STUDY}

The stratigraphic study of the Black River Group involved two phases: (1) a detailed investigation of the lithology of the Black River in three cores in Adams (S-2405), Brown (S-2507), and Highland (S-2499) Counties, Ohio, and (2) correlation of certain beds and units by use of drill cuttings and geophysical logs, primarily gamma rayneutron logs. All oil wells within the study area with available geophysical logs were used (fig. 1). The core study (Appendix D) was done on split core and 10 polished sections with a binocular microscope. Approximately 25 thin sections were studied with a petrographic microscope.

\section{X-RAY ANALYSIS}

Samples of the Black River Group were taken every foot in the Adams County and Brown County cores. These samples were crushed, pulverized to -80 mesh, and combined into 5-foot composites. Samples for X-ray diffraction analysis were taken from the composites. Approximately $0.45 \mathrm{~g}$ of sample was mixed with sufficient reagent-grade $\mathrm{CaF}_{2}$ as an internal standard to produce a mixture of 75 percent sample and 25 percent standard. The mixture was ground for 10 minutes in a SPEX mill and then made into a powder pack following a modification of the method described by McCreery (1949). The powder was backfilled into a standard aluminum holder placed on a glass slide and was tamped with the edge of a spatula; the excess was then scraped off with a razor blade. A glass slide was taped over the back of the holder with no further pressure applied to the powder. Quantitative analyses were made using a Norelco DCP control panel and diffractometer. The dataaccumulation technique used was the discrete preset time mode (total counts accumulated while scanning across the mineral diffraction peak). The count-accumulation time was determined for each peak based on peak width and goniometer scanning speed. Table 1 gives the $\mathrm{X}$-ray settings used. Background-corrected mineral-to-fluorite intensity

TABLE 1.-X-ray settings

\begin{tabular}{|c|c|c|c|c|}
\hline Mineral & $d \AA$ & $\{\mathrm{hkl}\}$ & $\begin{array}{c}\text { Degrees } 2 \theta \\
\text { start }\end{array}$ & $\begin{array}{c}\text { Counting time } \\
\text { (sec.) }\end{array}$ \\
\hline Background & & & 25.00 & 30 \\
\hline Quartz & 3.343 & $\{101\}$ & 26.30 & 30 \\
\hline Fluorite & 3.153 & $\{111\}$ & 27.55 & 75 \\
\hline Calcite & 3.035 & $\{211\}(\{10.4\})$ & 28.80 & 72 \\
\hline Dolomite & 2.89 & $\{211\}(\{10 \cdot 4\})$ & 30.20 & 78 \\
\hline Background & & & 32.00 & 30 \\
\hline
\end{tabular}

\begin{tabular}{l|l|l|l}
\hline Goniometer speed & $1^{\circ} 2 \theta / \mathrm{min}$ & Pulse-height analyzer & Integral, 285 \\
Radiation & $\mathrm{Cu}, \mathrm{Ka}$ & Time constant & 0.5 sec. \\
Filter & $\mathrm{Ni}$ & Receiving slit & .006 inch \\
Power & $35 \mathrm{kv}, 20 \mathrm{ma}$ & & \\
\hline
\end{tabular}




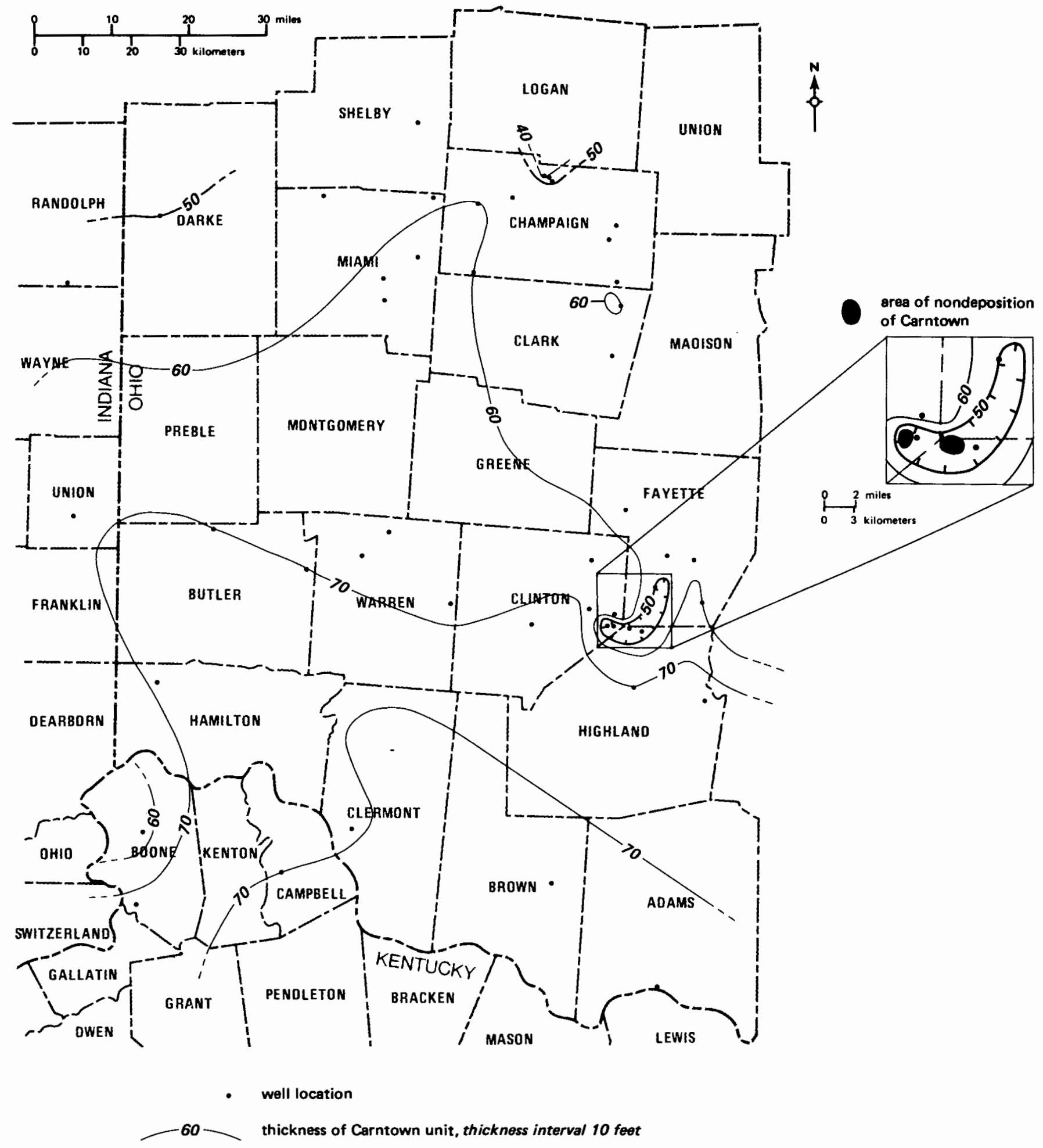

FIGURE 3.-Thickness of Carntown unit. 
ratios $I_{\boldsymbol{Q}} / \mathrm{I}_{\mathbf{F}}, \mathrm{I}_{\boldsymbol{C}} / \mathrm{I}_{\mathbf{F}}$, and $\mathrm{I}_{\mathbf{D}} / \mathrm{I}_{\mathbf{F}}$ were computed and percentages of quartz, calcite, and dolomite in the sample were determined from standard-mixture curves.

Samples of some well cuttings from a well in Greene County (S-290) and a short core in Fayette County (S-751) were analyzed in a similar manner.

\section{CHEMICAL ANALYSIS}

Chemical analyses were done on zones indicated as high carbonate by the X-ray study of the Adams County and Brown County cores. Samples were taken from the corecomposite powders. Calcium, magnesium, aluminum, iron, potassium, sodium, strontium, and manganese were determined by atomic absorption spectrophotometry (AAS) using a 0.2-g sample and a combined $\mathrm{HF}, \mathrm{HClO}_{\wedge}$ dissolution technique. Silicon was determined by AAS using a $0.2-\mathrm{g}$ sample and a $\mathrm{NaOH}$ flux technique. A limestone standard sample was analyzed as a control check with most batches of major element determinations. Sulfur was determined by a modified LECO method with semi-automatic titration using a 0.10-g sample. Phosphorus analyses were done by a modification of the ammonium molybdate/potassium antimonyl tartrate complexing method (U.S. Environmental Protection Agency, 1971) using a 0.5-g sample.

\section{STRATIGRAPHY}

\section{GENERAL STATEMENT}

The Black River Group in Ohio is not exposed at the surface. It is shallowest in extreme southwestem Ohio on the crest of the Cincinnati Arch. The Black River is 400 to 500 feet of micritic and pelletal limestone with some dolomitic and argillaceous zones. It is overlain by the Trenton Limestone, a fine- to coarse-grained bioclastic limestone. In most places the Black River is underlain by the Wells Creek Formation, a porous very argillaceous tan to light-gray dolomite with some intercalated green shale. In some places in the study area the Wells Creek-lower Black River section is thin or absent because of highs on the Knox unconformity (figs. 2, 3).

In Indiana the micritic limestone of Middle Ordovician age is termed the Black River Limestone. It is overlain by the Trenton Limestone as in Ohio, with the contact being drawn at the change from micritic to coarse-grained limestone. The rocks underlying the Black River are termed Chazyan in Indiana (pl. 1) (L. E. Becker, written commun., 1976), and include all or part of the lower argillaceous unit (this study) and the Wells Creek Formation of Ohio and nor them Kentucky.

The correlative of the Black River Group in Kentucky, the High Bridge Group, is composed of, in ascending order, the Camp Nelson Limestone, the Oregon Formation, and the Tyrone Limestone (pl. 2). The Tyrone is overlain by the Lexington Limestone; the contact is placed at a lithologic change similar to the change in Ohio. The basal Camp Nelson is not exposed in central Kentucky, but in the subsurface of northern Kentucky the Camp Nelson-Wells Creek contact is the same as the Black River-Wells Creek contact in southwestem Ohio (pl. 2).

The lower third of the Black River Group in Ohio is a mixture of micritic, burrowed, and argillaceous limestones that can be divided into three units, upper and lower argillaceous limestones and pure limestone in the middle. The middle third of the Black River is predominantly micritic limestone with dolomite-filled burrows. This is the typical Camp Nelson lithology of the central Kentucky outcrop area. There are two marker beds in the middle third. The upper third of the Black River is a mixture of micritic-limestone types that, in general, correlates with the Tyrone Limestone and the Oregon Formation of Kentucky. Six marker beds are found in the upper third. Present at or near the base of the upper third are dolomite beds that are the equivalent of the Oregon.

\section{LOWER THIRD OF THE BLACK RIVER GROUP}

The lowermost unit of the Black River Group, here termed the lower argillaceous unit (pl. 2), is made up of interbedded micrite, fine-grained dolomite, argillaceous micrite, and shaly greenish limestone. All are laminated in part. This unit is assigned to the Black River rather than to the underlying Wells Creek Formation primarily on the basis of lithology. Most of the limestone found in this unit in the Adams County and Brown County cores is essentially the same-micritic, pelletal, fossiliferous, laminated, and argillaceous in large part-as that in marker beds I and II and in the upper argillaceous unit.

The lower argillaceous unit of the Black River Group and the Wells Creek Formation are the units most affected by relief on the Knox unconformity. In three wells (Champaign County, P-14; Clinton County, P-5; Highland County, core) this section is absent because of highs that extend into the position of overlying units. In approximately 10 other wells the entire lower argillaceous unit-Wells Creek section is replaced by 10 to 50 feet of argillaceous dolomitic limestone that is difficult to assign to either unit. There are no known cores from wells with this particular lithology and sample recovery was too poor in the 10 wells to assign an exact unit to the section.

Overlying the lower argillaceous unit is the Carntown unit (pl. 2), a thick section of very pure limestone and dolomitic limestone. The unit normally ranges from 50 to 74 feet in thickness (fig. 3). In a few localities the Carntown is thin or absent because of nondeposition resulting from 100 to 150 feet of relief developed on the Knox unconformity. The top of the Carntown unit is 320 to 400 feet below the top of the Black River Group (fig. 4) and is generally less than 2,000 feet below the surface (table 2) in the study area. Structure contours on the top of this unit show a broad, gentle downward slope to the northeast with some irregularities in Champaign, Miami, Clinton, and Fayette Counties (fig. 5). There is an abrupt change in steepness and direction of slope from northeast to east along the edge of the Cincinnati Arch in Adams and Highland Counties.

The uppermost unit in the lower third of the Black River Group is the upper argillace ous unit, which consists of micritic and pelletal limestone with a moderate amount of dolomite. The limestone and dolomite are dark colored and argillaceous in part with partings and interbeds of dark-gray to black shale and shaly limestone. No chert was found in this unit. Argillaceous and shaly material is concentrated mainly in the upper quarter and to a lesser extent in the lower half of the upper argillaceous unit (pls. 1,2). 


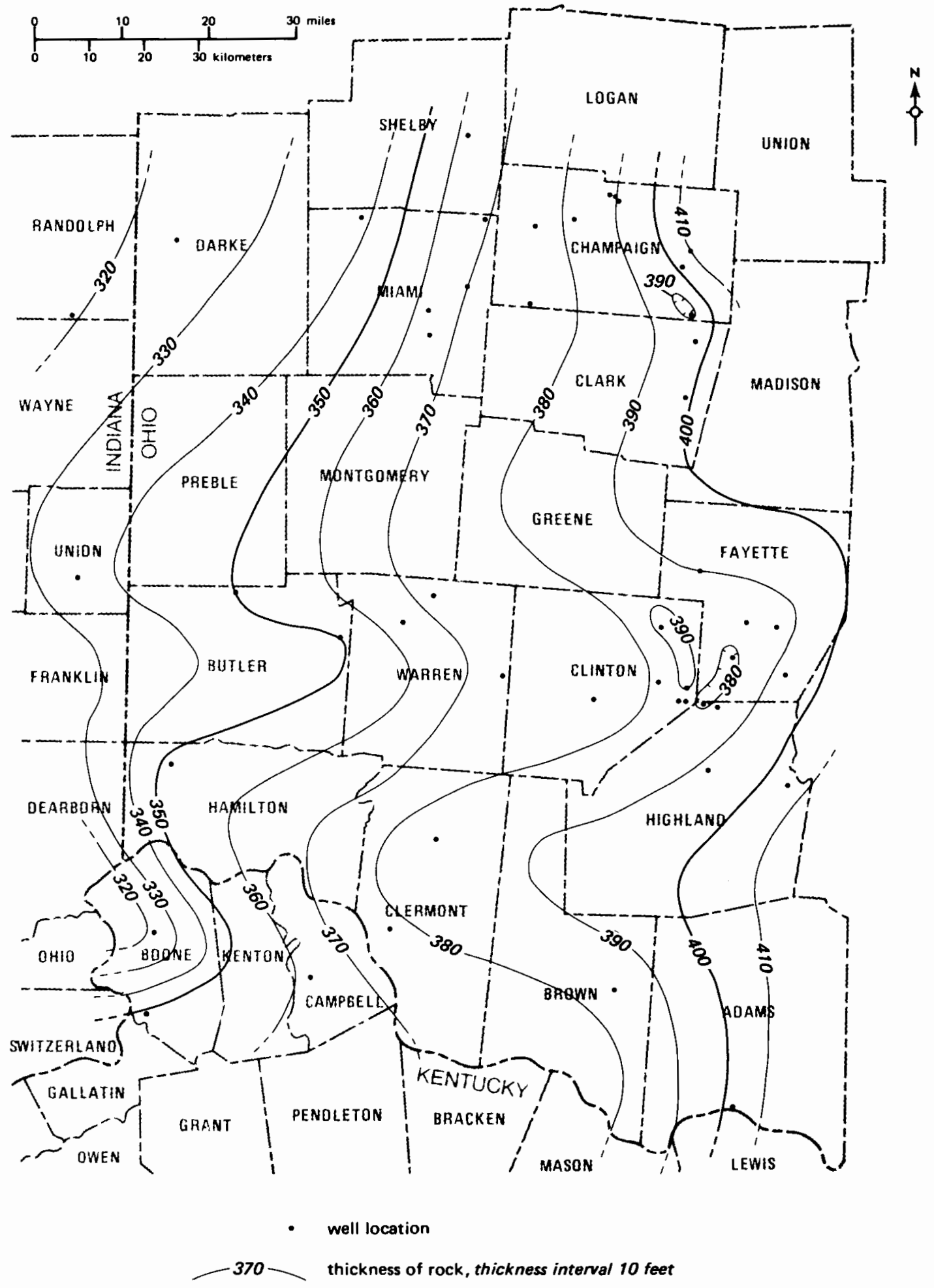

FIGURE 4.-Thickness of rock between marker bed $a$ and top of the Carntown unit. 


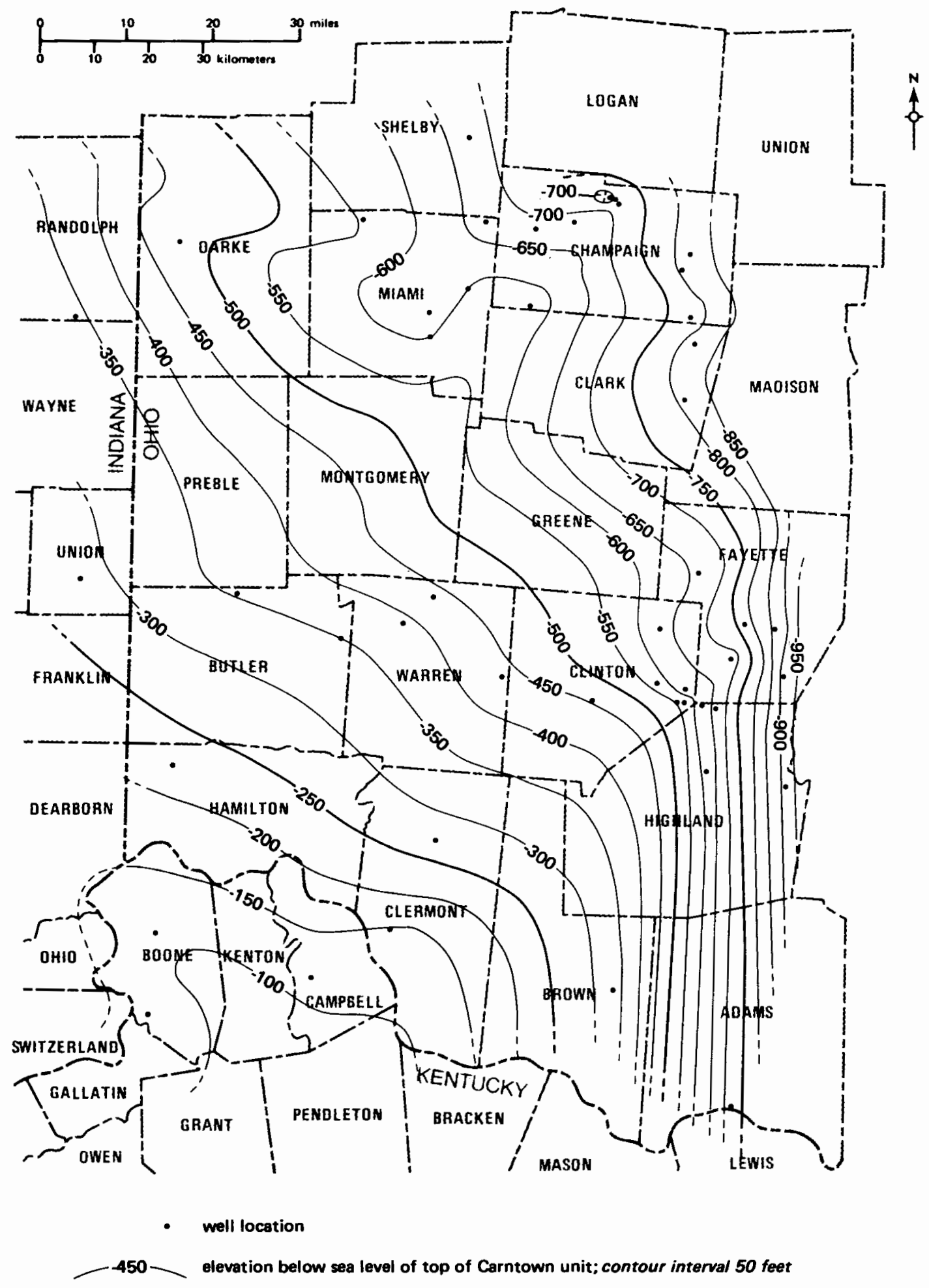

FIGURE 5.-Elevation of top of the Camtown unit. 
TABLE 2.-Depth to top of Camtown unit in Ohio wells

\begin{tabular}{l|c|c||l|r|c}
\hline County & $\begin{array}{c}\text { Permit } \\
\text { no. }\end{array}$ & $\begin{array}{c}\text { Depth (ft) } \\
\text { to } \\
\text { Carntown }\end{array}$ & County & $\begin{array}{c}\text { Permit } \\
\text { no. }\end{array}$ & $\begin{array}{c}\text { Depth (ft) } \\
\text { to } \\
\text { Carntown }\end{array}$ \\
\hline Adams & 6 & 1250 & & 5 & $\mathrm{x}^{\mathbf{1}}$ \\
Brown & 7 & 1256 & & 7 & 1656 \\
Butler & 5 & 1310 & Darke & 64 & 1562 \\
Champaign & 2 & 1342 & Fayette & 1 & 1820 \\
& 2 & 1017 & & 2 & 1700 \\
& 3 & 2042 & & 3 & 1767 \\
& 10 & 1820 & & 4 & 1700 \\
& 11 & 1783 & Hamilton & 1 & 1910 \\
& 12 & 1784 & Highland & 1 & 1041 \\
& 13 & 1810 & & 3 & 1806 \\
& 14 & 1774 & & 4 & 1750 \\
Clark & 16 & 2040 & & 6 & $x$ \\
& 17 & 1748 & Miami & 1 & 1547 \\
Clermont & 2 & 2070 & & 3 & 1635 \\
& 3 & 1974 & & 8 & 1401 \\
Clinton & 3 & 1090 & & 9 & 1468 \\
& 5 & 830 & & 11 & 1804 \\
& 1 & 1743 & Shelby & 12 & 1727 \\
& 2 & 1645 & Warren & 7 & 1320 \\
& 3 & 1685 & & 8 & 1387 \\
& 4 & 1522 & & 10 & 1494 \\
\hline
\end{tabular}

${ }^{1} x$, Carntown absent because of nondeposition.

\section{MIDDLE THIRD OF THE BLACK RIVER GROUP}

The two marker beds in the middle third of the Black River Group are about 95 to 120 feet apart; marker bed II is in the lower part of the section, and marker bed $I$ is at the top of the section (pls. 1,2). Almost all the middle third is burrow-mottled micritic and pelletal limestone. The burrows are dolomitized, and the matrix limestone is dolomitized in part. Marker bed II is 10 to 20 feet of burrowed micritic and pelletal limestone. It is dark colored and argillaceous in large part, with some carbonaceous shale and shaly limestone. Marker bed I is 5 to 10 feet of interbedded argillaceous dark-colored micritic limestone and fine-grained dolomite, with sparse to moderate amounts of carbonaceous shale and shaly limestone.

\section{UPPER THIRD OF THE BLACK RIVER GROUP}

The upper third of the Black River Group is composed of interbedded micritic and pelletal limestone and finegrained dolomite. The rocks are argillaceous in part and laminated in part. Argillaceous material is concentrated mainly above marker bed b. The six marker beds in this section are listed in table 3 and shown on plates 1 and 2 . Marker bed $b$ is recognizable in about three-quarters of the logs and cores, and marker bed $a$ is recognizable in about half the logs and cores. Marker beds $b$ and a are not always distinct bentonites. In the three cores, these beds are generally mixtures of thin bentonitic shale and thin argillaceous or bentonitic limestone. Marker bed $\Delta$ is the thickest, 7 to 15 feet, of the upper six marker beds and is the only nonben tonitic one. This thick shaly to argillaceous limestone is recognizable in all but one of the logs and cores in this study and has a somewhat multifold character. In most of the wells, the middle part of marker bed $\Delta$ is highly argillaceous and grades into slightly less argillaceous beds above and(or) below. The three uppermost marker beds are all bentonites that are probably zones of multiple ash falls and reworkings rather than three distinct continuous beds. A number of thin less distinct bentonites are shown on plates 1 and 2 and in the core descriptions. Marker beds $\gamma$ and $\beta$ are recognizable in all the logs and cores, and marker bed $a$ is well developed in three-quarters of the logs and cores (pls. 1, 2). Marker bed $\gamma$ is a distinct bentonite in the Highland County core, but is a thin bentonitic shale or limestone overlain by about 2 feet of argillaceous limestone in the Adams County and Brown County cores. Marker beds $\beta$ and $a$ are thick ( 6 inches to $1 \frac{1}{2}$ feet) bentonites in all three cores.

The change from micritic limestone of the Black River Group to fossiliferous medium- to coarse-grained limestone of the Trenton Limestone occurs 1 to 7 feet above marker bed $a$ in all three cores. Examination of sample cuttings and shorter cores from the other wells indicates that marker bed $a$ in effect marks the Black River-Trenton contact throughout the study area. Structure contours on marker bed a (fig. 6) show the same general structure as the top of the Carntown unit (fig. 5).

\section{LITHOLOGY AND DEPOSITIONAL ENVIRONMENTS}

Recently, numerous papers on tidal sediments in general (Ginsburg, 1975; Shinn, 1968; Shinn and others, 1969) and a few papers on tidal environments in the Black River Group (Cressman and Noger, 1976; Mukherji, 1969; Walker, 1973) have been published. Detailed examination of the three cores in this study indicates that extensive supratidal and intertidal environments are represented in the Black River carbonates in southwestern Ohio. The Black River is analogous to Middle Ordovician rocks in central Kentucky and to recent sediments in the Bahamas.

The cores in Adams, Brown, and Highland Counties are nominal 2-inch cores $(\approx 1 \mathrm{3} / \mathrm{e}$ inch core diameter) drilled for mineral exploration. Certain features, such as channels, bedding continuity, and mudcracks, cannot be determined accurately because of the small core diameter. Because the cores are fresh rock, certain other features such as laminations and burrows do not show up as well as on weathered rock.

Lithologic terminology is basically that used by Folk (1959) with the exception of micrite. Micrite in this study is not strictly a thin-section-derived term describing individual grain size. Instead, micrite is used as a rock name for

TABLE 3. - Character of marker beds, upper part of Black River Group

\begin{tabular}{|c|c|}
\hline Marker bed & Character \\
\hline$a$ & bentonite \\
\hline$\beta$ & bentonite \\
\hline $\boldsymbol{\gamma}$ & $\begin{array}{l}\text { bentonite commonly overlain by } \\
\text { argillaceous limestone }\end{array}$ \\
\hline$\Delta$ & thick very argillaceous limestone \\
\hline a & $\begin{array}{l}\text { mixed bentonitic shale and } \\
\text { argillaceous limestone }\end{array}$ \\
\hline b & bentonite and bentonitic limestone \\
\hline
\end{tabular}




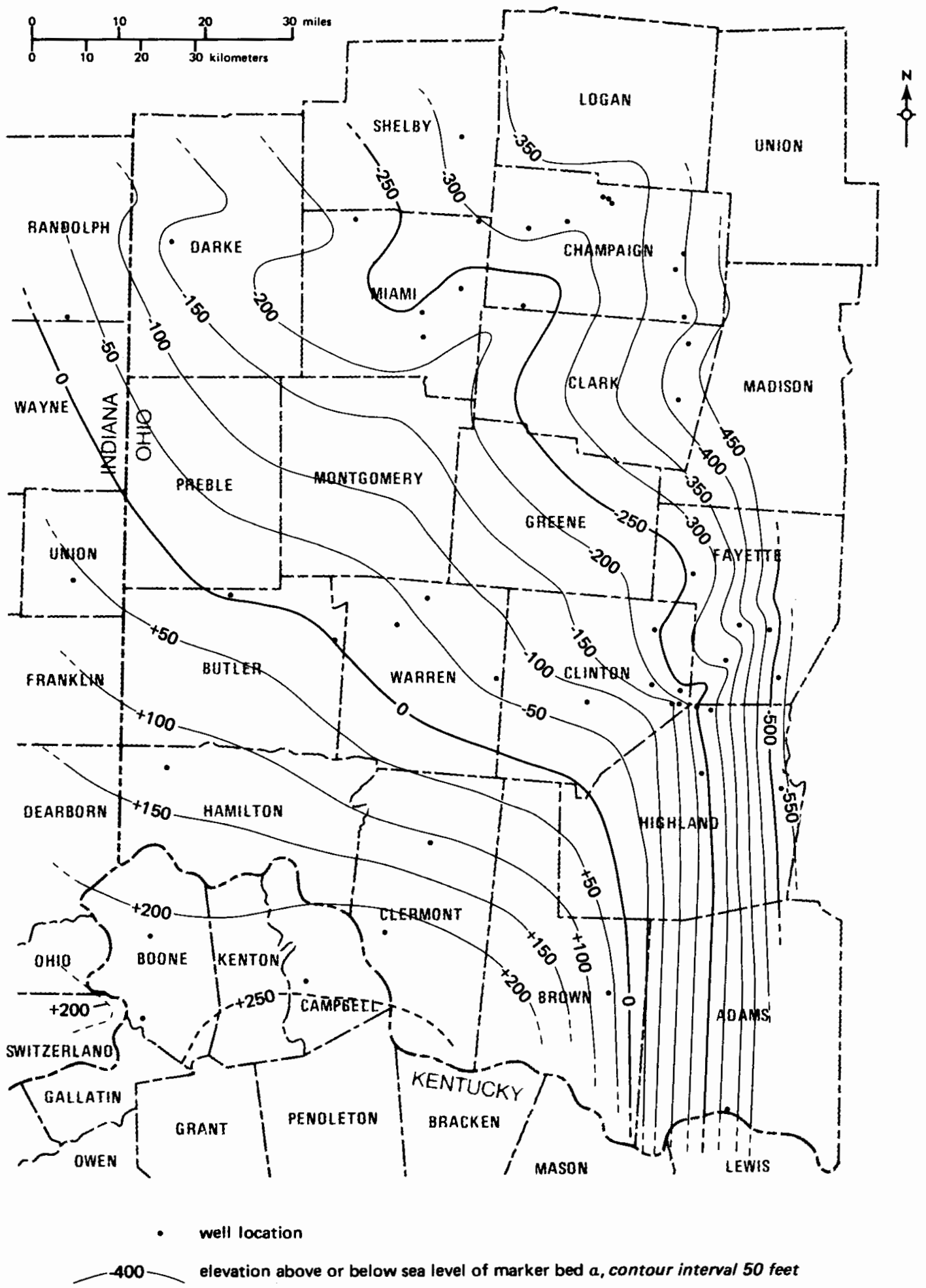

FIGURE 6.-Elevation of marker bed $a$. 
lithographic limestone as determined by use of a binocular microscope. Some thin sections were made of core samples with lithologies that were difficult to determine by use of a binocular microscope. The thin sections were used to make determinations of very fine-grained pelletal rocks versus micritic rocks in the split core. The term pellet (pel-) in this study does not necessarily denote fecal pellets. There seems to be a complete size range of rounded structureless micrite particles from true microscopic pellets to millimeter-size intraclasts. The pellets are very different from the blocky to platy laminated intraclasts composed of micrite. Within any one bed there is generally a high degree of sorting and roundness of the pellets, regardless of size.

In this study the terms supratidal, intertidal, and subtidal do not have any reference to water levels or tides. The terms refer to zones that were covered by marine waters rarely, often, and almost always, respectively. Although the individual lithologies described below do occur separately, they are considered more as end members because there is a considerable amount of interbedding and gradation.

\section{SUPRATIDAL FACIES}

\section{Laminated dolomite}

The dolomite in the Black River Group is very fine- to fine-grained, 0.01 to $0.08 \mathrm{~mm}$ in diameter. Most of the dolomite has faint laminations caused by differences in color and grain size. There are sparse micrite laminations, and the dolomite is unfossiliferous.

\section{Interlaminated micrite and dolomite}

The laminations are less than a millimeter to several millimeters thick, straight to wavy, and nodular to discontinuous in part (fig. 7A). Some of the micrite laminations are partially dolomitized, and there are a few intrasparite and pelsparite laminations. The micrite shows desiccation features (planar and nonplanar birdseyes and mudcracks) in part.

\section{Micrite interbedded with dolomite}

This lithology is similar to the previous one, but on a larger scale (fig. 7B). Micrite layers are about a centimeter thick, are faintly laminated, and show desiccation features in part. The dolomite layers generally are less than $1 / 3$ as thick as the micrite layers and are laminated in part.

\section{Laminated micrite}

The micrite is faintly to distinctly laminated (fig. 7C). Most laminations are caused by color differences, but a few laminations are formed from single layers of pellets or of dolomite rhombs. There are some interbeds of pelsparite (fig. 7D) and intrasparite. Desiccation features are numerous, and the planar birdseyes commonly coalesce into sheet cracks. Vertical burrows are sparse; some are filled with pelsparite and some with sparry calcite. Fossils are limited to a few scattered ostracod valves. The micrite is dolomitized in part with a sparse to moderate number of scattered dolomite rhombs.
Laminated argillaceous limestone

These rocks are a mixture of micrite and fine-grained shaly limestone with a minor amount of pelsparite and intrasparite. They are very argillaceous and generally laminated. Some beds are dolomitic, and desiccation features are abundant. The color generally is darker than in the clean micrites and has a greenish cast.

\section{Environment}

The rocks in this study more closely resemble the recent supratidal sediments of the Bahamas than the sediments of Western Australia or the Persian Gulf (Ginsburg, 1975). Consequently, the laminations (Shinn and others, 1969), planar to nonplanar birdseye fabric (Shinn, 1968), and dolomite are considered indicative of supratidal deposition. No evidence of evaporites such as crystal molds or collapse breccia was found in any of the three cores, indicating the climate was more humid than arid. Some mudcracks are present, but their apparent absence in many samples is probably due to the small core diameter.

\section{INTERTIDAL FACIES}

\section{Micrite}

The micrite has most of the features of supratidal laminated micrite, but the features are much more subdued. Laminations are very faint to faint and sparse to moderate in number. Birdseyes are generally small and sparse to moderate in number. Some of the thicker nonlaminated beds have sparse to moderate numbers of sparry-calcite-filled vertical shrinkage cracks. A few mudcracks are present.

\section{Limestone with vertical and U-shaped burrows}

The rock is composed of micrite and pelsparite that is intraclastic in part. The burrows are sparse to numerous and mainly vertical; a few are $\mathrm{U}$ shaped (fig. 8A). The burrows are commonly filled with sparry calcite or pelsparite; a few are filled with fine-grained dolomite. The burrows range from 1 to $6 \mathrm{~mm}$ in diameter and may be as long as $6 \mathrm{~cm}$. A few fossils, mainly ostracods and small fragments of the tabulate coral Tetradium, are found in the limestone. Any or all of the following features may be present in this rock: sparse to moderate number of faint laminations; sparse small birdseyes, mainly planar; thin dolomite interbeds or laminations; mudcracks; sparse to moderate number of sparry. calcite-filled vertical shrinkage cracks.

\section{Ostracod biomicrite}

The rock is an ostracod biomicrite with minor amounts of interbedded micrite, pelsparite, and fine-grained dolomite. There are a few vertical burrows; some are filled with sparry calcite and some with pelsparite. Faint laminations of color, grain size, or dolomite rhombs are present in a few beds. Some beds are pelsparite with a vaguely churned and bioturbated appearance. The rock is generally very light $\tan$ or gray. 

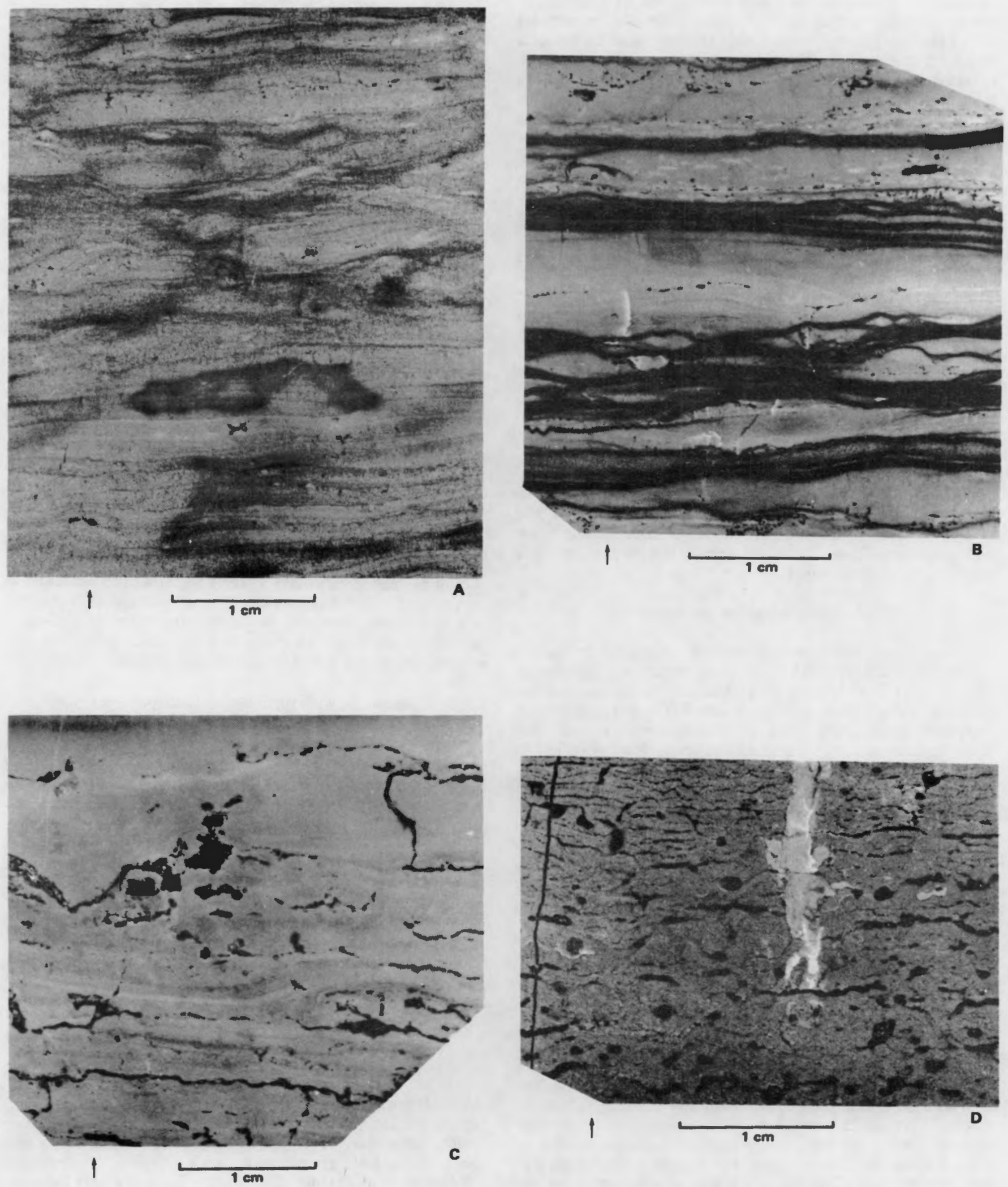

FIGURE 1 -Polished sections of supratidal facies. A, interlaminated micrite and dolomite. S-2405, 995'3". B, partially laminated micrite (light) interbedded with partially laminated dolomite (dark). S-2405, 956'6". C, laminated micrite with minor number of birdseyes and sheet cracks. S-2405, 882'. D, pelsparite with numerous sheet cracks and planar and nonplanar birdseyes. S-2507, 1011'. 

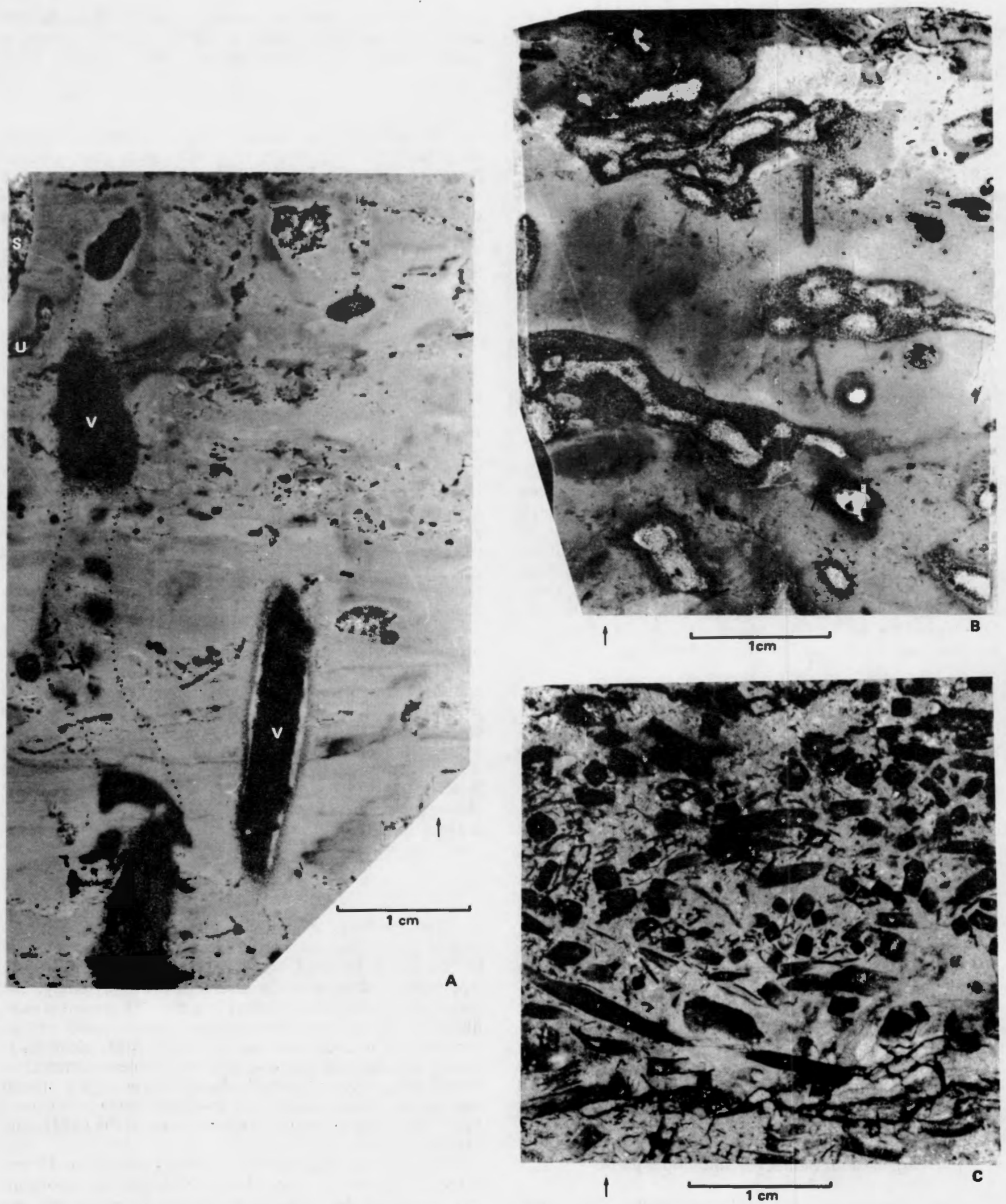

FIGURE 8.-Polished sections of intertidal and subtidal facies. $A$, intertidal; faintly laminated intraclastic micrite with vertical and U-shaped burrows; s, vertical burrow, sparry-calcite-filled; $u$, U-shaped burrow, sparry-calcite-filled; $v$, vertical burrow, dolomite-filled dotted where out of plane of section. S-2499, 1323'3". B, subtidal; micrite with dolomite-filled horizontal burrows. S-2405, 1049'. C, subtidal, Tetradium biomicrite. S-2507, 1094'8". 


\section{Environment}

Intertidal facies are the hardest to recognize because of the narrow diameter of the core samples available. Vertical and $U$-shaped burrows (Walker, 1973) are considered the most reliable indicators of intertidal deposition. The reduced numbers, small size, and faintness of desiccation features such as birdseyes and laminations also are considered indicative of intertidal deposition because of the common association of these features with vertical burrows. Mudcracks are present, but, as in the supratidal facies, the core size prevents recognition of the number and size of the polygons. Fossils, although more plentiful than in the supratidal facies, are relatively sparse. They are mainly articulated and disarticulated ostracod valves and small broken Tetradium fragments. The ostracod biomicrite lithology is somewhat anomalous because in places it is laminated and has vertical burrows, and in other places it is pelsparite with a chumed and burrowed appearance.

\section{SUBTIDAL FACIES}

\section{Limestone with horizontal burrows}

The limestone is a mixture of micrite and various combinations of bio-, pel-, and intra- micrite and sparite. The burrows are horizontal to inclined, range from $2 \mathrm{~mm}$ to $1 \mathrm{~cm}$ in diameter, and are mostly dolomitized (fig. 8B). A few burrows show relict pelsparite texture. Recognizable fossils include fragments of echinoderms, bryozoans, ostracods, brachiopods, pelecypods, gastropods, and Tetradium. In addition to the burrows, there are irregular to nodular interbeds and partings of fine-grained dolomite.

\section{Limestone with dolomite interbeds}

The limestone is biomicrite and biosparite and is pelletal and intraclastic in part. There are a moderate number to numerous irregular to nodular thin interbeds and partings of fine-grained dolomite. The rock is very similar to the burrowed limestone, but has no burrows.

\section{Micrite with Tetradium fragments}

The rock is micrite and biomicrite and is pelletal, intraclastic, and sparry in part. Tetradium fragments are moderate to numerous. Some fragments are unreplaced, others are replaced by sparry calcite (fig. $8 \mathrm{C}$ ). Tetradium is the main faunal element, but some beds have a diverse fauna like the burrowed limestone.

\section{Biopelsparite}

The biopelsparite has a large, diverse fauna like the burrowed limestone. Fossils range from whole valves and tests to fragments nearly as small as pellets. There is faint crossbedding preserved in a few beds.

\section{Argillaceous biomicrite and biopelsparite}

This lithology is the subtidal equivalent of the laminated argillaceous limestone. The rock is interbedded biomicrite and biopelsparite and is very argillaceous and generally dark colored. The fauna is diverse, containing corals, bryozoans, and gastropods, as well as others. Bioturbation is extensive, creating a lumpy, churned texture in part; however, some burrows are preserved.

\section{Environment}

The most obvious indicator of a subtidal environment in these rocks is the generally large and diverse marine fauna. Many of the Tetradium-bearing rocks are indicative of a somewhat restricted environment as shown by the lack of other fossils. Horizontal burrows are also a common indicator of subtidal sediments (Cressman and Noger, 1976). The limestone with dolomite interbeds is considered subtidal because of the presence of a marine fauna and the similarity of the dolomite interbeds to the dolomite associated with the horizontal burrows.

\section{FACIES DISTRIBUTION}

Distribution of the supratidal, intertidal, and subtidal facies in the Adams County and Brown County cores is shown in plate 3. The lower part of the Black River Group present in the Highland County core is mostly marine limestone that does not resemble the other two cores. The top of the upper argillaceous unit is the first recognizable horizon in the Highland County core because the lower argillaceous unit, the Carntown unit, and the lower part of the upper argillaceous unit are absent because of nondeposition. A few thin laminated limestone beds of the intertidal facies are found-in the upper argillaceous unit in the Highland County core.

In all three cores, the first few feet of rock immediately below marker bed II are of the intertidal facies. Rocks of the supratidal and intertidal facies are concentrated in the lower and upper argillaceous units in the Adams County and Brown County cores and above marker bed $I$ in all three cores. The upper third of the Black River is about two-thirds supratidal and intertidal facies in the Adams County and Brown County cores and one-third supratidal and intertidal facies in the Highland County core. Dolomite beds just above marker bed I, correlative to the Oregon Formation, are mostly of the supratidal and intertidal facies.

\section{CHEMICAL RESULTS}

The results of chemical analyses, computed as oxides except for sulfur and phosphorus, of the Adams County (S-2405) and Brown County (S-2507) cores are shown in Appendix B along with the results of the X-ray study. The major error in samples totalling less than 99 percent is most likely a low calcium determination. This is based on two factors: the accuracy of analyses of the other elements as shown by standard samples, and the problems inherent in determining calcium by AAS when it makes up the bulk of the sample. Consequently, the insoluble oxide totals are a better indicator of purity than is the total of the $\mathrm{CaCO}_{2}$ and $\mathrm{MgCO}_{3}$ columns.

Averages for high-carbonate zones greater than 15 feet thick are shown in Appendix C. Although no significant thicknesses of high-calcium rock were found in the two cores studied, there are several zones of high-carbonate rock of mineable thickness in each core. In general, the highcarbonate zones are the same as those found in the core 
from Boone County, Kentucky (Dever, 1974).

The uppermost high-carbonate zone is not quite as pure as zones found lower in the Black River Group. This upper zone includes the upper part of the dolomite correlative to the Oregon Formation and 10 to 15 feet of rock immediately overlying the dolomite. Sample 2405,960 feet to 1009 feet, and sample 2507, 1035 feet to 1054 feet, show almost 97 percent total carbonate (just over 3 percent insoluble oxides). The rocks in the middle third of the Black River contain one or two zones of high-carbonate rock between marker beds I and II and another zone immediately below marker bed II. The rock in these zones (S-2405, 1065 feet to 1134 feet and 1140 feet to 1179 feet; S-2507, 1090 feet to 1109 feet, 1140 feet to 1174 feet, and 1200 feet to 1234 feet) have between 97 and 98 percent total carbonate. The deepest and purest zone of high-carbonate rock in the Black River is the Carntown unit (S-2405, 1257 feet to 1317 feet; S-2507, 1310 feet to 1374 feet). This unit averages less than 2 percent insoluble oxides. Silica content is just over 1 percent; alumina and iron oxide are less than 0.5 and 0.2 percent, respectively. Sulfur is less than 0.1 percent and phosphorus is $\mathbf{0 . 0 0 2}$ percent (Appendix C).

Both cores analyzed in this study contain appreciable amounts of dolomite throughout the Carntown unit. The dolomitized zone in the lower part of the unit is more persistent regionally than the dolomite in the upper and middle portions. The mine at Carntown, Kentucky, is in fairly low-magnesium stone, 1.80 percent $\mathrm{MgO}$ (Levine, 1971), of the Carntown unit. The core from southwestern Boone County, Kentucky, has approximately 15 feet of high-calcium stone near the middle of the Carntown unit (Dever, 1974). Dolomite can generally be inferred from the neutron side of a radioactivity log. Because the dolomite in the Black River Group generally is more porous than limestone, the neutron log will have a lower reading in dolomitic zones owing to the increased fluid content in the rock. Examination of gamma ray-neutron logs throughout southwestern Ohio indicates the dolomite content of the Carntown unit is as follows: upper section, low to moderate; middle section, low; basal section, moderate to high. The neutron logs also show that five wells in the study area may have 15 to 45 feet of high-calcium stone in the Carntown unit. These wells are listed in table 4 (some of the logs are shown on plates 1 and 2).

The other two wells (S-290 and S-751) in the X-ray study were not chemically analyzed, but the X-ray data on both confirm the high quality of the Carntown unit. Sample 290 is composed of cuttings from a well in Spring Valley Township, Greene County, Ohio; this well has no geophysical log. The cuttings X-rayed were from the Carntown unit and show a high-carbonate zone that is more dolomitic at the bottom than at the top (Appendix B). Sample 751 is a

TABLE 4. - Gamma ray-neutron logs showing apparent very low dolomite rock in the Carntown unit

\begin{tabular}{l|l|l|c}
\hline \multicolumn{1}{c|}{ State } & County & Township & $\begin{array}{c}\text { Well permit } \\
\text { no. or name }\end{array}$ \\
\hline Ohio & Clermont & Pierce & 5 \\
& Butler & Lemon & 4 \\
& Butler & Wayne & 2 \\
Miami & Staunton & 8 \\
Kentucky & Boone & & Clarence Snow \#1 \\
\hline
\end{tabular}

short core from a well (P-2) in Concord Township, Fayette County. The core had been sampled previously and has broken unmatched core ends and uncertain continuity. A continuous quarter-split was made of this core; the splits from each 2-foot core box were crushed as one sample. $\mathrm{X}$-ray diffraction analysis and insoluble residue determinations showed 18 feet of high-carbonate rock in the upper 20 feet of the Carntown unit (Appendix B).

\section{SUMMARY}

The Black River Group in southwestern Ohio contains large reserves of high-carbonate rock at depths of less than $2,000$ feet (table 2$)$. The highest quality rock $(98+$ percent carbonate) is found in the Carntown unit, in the lower part of the group. This unit is shallowest in the extreme southwestern part of the state. Along the Miami, Little Miami, and Ohio River valleys, depth to the top of the Carntown unit is 650 to 800 feet. Substantial thicknesses of 96 to $97+$ percent carbonate rock are present in the 200 to 300 feet of section overlying the Carntown unit. Although the Black River is generally dolomitic to some extent, mineable thicknesses of high-calcium stone are probably present in some locations in Ohio (table 4).

The upper two-thirds of the Black River Group contains eight bentonitic and argillaceous marker beds that generally can be traced across the entire study area on geophysical logs. Micrite and dolomite in the upper third of the Black River correlate roughly with the Oregon Formation and Tyrone Limestone in Kentucky. The middle third of the Black River is similar in appearance to the typical outcrop lithology of the Camp Nelson Limestone. The lower third of the group can be divided into three units. The upper argillaceous unit and the Carntown unit correspond to Calvert's (1962) upper and middle Chazy Limestone. The lower argillaceous unit is the same as the argillaceous micritic limestone in the upper part of Calvert's lower Chazy.

The lithology of the Black River Group in the study area closely resembles that of the High Bridge Group in central Kentucky. The laminated and interlaminated micrite and dolomite, limestone with vertical burrows, Tetradiumbearing limestone, limestone with horizontal burrows, and biopelsparite are very similar to the rocks of the High Bridge described by Cressman and Noger (1976). Dolomite, laminations, Tetradium fragments, and vertical, U-shaped, and horizontal burrows are found in southwestern Ohio as they are in the type area of the Black River in New York. However, oolites, oncolites, calcareous algae fragments, and Tetradium supercolonies as reported by Walker (1973) in the type area were not found in this study. No crystal molds or other evidence of evaporites like those in Ontario (Mukherji, 1969) and in Arkansas (Young and others, 1972) were found.

Rocks of the supratidal and intertidal facies make up a large part of the Black River Group, particularly the upper third. Overall, supratidal and intertidal facies compose 40 percent of the Black River in the Adams County core and 30 percent in the Brown County core. Less than 20 percent of the Highland County core is supratidal and intertidal facies, but the Carntown unit and lower argillaceous unit are missing from this core because of nondeposition. 


\section{REFERENCES CITED}

Calvert, W. L., 1962, Sub-Trenton rocks from Lee County, Virginia, to Fayette County, Ohio: Ohio Geological Survey Report of Investigations $45,57 \mathrm{p}$.

Carpenter, G. C., 1965, The lower dolomite member of the Ordovician Chazy Limestone and the St. Peter Sandstone of north-central Kentucky and southwestern Ohio: Ohio Journal of Science, v. 65, p. 85-94.

Cressman, E. R, and Noger, M. C., 1976, Tidal-flat carbonate environments in the High Bridge Group (Middle Ordovician) of central Kentucky: Kentucky Geological Survey, ser. X, Report of Investigations $18,15 \mathrm{p}$.

Dever, G. R., Jr., 1974, High-carbonate rock in the High Bridge Group (Middle Ordovician), Boone County, Kentucky: Kentucky Geological Survey, ser. X, Information Circular 22, 35 p.

Folk, R. L., 1959, Practical petrographic classification of limestones: American Association of Petroleum Geologists Bulletin, v. 43, p. $1-38$.

Ginsburg, R. N., ed., 1975, Tidal deposits, a casebook of Recent examples and fossil counterparts: New York, Springer-Verlag, $428 \mathrm{p}$.

Huff, W. D., 1963, A study of Middle Ordovican K-bentonites in Kentucky and southern Ohio: University of Cincinnati, Ph.D. dissertation (unpublished), $115 \mathrm{p}$.

Levine, Sidney, 1971, Radiation-convection coolers lower kiln gas temperatures: Rock Products, v. 74, no. 7, p. $51-56$.

McCreery, G. L., 1949, Improved mount for powdered specimens used on the geiger-counter X-ray spectrometer: American Ceramic Society Journal, v. 32, no. 4, p. 141-146.

Mukherji, K. K., 1969, Supratidal carbonate rocks in the Black River (Middle Ordovician) Group of southwestem Ontario, Canada: Journal of Sedimentary Petrology, v. 39, p. 1530-1545.

Shinn, E. A., 1968, Practical significance of birdseye structures in carbonate rocks: Joumal of Sedimentary Petrology, v. 38, p. 215-223.

Shinn, E. A., Lloyd, R. M., and Ginsburg, R. N., 1969, Anatomy of a modem carbonate tidal-flat, Andros Island, Bahamas: Joumal of Sedimentary Petrology, v. 39, p. 1202-1228.

U.S. Environmental Protection Agency, 1971, Methods for chemical analysis of water and wastes: Cincinnati, U.S. Environmental Protection Agency, Water Quality Office, Analytical Control Laboratory, p. 235-245.

Votaw, R. B., 1972, Conodont biostratigraphy of the Black River Group (Middle Ordovician) and equivalent rocks of the eastern midcontinent, North America: Ohio State University, Ph.D. dissertation (unpublished), $170 \mathrm{p}$.

Walker, K. R., 1973, Stratigraphy and environmental sedimentology of Middle Ordovician Black River Group in the type area-New York State: New York State Museum and Science Service Bulletin 419, 43 p.

Young, L. M., Fiddler, L. C., and Jones, R. W., 1972, Carbonate facies in Ordovician of northern Arkansas: American Association of Petroleum Geologists Bulletin, v. 56, p. 68-80. 
APPENDIXES 


\section{APPENDIX A.-SUMMARY OF WELL DATA}

\section{ABBREVIATIONS}

Elevation

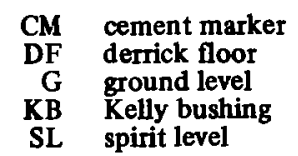

Type of information

$\begin{array}{cl}\text { EL } & \text { electrical log } \\ \text { IL } & \text { induction log } \\ \text { IEL } & \text { induction-electrical log } \\ \text { GRD } & \text { gamma ray-density } \\ \text { GRN } & \text { gamma ray-neutron } \\ \text { LL } & \text { laterolog }\end{array}$

\section{Depth}

K Knox Group

? identification uncertain

$x$ unit absent because of nondeposition

\begin{tabular}{|c|c|c|c|c|c|c|c|c|c|c|}
\hline \multirow[b]{2}{*}{ Permit no. } & \multirow[b]{2}{*}{ Township } & \multirow[b]{2}{*}{ Operator } & \multirow[b]{2}{*}{ Well no. and name } & \multirow[b]{2}{*}{ 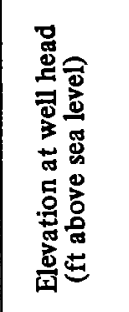 } & \multirow[b]{2}{*}{ 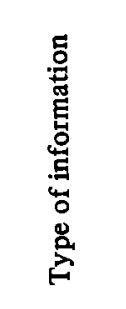 } & \multicolumn{5}{|c|}{ Depth (ft) to top of } \\
\hline & & & & & & 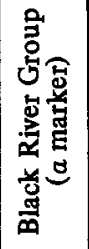 & 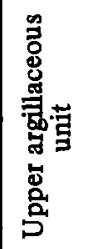 & 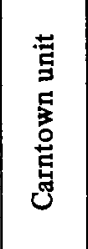 & 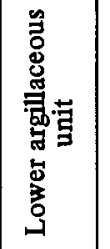 & 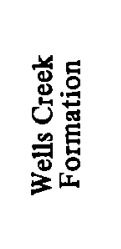 \\
\hline \multicolumn{11}{|c|}{ ADAMS CO. } \\
\hline $\begin{array}{l}6 \\
7\end{array}$ & $\begin{array}{l}\text { Monroe } \\
\text { Monroe }\end{array}$ & $\begin{array}{l}\text { Benz } \\
\text { Cominco }\end{array}$ & $\begin{array}{r}1 \text { Hughes } \\
\text { CA-51 Hughes }\end{array}$ & $\begin{array}{l}527 \mathrm{~KB} \\
532 \mathrm{G}\end{array}$ & $\begin{array}{l}\text { GRN } \\
\text { Core }\end{array}$ & $\begin{array}{l}848 \\
857\end{array}$ & $\begin{array}{l}1187 \\
1191\end{array}$ & $\begin{array}{l}1250 \\
1256\end{array}$ & $\begin{array}{l}1313 \\
1318\end{array}$ & $\begin{array}{l}1355 \\
1359\end{array}$ \\
\hline \multicolumn{11}{|c|}{ BROWN CO. } \\
\hline 5 & Jackson & Cominco & CA-52 Rockey & $990 \mathrm{G}$ & Core & 928 & 1249 & 1310 & 1375 & 1416 \\
\hline \multicolumn{11}{|c|}{ BUTLER CO. } \\
\hline $\begin{array}{l}2 \\
4\end{array}$ & $\begin{array}{l}\text { Wayne } \\
\text { Lemon }\end{array}$ & $\begin{array}{l}\text { Continental } \\
\text { Armco }\end{array}$ & $\begin{array}{l}1 \text { Crist } \\
1 \text { Armco }\end{array}$ & $\begin{array}{l}990 \mathrm{~KB} \\
667 \mathrm{~KB}\end{array}$ & $\begin{array}{l}\text { LL/GRN } \\
\text { GRN }\end{array}$ & $\begin{array}{l}992 \\
667\end{array}$ & $\begin{array}{r}1292 \\
975\end{array}$ & $\begin{array}{l}1342 \\
1017\end{array}$ & $\begin{array}{l}1412 \\
1087\end{array}$ & $\begin{array}{l}1440 \\
1117\end{array}$ \\
\hline \multicolumn{11}{|c|}{ CHAMPAIGN CO. } \\
\hline $\begin{array}{r}2 \\
3 \\
10 \\
11 \\
12\end{array}$ & $\begin{array}{l}\text { Goshen } \\
\text { Union } \\
\text { Concord } \\
\text { Salem } \\
\text { Salem }\end{array}$ & $\begin{array}{l}\text { Hodges } \\
\text { Kelly } \\
\text { Southern Independent } \\
\text { Southern Independent } \\
\text { Southern Independent }\end{array}$ & $\begin{array}{l}1 \text { Ropp } \\
1 \text { Yocum } \\
1 \text { Schultz } \\
1 \text { McCandless } \\
1 \text { Detweiler }\end{array}$ & $\begin{array}{l}1267 \mathrm{~KB} \\
1227 \mathrm{~KB} \\
1133 \mathrm{DF} \\
1072 \mathrm{DF} \\
1069 \mathrm{DF}\end{array}$ & $\begin{array}{l}\text { GRN } \\
\text { GRN } \\
\text { GRN } \\
\text { GRN } \\
\text { GRN }\end{array}$ & $\begin{array}{l}1656 \\
1627 \\
1438 \\
1398 \\
1393\end{array}$ & $\begin{array}{l}2008 \\
1992 \\
1770 \\
1728 \\
1727\end{array}$ & $\begin{array}{l}2042 \\
2037 \\
1820 \\
1783 \\
1784\end{array}$ & \multicolumn{2}{|c|}{\begin{tabular}{c|c}
\multicolumn{2}{c}{$2094 ?$} \\
2096 & $2116 ?$ \\
1876 & $1898 ?$ \\
$1826 ?$ & $1835 ?$ \\
\multicolumn{2}{c}{$1833 ?$}
\end{tabular}} \\
\hline $\begin{array}{l}13 \\
14 \\
16 \\
17\end{array}$ & $\begin{array}{l}\text { Johnson } \\
\text { Salem } \\
\text { Union } \\
\text { Jackson }\end{array}$ & $\begin{array}{l}\text { Teeters } \\
\text { Tartan } \\
\text { Teeters } \\
\text { Teeters }\end{array}$ & $\begin{array}{l}1 \text { Vaughn } \\
2 \text { McCandless } \\
1 \text { Perry } \\
1 \text { Circle }\end{array}$ & $\begin{array}{l}1126 \mathrm{DF} \\
1076 \mathrm{DF} \\
1239 \mathrm{DF} \\
1162 \mathrm{DF}\end{array}$ & $\begin{array}{l}\text { GRD } \\
\text { GRN } \\
\text { GRN } \\
\text { GRN }\end{array}$ & $\begin{array}{l}1437 \\
1394 \\
1634 \\
1376\end{array}$ & $\begin{array}{l}1757 \\
1723 \\
1994 \\
1698\end{array}$ & $\begin{array}{l}1810 \\
1774 \\
2040 \\
1748\end{array}$ & \multicolumn{2}{|c|}{\begin{tabular}{c|c}
$1870 ?$ \\
$1812 ?(\mathrm{~K} ?)$ \\
2096 & 2118 \\
1808 & 1817
\end{tabular}} \\
\hline \multicolumn{11}{|c|}{ CLARK CO. } \\
\hline $\begin{array}{l}2 \\
3\end{array}$ & $\begin{array}{l}\text { Pleasant } \\
\text { Harmony }\end{array}$ & $\begin{array}{l}\text { Edmund et al. } \\
\text { Hodges }\end{array}$ & $\begin{array}{l}1 \text { Brown } \\
1 \text { Elcamere Farms }\end{array}$ & $\begin{array}{l}1249 \mathrm{~KB} \\
1167 \mathrm{DF}\end{array}$ & $\begin{array}{l}\text { IEL } \\
\text { GRN }\end{array}$ & $\begin{array}{l}1674 \\
1576\end{array}$ & $\begin{array}{l}2035 \\
1936\end{array}$ & $\begin{array}{l}2070 \\
1974\end{array}$ & $\begin{array}{l}2130 \\
2026\end{array}$ & $\begin{array}{l}2158 \\
2055\end{array}$ \\
\hline \multicolumn{11}{|c|}{ CLERMONT CO. } \\
\hline $\begin{array}{l}3 \\
5\end{array}$ & $\begin{array}{l}\text { Stonelick } \\
\text { Pierce }\end{array}$ & $\begin{array}{l}\text { Continental } \\
\text { Earth Sci. Labs. }\end{array}$ & $\begin{array}{l}1 \text { Wikoff } \\
1 \text { Callaway }\end{array}$ & $\begin{array}{l}817 \mathrm{~KB} \\
681 \mathrm{DF}\end{array}$ & $\begin{array}{l}\text { LL/GRN } \\
\text { GRN }\end{array}$ & $\begin{array}{l}704 \\
452\end{array}$ & $\begin{array}{r}1030 \\
776\end{array}$ & $\begin{array}{r}1090 \\
830\end{array}$ & $\begin{array}{r}1154 \\
902\end{array}$ & $\begin{array}{r}1184 \\
935\end{array}$ \\
\hline \multicolumn{11}{|c|}{ CLINTON CO. } \\
\hline $\begin{array}{l}1 \\
2 \\
3 \\
4 \\
5 \\
7\end{array}$ & $\begin{array}{l}\text { Wayne } \\
\text { Wayne } \\
\text { Wilson } \\
\text { Washington } \\
\text { Wayne } \\
\text { Wayne }\end{array}$ & $\begin{array}{l}\text { Kewanee } \\
\text { Kewanee } \\
\text { Kewanee } \\
\text { Kewanee } \\
\text { Kewanee } \\
\text { Kewanee }\end{array}$ & $\begin{array}{l}1 \text { Luttrell } \\
1 \text { Adams } \\
1 \text { Bock } \\
1 \text { Igo } \\
1 \text { Van Pelt } \\
1 \text { McVey }\end{array}$ & $\begin{array}{l}1112 \mathrm{CM} \\
1080 \mathrm{CM} \\
1047 \mathrm{CM} \\
1069 \mathrm{CM} \\
1092 \mathrm{~KB} \\
1087 \mathrm{CM}\end{array}$ & $\begin{array}{l}\text { GRN } \\
\text { EL } \\
\text { LL } \\
\text { IEL } \\
\text { IL } \\
\text { IEL }\end{array}$ & $\begin{array}{l}1353 \\
1260 \\
1293 \\
1145 \\
1241 \\
1274\end{array}$ & $\begin{array}{l}1703 \\
1600 \\
1638 \\
1480 \\
1570 ? \\
1610\end{array}$ & \begin{tabular}{c|}
1743 \\
1645 \\
1685 \\
1522 \\
$x$ \\
1656
\end{tabular} & $\begin{array}{c}1805 \\
169 \\
1750 \\
1596 \\
x \\
1725\end{array}$ & $\begin{array}{l}1838 \\
0 ? \\
1780 \\
1620 \\
1630(\mathrm{~K}) \\
1756\end{array}$ \\
\hline
\end{tabular}




\section{APPENDIX A.-SUMMARY OF WELL DATA-Continued}

\begin{tabular}{|c|c|c|c|c|c|c|c|c|c|c|}
\hline \multirow[b]{2}{*}{ Permit no. } & \multirow[b]{2}{*}{ Township } & \multirow[b]{2}{*}{ Operator } & \multirow[b]{2}{*}{ Well no. and name } & \multirow[b]{2}{*}{ 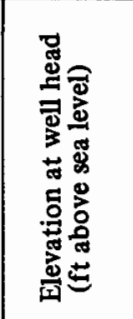 } & \multirow[b]{2}{*}{ 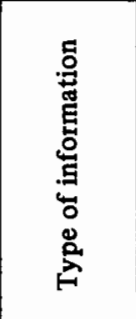 } & \multicolumn{5}{|c|}{ Depth $(f t)$ to top of } \\
\hline & & & & & & 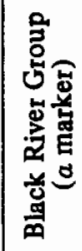 & 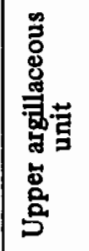 & 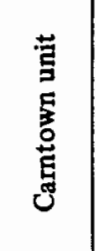 & 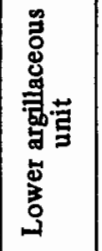 & 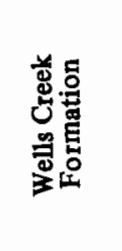 \\
\hline \multicolumn{11}{|c|}{ DARKE CO. } \\
\hline 64 & Washington & An-Car & 1 Martin & $1077 \mathrm{DF}$ & GRN & 1238 & 1520 & 1562 & 1612 & 1632 \\
\hline \multicolumn{11}{|c|}{ FAYETTE CO. } \\
\hline $\begin{array}{l}1 \\
2 \\
3 \\
4 \\
7\end{array}$ & $\begin{array}{l}\text { Union } \\
\text { Concord } \\
\text { Union } \\
\text { Jasper } \\
\text { Perry }\end{array}$ & $\begin{array}{l}\text { Kewanee } \\
\text { Kewanee } \\
\text { Kewanee } \\
\text { Kewanee } \\
\text { Barnwell }\end{array}$ & $\begin{array}{l}1 \text { Hopkins } \\
1 \text { Wilson } \\
1 \text { Cavinee } \\
1 \text { Barnes } \\
1 \text { Cockrill }\end{array}$ & $\begin{array}{r}965 \mathrm{CM} \\
1017 \mathrm{CM} \\
992 \mathrm{CM} \\
1043 \mathrm{CM} \\
1002 \mathrm{~KB}\end{array}$ & $\begin{array}{l}\text { GRN } \\
\text { GRN } \\
\text { GRN } \\
\text { GRN } \\
\text { IEL }\end{array}$ & $\begin{array}{l}1435 \\
1322 \\
1380 \\
1310 \\
1517\end{array}$ & $\begin{array}{l}1783 \\
1654 \\
1723 \\
1650 \\
1850\end{array}$ & $\begin{array}{l}1820 \\
1700 \\
1767 \\
1700 \\
1910\end{array}$ & \multicolumn{2}{|c|}{$\begin{array}{c}1878 ? \\
1750 ? \\
1825 ? \\
1755 ? \\
1970 \mid 2004\end{array}$} \\
\hline \multicolumn{11}{|c|}{ HAMILTON CO. } \\
\hline 1 & Crosby & Continental & 1 Brisbin & $815 \mathrm{~KB}$ & LL/GRN & 688 & 987 & 1041 & 1112 & 1133 \\
\hline \multicolumn{11}{|c|}{ HIGHLAND CO. } \\
\hline $\begin{array}{l}1 \\
3 \\
4 \\
6\end{array}$ & $\begin{array}{l}\text { Fairfield } \\
\text { Paint } \\
\text { Penn } \\
\text { Fairfield }\end{array}$ & $\begin{array}{l}\text { Kewanee } \\
\text { Ohio Valley } \\
\text { Amerada } \\
\text { Cominco }\end{array}$ & $\begin{array}{c}1 \text { Pavey } \\
1 \text { Peabodys } \\
1 \text { Wright } \\
\text { CA-54 Swingley }\end{array}$ & $\begin{array}{r}1043 \mathrm{~KB} \\
880 \mathrm{SL} \\
1139 \mathrm{~KB} \\
1056 \mathrm{G}\end{array}$ & $\begin{array}{l}\text { EL } \\
\text { GRN } \\
\text { GRN } \\
\text { Core }\end{array}$ & $\begin{array}{l}1324 \\
1394 \\
1359 \\
1306\end{array}$ & $\begin{array}{l}1658 \\
1750 \\
1700 \\
1632\end{array}$ & $\begin{array}{c}1706 \\
1800 \\
1750 \\
\mathbf{x}\end{array}$ & $\begin{array}{c}1750 ? \\
1872 \\
1820 \\
x\end{array}$ & $\begin{array}{l}1783 ? \\
1904 \\
1852 \\
1681(\mathrm{~K})\end{array}$ \\
\hline \multicolumn{11}{|c|}{ MIAMI CO. } \\
\hline $\begin{array}{r}1 \\
3 \\
8 \\
9 \\
11\end{array}$ & $\begin{array}{l}\text { Washington } \\
\text { Lost Creek } \\
\text { Staunton } \\
\text { Staunton } \\
\text { Brown }\end{array}$ & $\begin{array}{l}\text { Sun } \\
\text { National Assoc. } \\
\text { Pettit } \\
\text { Pettit } \\
\text { McHale }\end{array}$ & $\begin{array}{l}1 \text { Levering } \\
1 \text { Walker } \\
1 \text { Trojan Farms } \\
1 \text { Knoop } \\
1 \text { Roemisch }\end{array}$ & $\begin{array}{r}994 \mathrm{DF} \\
1035 \mathrm{~KB} \\
801 \mathrm{SL} \\
859 \mathrm{SL} \\
1138 \mathrm{DF}\end{array}$ & $\begin{array}{l}\text { GRN } \\
\text { GRN } \\
\text { GRN } \\
\text { GRN } \\
\text { GRN }\end{array}$ & $\begin{array}{l}1210 \\
1265 \\
1037 \\
1104 \\
1435\end{array}$ & $\begin{array}{l}1503 \\
1582 \\
1348 \\
1418 \\
1752\end{array}$ & $\begin{array}{l}1547 \\
1635 \\
1401 \\
1468 \\
1804\end{array}$ & \begin{tabular}{|l|}
$\mid 2$ \\
160 \\
1696 \\
1463 \\
1530 \\
1863
\end{tabular} & $\begin{array}{l}0 ? \\
1714 \\
1486 \\
1550 \\
1883\end{array}$ \\
\hline \multicolumn{11}{|c|}{ SHELBY CO. } \\
\hline 12 & Perry & Sun & 1 Nelson & $1050 \mathrm{DF}$ & GRN & 1364 & 1684 & 1727 & \multicolumn{2}{|c|}{$1786 ?$} \\
\hline \multicolumn{11}{|c|}{ WARREN CO. } \\
\hline $\begin{array}{r}7 \\
8 \\
10\end{array}$ & $\begin{array}{l}\text { Clear Creek } \\
\text { Washington } \\
\text { Clear Creek }\end{array}$ & $\begin{array}{l}\text { Continental } \\
\text { Continental } \\
\text { Carter }\end{array}$ & $\begin{array}{l}1 \text { Sellars } \\
1 \text { Kittridge } \\
1 \text { Rainey-Whitaker }\end{array}$ & $\begin{array}{r}927 \mathrm{~KB} \\
945 \mathrm{~KB} \\
1048 \mathrm{~KB}\end{array}$ & $\begin{array}{l}\text { LL/GRN } \\
\text { LL/GRN } \\
\text { GRN }\end{array}$ & $\begin{array}{r}955 \\
1012 \\
1120\end{array}$ & $\begin{array}{l}1275 \\
1340 \\
1445\end{array}$ & $\begin{array}{l}1320 \\
1387 \\
1494\end{array}$ & $\begin{array}{l}1385 \\
1455 \\
1558\end{array}$ & $\begin{array}{l}1415 \\
1484 \\
1584\end{array}$ \\
\hline \multicolumn{11}{|c|}{ INDIANA-RANDOLPH Co. } \\
\hline IND & \multicolumn{9}{|c|}{ INDIANA-UNION CO. } & 1570 \\
\hline & T11N, R1W & Continental & 1 Sheets & $1002 \mathrm{~KB}$ & GRN & 950 & 1240 & 1286 & 1353 & 1384 \\
\hline \multicolumn{11}{|c|}{ KENTUCKY-BOONE CO. } \\
\hline & & $\begin{array}{l}\text { Continental } \\
\text { Earth Sci. Labs. }\end{array}$ & $\begin{array}{l}1 \text { Snow } \\
1 \text { Bender }\end{array}$ & $\begin{array}{l}865 \mathrm{~KB} \\
461 \mathrm{DF}\end{array}$ & $\begin{array}{l}\text { LL/GRN } \\
\text { GRN }\end{array}$ & $\begin{array}{l}653 \\
247\end{array}$ & $\begin{array}{l}921 \\
537\end{array}$ & $\begin{array}{l}974 \\
600\end{array}$ & $673^{103}$ & ${ }^{0 ?}{ }_{716}$ \\
\hline \multicolumn{11}{|c|}{ KENTUCKY-CAMPBELL CO. } \\
\hline & & Ashland & 1 Wilson et $u x$. & $758 \mathrm{~KB}$ & GRN & 518 & 820 & 880 & 950 & 990 \\
\hline
\end{tabular}




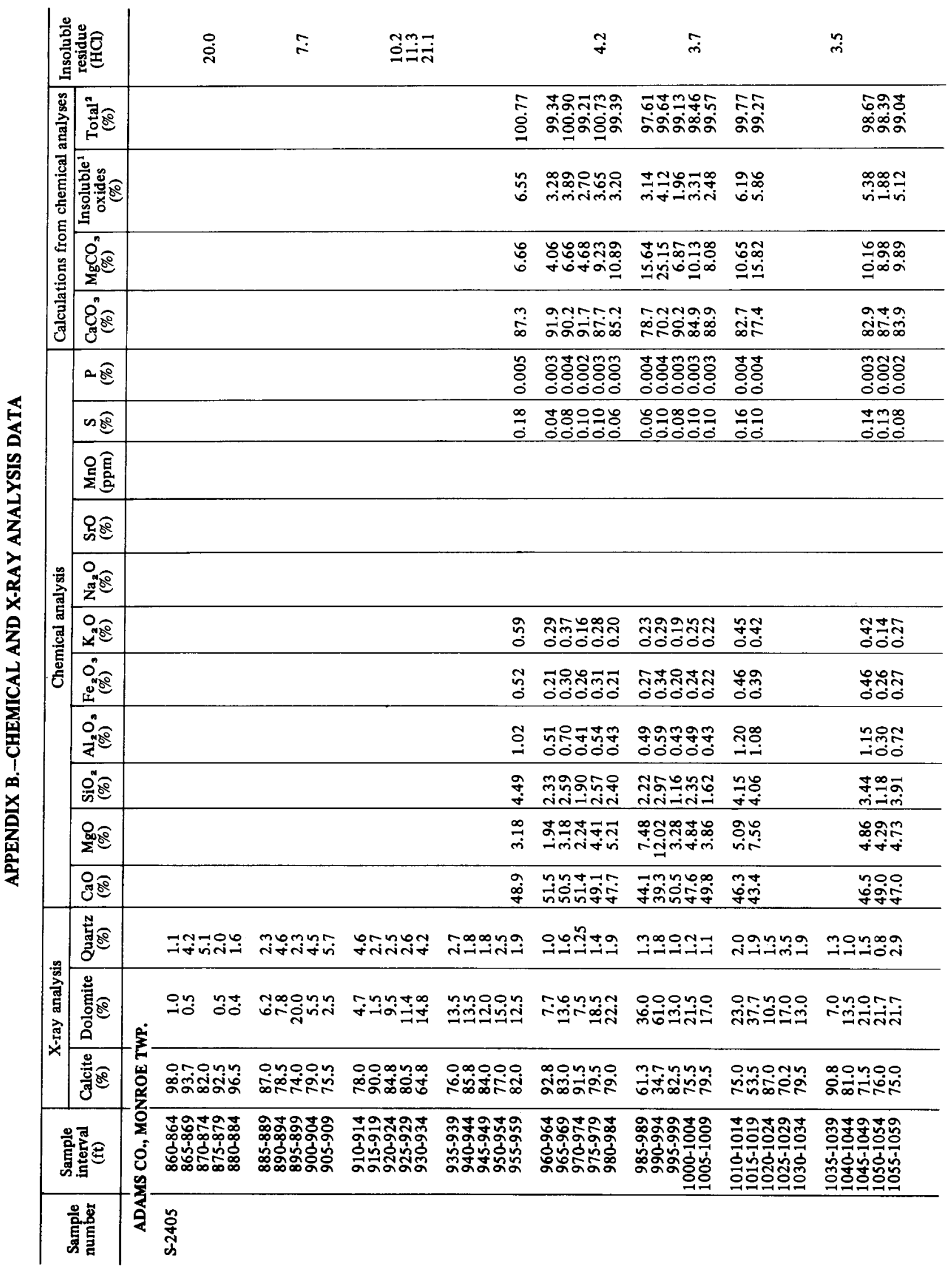



9
ஸ̊
สำ

\begin{tabular}{|c|c|c|c|c|c|c|c|c|c|c|}
\hline 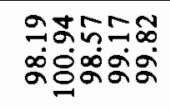 & 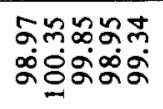 & 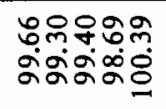 & 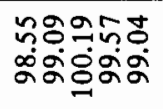 & 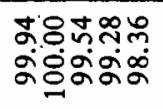 & & & 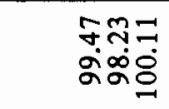 & 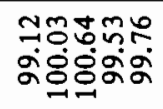 & 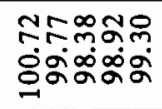 & $\begin{array}{l}5 \frac{2}{5} \\
\text { 5ू }\end{array}$ \\
\hline 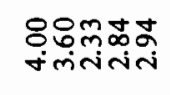 & 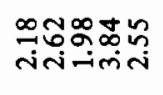 & 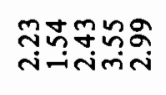 & 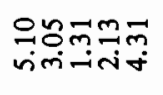 & 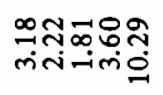 & & & $\begin{array}{l}\text { gagion } \\
\text { oivin }\end{array}$ & ชูㅇำ & 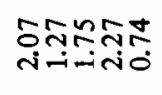 & $\underset{4 \infty}{\pi \infty}$ \\
\hline 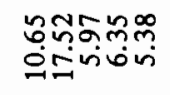 & 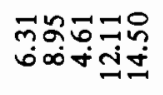 & 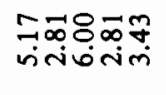 & 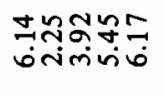 & 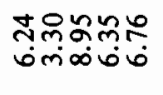 & & & 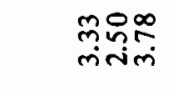 & 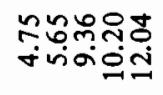 & 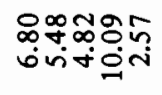 & $\underset{m}{m \infty}$ \\
\hline 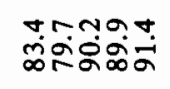 & 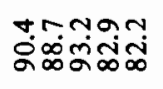 & 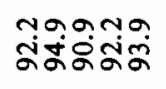 & 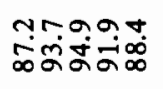 & 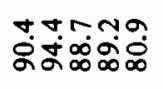 & & & $\begin{array}{l}\infty \infty \sigma \\
\dot{\infty} \dot{\infty} \bar{\alpha}\end{array}$ & 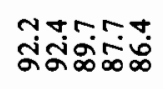 & 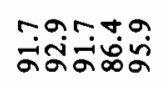 & Nָd \\
\hline 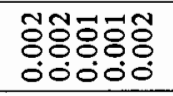 & 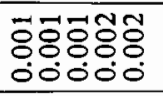 & 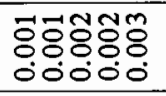 & 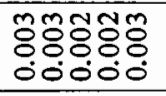 & 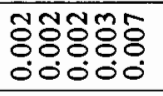 & & & 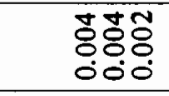 & 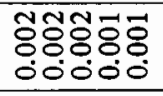 & 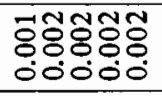 & $\begin{array}{l}\text { T⿱宀 } 80 \\
80 \\
00\end{array}$ \\
\hline \multirow[t]{4}{*}{ 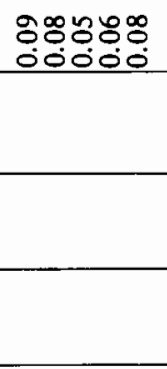 } & 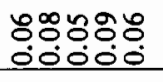 & 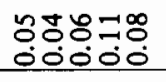 & 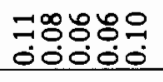 & 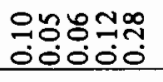 & & & $\begin{array}{l}\infty=0 \\
0=1 \\
000 \\
000\end{array}$ & 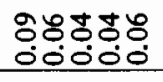 & $\begin{array}{l}\text { 응은웡 } \\
\text { :0ㅇㅇㅇㅇ }\end{array}$ & 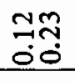 \\
\hline & & & & & & & 퐁워 & 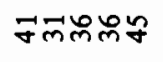 & 흠요요 & 62 \\
\hline & & & & & & & 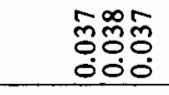 & 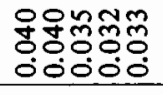 & 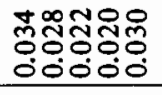 & 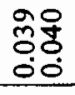 \\
\hline & & & & & & & 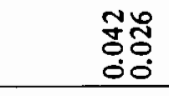 & 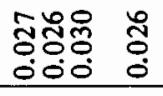 & 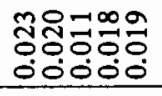 & 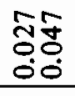 \\
\hline 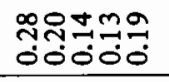 & 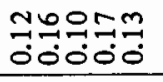 & 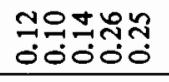 & 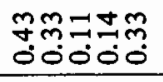 & 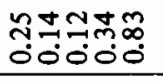 & & & 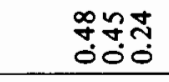 & 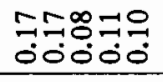 & 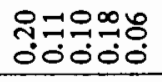 & 궁 \\
\hline 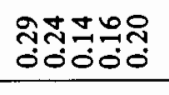 & 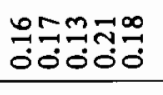 & 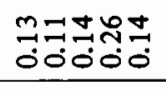 & 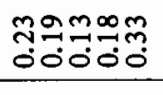 & 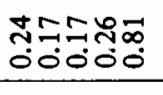 & & & 유: & 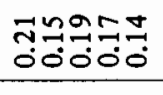 & 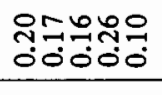 & कृष \\
\hline 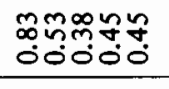 & 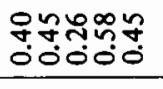 & 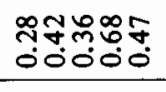 & 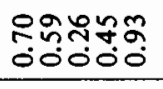 & 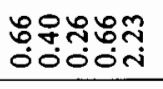 & & & 馨 & 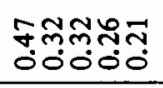 & 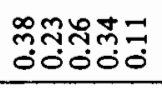 & $\stackrel{\text { f̊o }}{\circ}$ \\
\hline 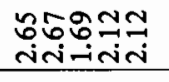 & 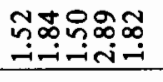 & 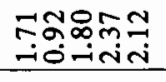 & 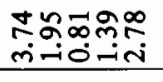 & 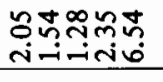 & & & 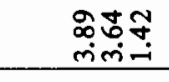 & 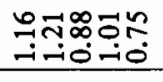 & సిన్సి & 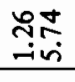 \\
\hline 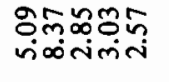 & 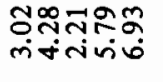 & 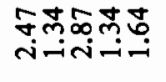 & 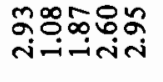 & 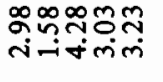 & & & 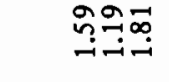 & 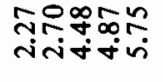 & 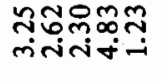 & กุल \\
\hline 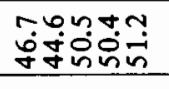 & 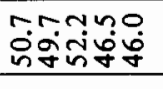 & 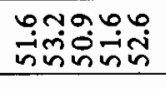 & 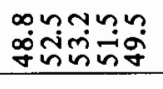 & 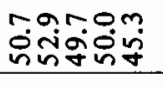 & & & $\begin{array}{l}\text { mono } \\
\text { iñiñ }\end{array}$ & 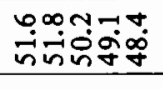 & 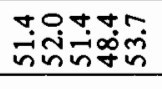 & 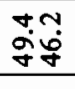 \\
\hline 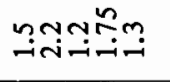 & ت윢ำ & অơrin & 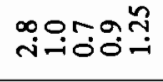 & 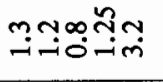 & 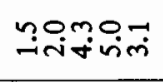 & 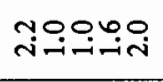 & 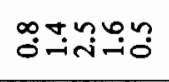 & mூ00\% & 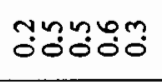 & 我 \\
\hline 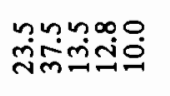 & 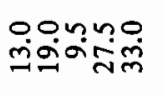 & 웜ํํำ & 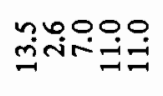 & 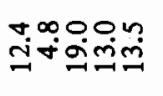 & 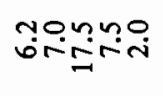 & 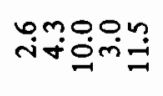 & 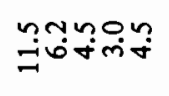 & 염휴유 & 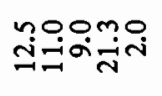 & $\begin{array}{l}00 \\
\dot{0}\end{array}$ \\
\hline 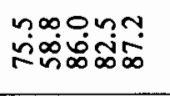 & 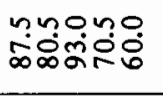 & 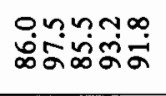 & 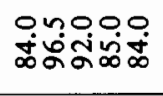 & 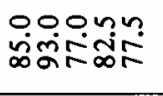 & 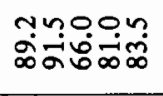 & 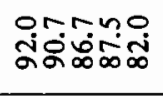 & 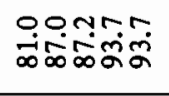 & 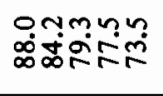 & 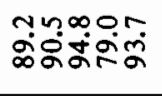 & $\begin{array}{l}n=0 \\
\text { con } \\
\text { con }\end{array}$ \\
\hline 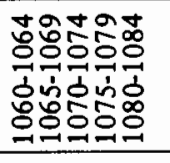 & 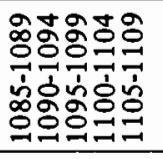 & 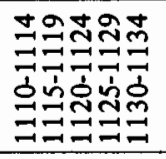 & 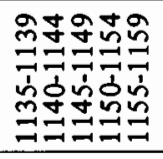 & 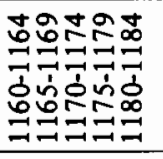 & 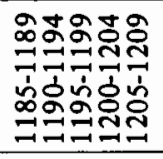 & 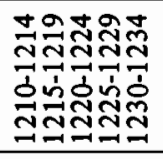 & 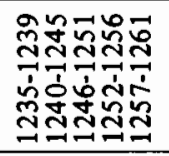 & 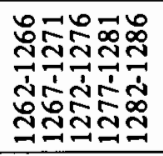 & 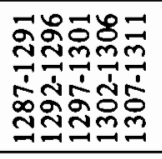 & 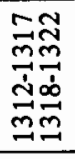 \\
\hline
\end{tabular}




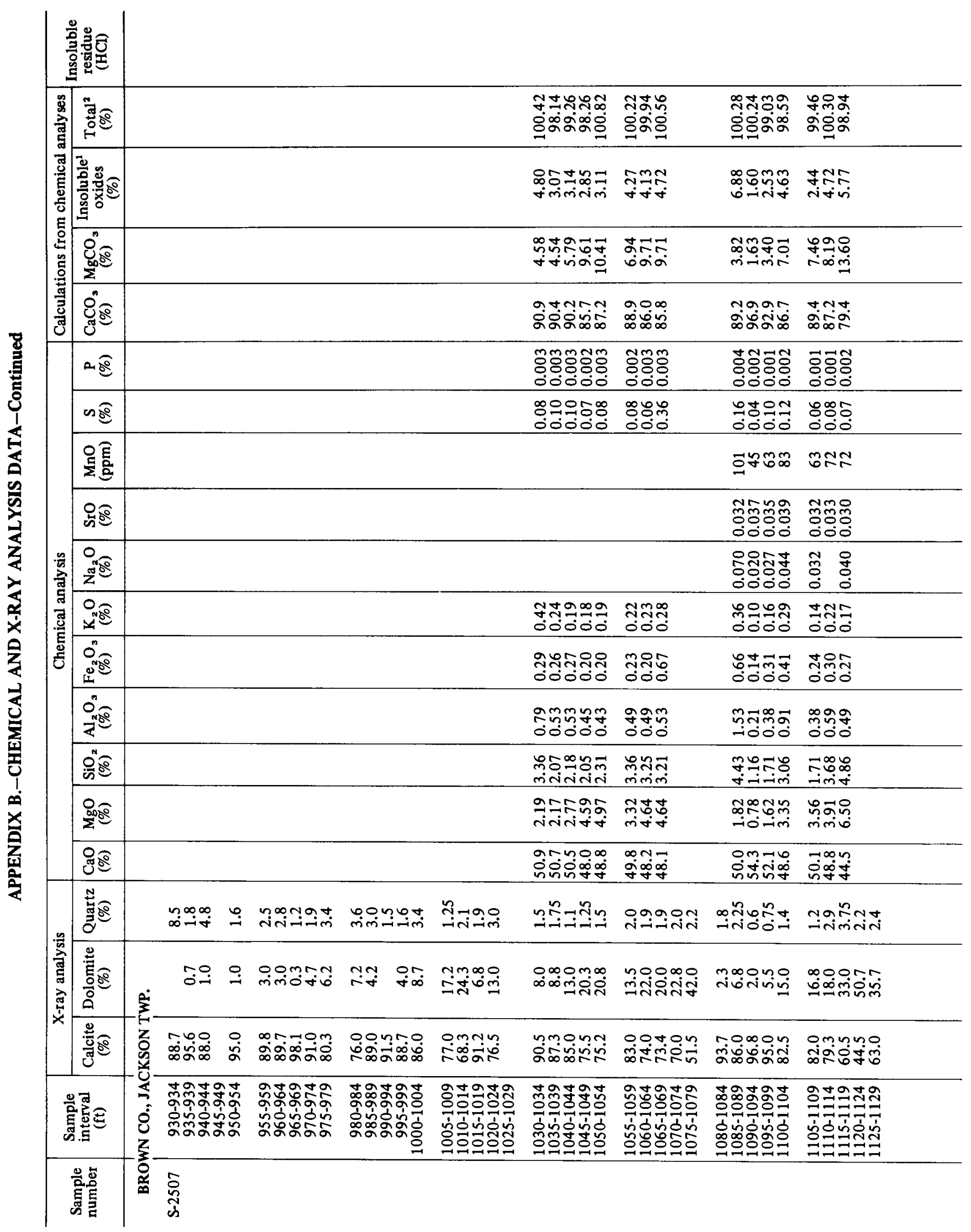




\begin{tabular}{|c|c|c|c|c|c|c|c|c|c|}
\hline 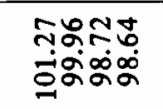 & 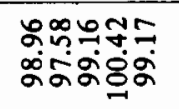 & $\begin{array}{l}\text { مेके } \\
\text { รूरे }\end{array}$ & 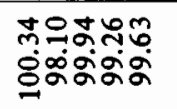 & $\begin{array}{l}\text { ㅎㅇㅇㅝ } \\
\text { ऊiळó }\end{array}$ & & के & 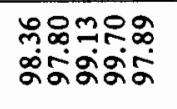 & 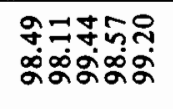 & 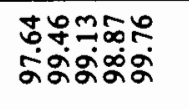 \\
\hline 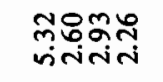 & 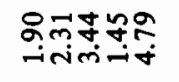 & $\underset{\infty}{\exists}$ & 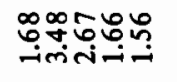 & 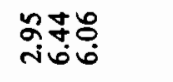 & & $\stackrel{m}{=}$ & 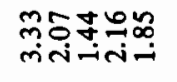 & 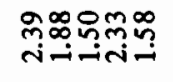 & 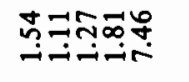 \\
\hline 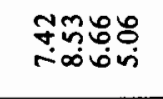 & 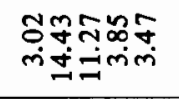 & $\stackrel{0 m}{79}$ & 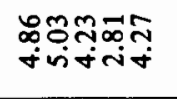 & 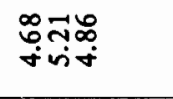 & & $\stackrel{\circ}{\stackrel{\circ}{+}}$ & 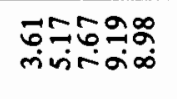 & 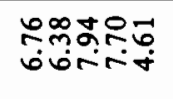 & 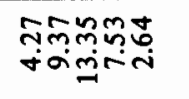 \\
\hline 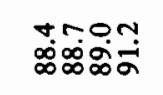 & 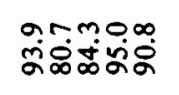 & $\begin{array}{l}\text { åm } \\
\text { ฌूँ }\end{array}$ & 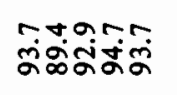 & 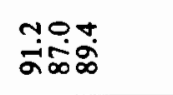 & & $\underset{\infty}{9}$ & 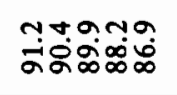 & 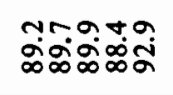 & 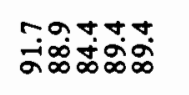 \\
\hline 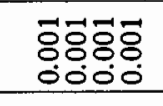 & 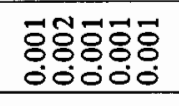 & 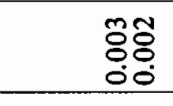 & 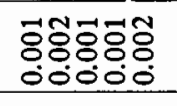 & $\begin{array}{l}\text { ํํㅇㅇ } \\
\text { ㅇํㅇ }\end{array}$ & & 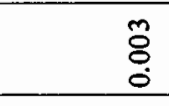 & 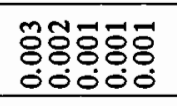 & 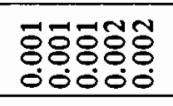 & 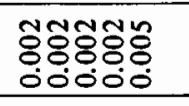 \\
\hline 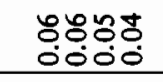 & 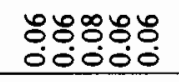 & ๙ָฒ0 & 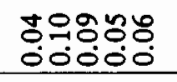 & 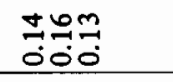 & & $\stackrel{ \pm}{0}$ & 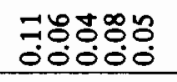 & 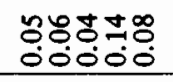 & 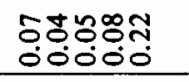 \\
\hline 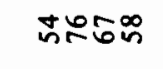 & 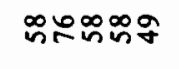 & స̊ & 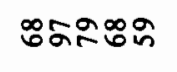 & 9 & & $\tilde{c}$ & : $\forall$ 대요 & ザヂ゚ & 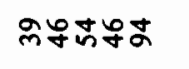 \\
\hline 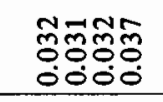 & 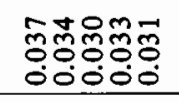 & 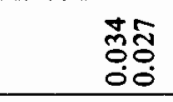 & 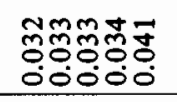 & 官 & & @̊ & 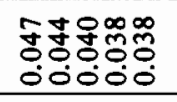 & 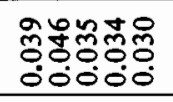 & 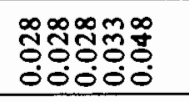 \\
\hline 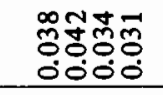 & 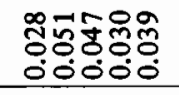 & $\begin{array}{l}\infty \infty \\
0 \\
00 \\
00 \\
0\end{array}$ & 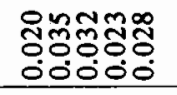 & $\stackrel{\tilde{O}}{\circ}$ & & & & & \\
\hline 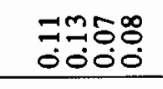 & $\begin{array}{l}050 \% \\
0000 \\
0000\end{array}$ & $\begin{array}{l}\infty \\
\infty \\
\infty \\
0 \\
0\end{array}$ & 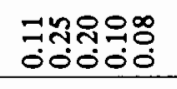 & సి广ా & & $\tilde{n}$ & 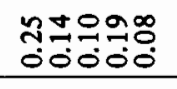 & 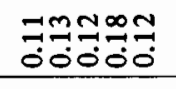 & 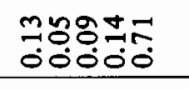 \\
\hline 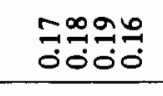 & 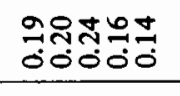 & $\begin{array}{l}\text { 50. } \\
\text { :0 }\end{array}$ & 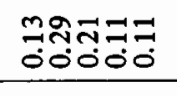 & 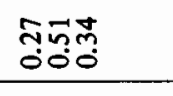 & & 于 & $\begin{array}{l}\text { mైషస్స్ } \\
00000 \\
0000\end{array}$ & 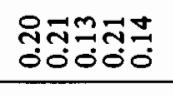 & 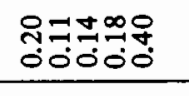 \\
\hline 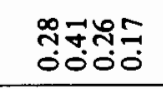 & 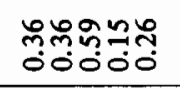 & ڤึָ̃ & 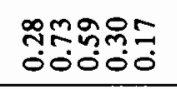 & 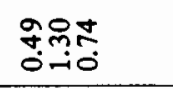 & & $\underset{\sim}{\stackrel{\infty}{\sim}}$ & 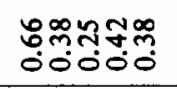 & 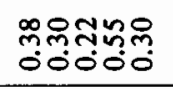 & 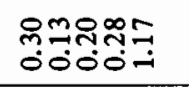 \\
\hline 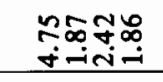 & 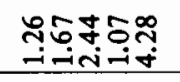 & $\begin{array}{l}\forall_{\infty}^{\infty} \\
\text { i. }\end{array}$ & 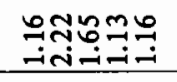 & 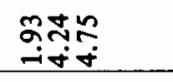 & & 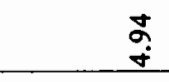 & 士̄måñ & 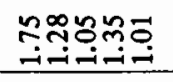 & 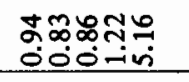 \\
\hline 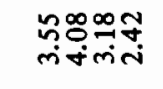 & 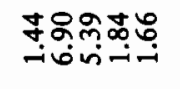 & 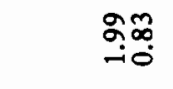 & 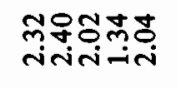 & 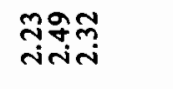 & & $\stackrel{\forall}{-}$ & 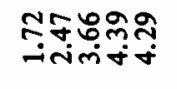 & 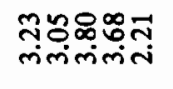 & 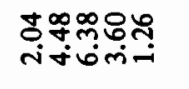 \\
\hline 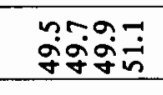 & 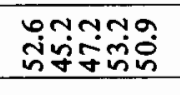 & क्षे & 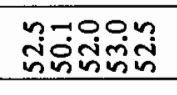 & 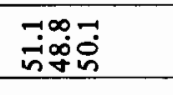 & & $\frac{m}{a}$ & 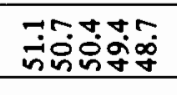 & 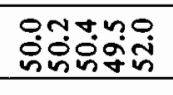 & 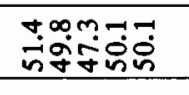 \\
\hline 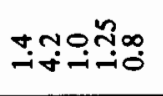 & 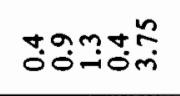 & 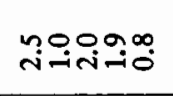 & 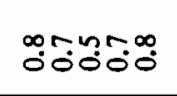 & 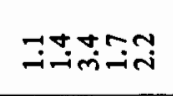 & 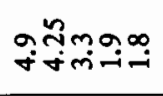 & mmo & 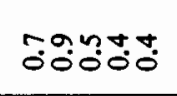 & 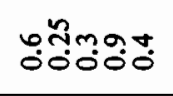 & 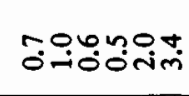 \\
\hline 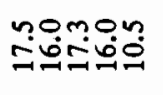 & 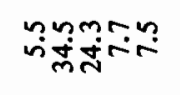 & 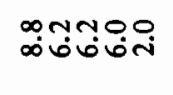 & 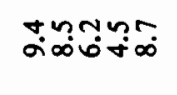 & 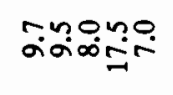 & ఇọming & minisiö: & 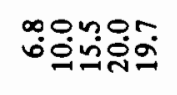 & 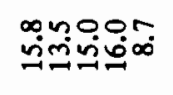 & 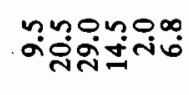 \\
\hline 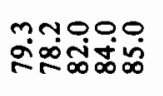 & 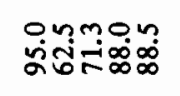 & 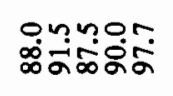 & 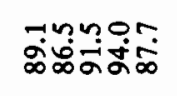 & 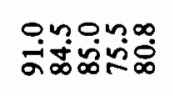 & 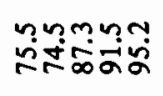 & 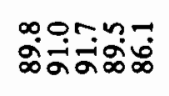 & 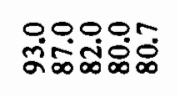 & 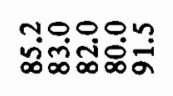 & 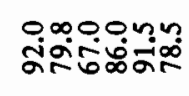 \\
\hline 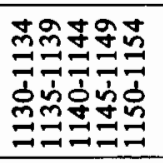 & 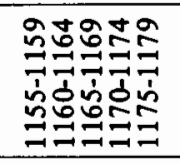 & 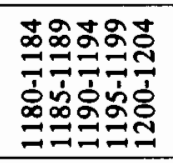 & 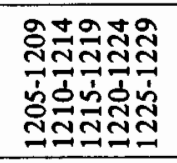 & 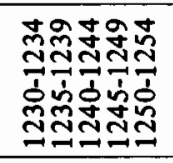 & 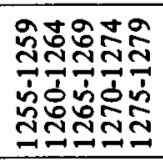 & 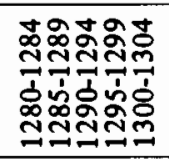 & 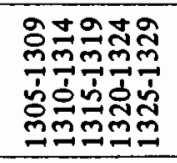 & 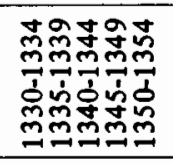 & 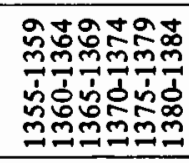 \\
\hline
\end{tabular}




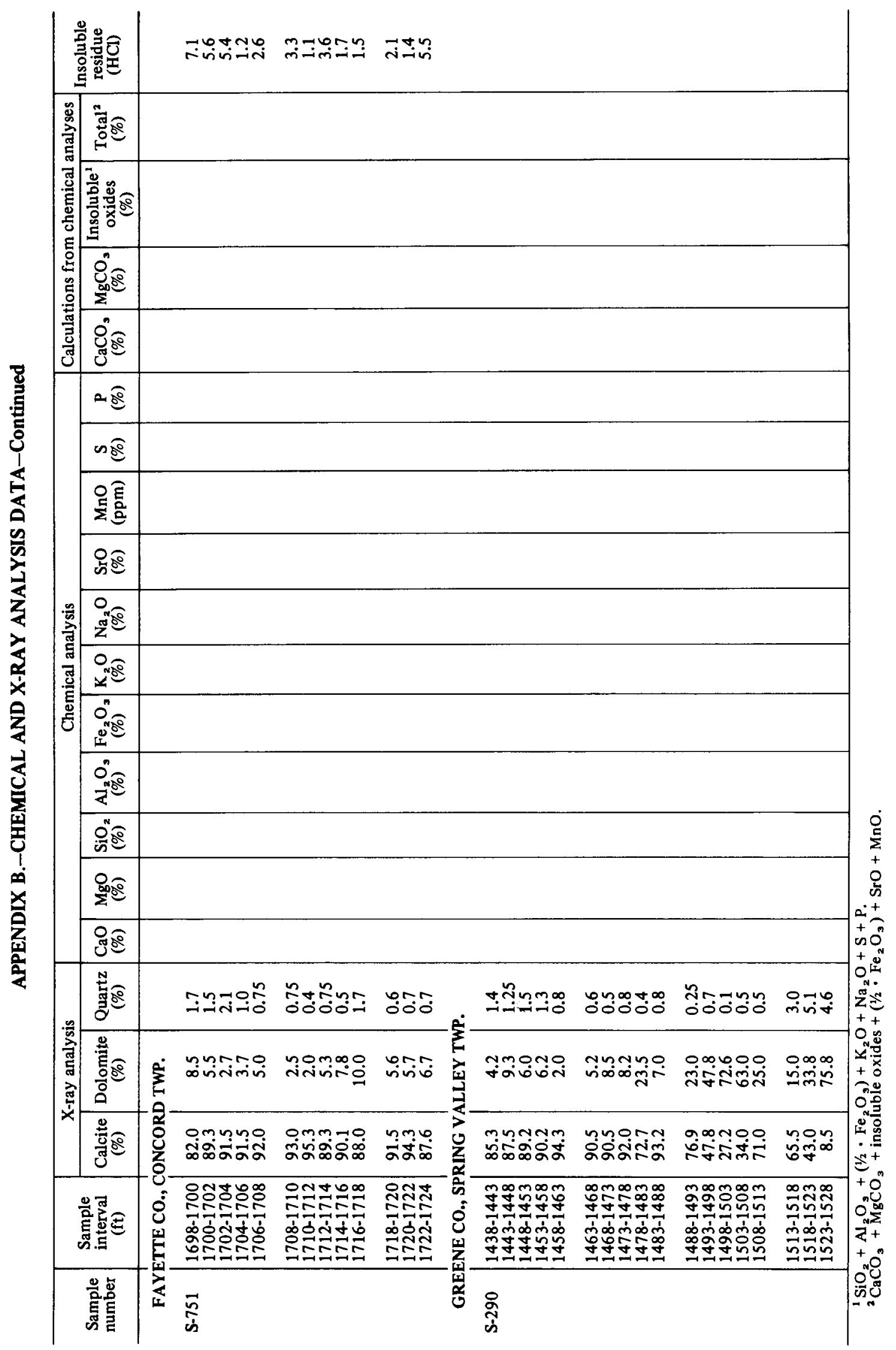


APPENDIX C.-CHEMICAL ANALYSIS AVERAGES FOR HIGH-CARBONATE ZONES'

\begin{tabular}{|c|c|c|c|c|c|c|c|c|c|c|c|c|c|c|c|}
\hline \multirow{2}{*}{$\begin{array}{l}\text { Sample } \\
\text { number }\end{array}$} & \multirow{2}{*}{$\begin{array}{c}\text { Sample } \\
\text { interval } \\
\text { (ft) }\end{array}$} & \multicolumn{11}{|c|}{ Chemical analysis } & \multicolumn{3}{|c|}{$\begin{array}{l}\text { Calculations from } \\
\text { chemical analyses }\end{array}$} \\
\hline & & $\begin{array}{l}\mathrm{CaO} \\
(\%)\end{array}$ & $\begin{array}{c}\mathrm{MgO} \\
(\%)\end{array}$ & $\mid \begin{array}{l}\mathrm{SiO}_{2} \\
(\%)\end{array}$ & $\stackrel{\mathrm{Al}_{2} \mathrm{O}_{3}}{(\%)}$ & $\begin{array}{c}\mathrm{Fe}_{2} \mathrm{O}_{3} \\
(\%)\end{array}$ & $\begin{array}{l}\mathrm{K}_{2} \mathrm{O} \\
(\%)\end{array}$ & $\begin{array}{l}\mathrm{Na}_{2} \mathrm{O} \\
(\%)\end{array}$ & $\begin{array}{l}\mathrm{SrO} \\
(\%)\end{array}$ & $\begin{array}{c}\mathrm{MnO} \\
(\mathrm{ppm})\end{array}$ & $\underset{(\%)}{S}$ & $\underset{(\%)}{\mathbf{P}}$ & $\underset{(\%)}{\mathrm{CaCO}_{3}}$ & $\underset{(\%)}{\mathrm{MgCO}_{3}}$ & $\begin{array}{c}\text { Insoluble } \\
\text { oxides } \\
(\%)\end{array}$ \\
\hline \multicolumn{5}{|c|}{ ADAMS CO., MONROE TWP. } & & & & & & & & & & & \\
\hline S-2405 & $\begin{array}{r}960-1009 \\
1065-1134 \\
1140-1179 \\
1257-1317\end{array}$ & $\begin{array}{l}48.2 \\
50.1 \\
51.2 \\
50.8\end{array}$ & \begin{tabular}{|l|}
4.85 \\
3.48 \\
2.55 \\
3.30
\end{tabular} & $\begin{array}{l}2.21 \\
1.94 \\
1.77 \\
1.07\end{array} \mid$ & $\begin{array}{l}0.50 \\
0.44 \\
0.53 \\
0.31\end{array}$ & $\begin{array}{l}0.26 \\
0.17 \\
0.21 \\
0.19\end{array}$ & $\begin{array}{l}0.25 \\
0.16 \\
0.22 \\
0.14\end{array}$ & 0.023 & 0.032 & 50 & $\begin{array}{l}0.08 \\
0.07 \\
0.08 \\
0.08\end{array}$ & $\begin{array}{l}0.003 \\
0.002 \\
0.002 \\
0.002\end{array}$ & $\begin{array}{l}86.0 \\
89.5 \\
91.4 \\
90.8\end{array}$ & \begin{tabular}{|r|}
10.14 \\
7.28 \\
5.33 \\
6.91
\end{tabular} & $\begin{array}{l}3.17 \\
2.69 \\
2.70 \\
1.72\end{array}$ \\
\hline \multicolumn{16}{|c|}{ BROWN CO., JACKSON TWP. } \\
\hline S-2507 & $\begin{array}{l}1035-1054 \\
1090-1109 \\
1140-1174 \\
1200-1234 \\
1310-1374\end{array}$ & $\begin{array}{l}49.5 \\
51.3 \\
49.8 \\
52.2 \\
50.0\end{array}$ & $\begin{array}{l}3.62 \\
2.33 \\
3.61 \\
1.88 \\
3.64\end{array}$ & $\begin{array}{l}2.15 \\
1.91 \\
1.80 \\
1.45 \\
1.17\end{array}$ & $\begin{array}{l}0.48 \\
0.47 \\
0.33 \\
0.40 \\
0.31\end{array}$ & $\begin{array}{l}0.23 \\
0.28 \\
0.19 \\
0.17 \\
0.18\end{array}$ & $\begin{array}{l}0.20 \\
0.17 \\
0.10 \\
0.15 \\
0.12\end{array}$ & $\begin{array}{l}0.031 \\
0.038 \\
0.027\end{array}$ & $\begin{array}{l}0.036 \\
0.033 \\
0.034 \\
0.035\end{array}$ & $\begin{array}{l}64 \\
64 \\
74 \\
48\end{array}$ & $\begin{array}{l}0.09 \\
0.08 \\
0.06 \\
0.07 \\
0.06\end{array}$ & $\begin{array}{l}0.003 \\
0.002 \\
0.001 \\
0.002 \\
0.002\end{array}$ & $\begin{array}{l}88.4 \\
91.5 \\
89.0 \\
93.1 \\
89.2\end{array}$ & $\begin{array}{l}7.59 \\
4.88 \\
7.54 \\
3.94 \\
7.61\end{array}$ & $\begin{array}{l}3.04 \\
2.80 \\
2.41 \\
2.18 \\
1.76\end{array}$ \\
\hline
\end{tabular}

${ }^{1}$ Only analyses for zones greater than 15 feet thick were averaged.

${ }^{2} \mathrm{SiO}_{2}+\mathrm{Al}_{2} \mathrm{O}_{3}+\left(1 / 2 \cdot \mathrm{Fe}_{2} \mathrm{O}_{3}\right)+\mathrm{K}_{2} \mathrm{O}+\mathrm{Na}_{2} \mathrm{O}+\mathrm{S}+\mathrm{P}$. 


\section{APPENDIX D.-DESCRIPTIONS OF ADAMS COUNTY AND BROWN COUNTY CORES}

Adams County

Monroe Township

Manchester lslands quadrangle

840'0" Depth 856'0" $\quad \begin{aligned} & \text { Limestone, light- to medium-gray, fine- to } \\ & \text { coarse-grained, fossiliferous; some car- } \\ & \text { bonaceous partings; some 1- to 2-inch } \\ & \text { black shaly zones. Chert, red-stained, } \\ & \text { argillaceous, shaly; } 11 \% \text { inches at } 847 \\ & \text { feet }\end{aligned}$

\section{BLACK RIVER GROUP}

\begin{tabular}{|c|c|c|}
\hline $856^{\prime} 0$ " & $856^{\prime} 10^{\prime \prime}$ & $\begin{array}{l}\text { Limestone, medium-brown and medium- } \\
\text { brownish-gray; biopelsparite and intra- } \\
\text { sparite }\end{array}$ \\
\hline $856^{\prime} 10^{\prime \prime}$ & $857 ' 51 / 2 "$ & $\begin{array}{l}\text { Shale, green and greenish-gray, benton- } \\
\text { itic, fissile, exfoliated; abundant biotite } \\
\text { (up to } 2 \mathrm{~mm} \text { in diameter). Marker bed } a\end{array}$ \\
\hline $857 ' 51 / 2 "$ & $864^{\prime} 6 "$ & $\begin{array}{l}\text { Limestone, light- to medium-gray and } \\
\text { light- to medium-brown; biomicrite, } \\
\text { biointrasparite, and micrite; abundant } \\
\text { Tetradium; moderate number randomly } \\
\text { orien ted sparry-calcite-filled cracks } \\
\text { (shrinkage?) in featureless micrite; nu- } \\
\text { merous nodular carbonaceous partings }\end{array}$ \\
\hline $864^{\prime} 6$ " & 875'6"' & $\begin{array}{l}\text { Limestone, light- to medium-gray and } \\
\text { light-brownish-gray; mottled dark-gray } \\
\text { and light-greenish-gray in places; bio- } \\
\text { turbated argillaceous biomicrite and } \\
\text { biopelsparite (corals, bryozoans, gastro- } \\
\text { pods); some burrows filled with spar, } \\
\text { others filled with coarse-grained argilla- } \\
\text { ceous green limestone }\end{array}$ \\
\hline 875 '6" & 876 '0" & $\begin{array}{l}\text { Shale, light-greenish-gray, bentonitic; } \\
\text { sparse to moderate amount biotite (up } \\
\text { to } 1 \mathrm{~mm} \text { in diameter). Marker bed } \beta\end{array}$ \\
\hline $876^{\prime} 0^{\prime \prime}$ & 881'2" & $\begin{array}{l}\text { Limestone, light- to medium-gray and } \\
\text { light- to medium-brownish-gray; biopel- } \\
\text { sparite; sparse micrite and biomicrite; } \\
\text { Tetradium, ostracods, bryozoans, gas- } \\
\text { tropods; sparse carbonaceous partings }\end{array}$ \\
\hline $881^{\prime 2}$ & 888'1" & $\begin{array}{l}\text { Limestone, light-gray, light- to medium- } \\
\text { brownish-gray; mottled medium-gray in } \\
\text { part; laminated micrite; numerous pla- } \\
\text { nar birdseyes; sparse carbonaceous part- } \\
\text { ings. Shale, green, bentonitic (biotite } \\
\text { <1 mm in diameter); } 1 \text { inch at } 882 \text { feet } \\
2 \text { inches }\end{array}$ \\
\hline 888'1" & 890'11" & $\begin{array}{l}\text { Limestone, light- to medium-gray; lami- } \\
\text { na ted argillaceous biomicrite with } \\
\text { minor amount pelsparite; sparse to } \\
\text { moderate number carbonaceous and } \\
\text { shaly medium- to dark-gray limestone } \\
\text { partings and laminations; moderate } \\
\text { number small planar birdseyes; numer- } \\
\text { ous bubblelike birdseyes }\end{array}$ \\
\hline 890 '11" & 891'4"' & $\begin{array}{l}\text { Limestone as above; abundant carbona- } \\
\text { ceous and shaly laminations; } 21 / 2 \text { inches. } \\
\text { Shale, greenish-gray, bentonitic (biotite } \\
<1 \mathrm{~mm} \text { in diameter); } 2312 \text { inches. Marker } \\
\text { bed } \gamma\end{array}$ \\
\hline 891'4" & 897'1" & $\begin{array}{l}\text { Limestone, light-brownish-gray and light- } \\
\text { gray; mottled medium-gray in part; } \\
\text { laminated micrite; interbedded medi- } \\
\text { um- to dark-brown and medium-gray } \\
\text { dolomite and laminated dolomitic mi- } \\
\text { crite. Clay, green, disseminated; in low- }\end{array}$ \\
\hline
\end{tabular}
Cominco American lnc. CA 51 Permit No. 7

Sample No. 2405

Elevation (G) 531.7 feet
Property Owner: Noah Hughes

897'1"

903'9"

est 4 inches. Chert nodules, white, $1^{1 / 2}$ inches long; at 892 feet and 893 feet 2 inches

Limestone, light- to dark-gray; minor amount light-brownish-gray; micrite and biopelsparite; argillaceous in part laminations and nodular interbeds of fine-grained argillaceous dark-gray dolomitic limestone; minor number horizontal burrows filled with argillaceous dark dolomite

903'9" 910'6"

Limestone, light-brownish-gray, light- to medium-gray, and light- to mediumgreenish-gray; mottled and laminated dark-gray and dark-greenish-gray; laminated micrite and very argillaceous limestone; minor amount pelsparite; numerous planar birdseyes; numerous bubblelike birdseyes; sparse vertical burrows, some filled with sparry calcite, some filled with light-green biosparite. Marker bed $\triangle$

910'6" 916'8" Limestone as in sample from 897 feet 1 inch to 903 feet 9 inches, but dolomitic limestone dark gray and medium to dark greenish gray

916'8" 920'1" Limestone as in sample from 903 feet 9 inches to 910 feet 6 inches; mudcrack from 917 feet 7 inches to 917 feet 8 inches; lowermost 5 inches predominantly laminated shaly medium- to dark-greenish-gray limestone

920'1" 928'6" Limestone, light- to medium-gray and light- to medium-brownish-gray; laminated micrite; numerous planar birdseyes; sparse to numerous layers and partings of fine-grained laminated medium- to dark-brown dolomitic limestone minor number sparry-calcite-filled burrows; intrasparite in lowermost 6 inches

928'6" 932'4" Shale, greenish-gray. Limestone, greenish-gray, shaly, laminated, dense to fine-grained; burrowed in part; sparse planar birdseyes

932'4" 936'3" Limestone, light-gray and light-brownishgray; interbedded laminated micrite, pelsparite, and intrasparite; sparrycalcite-filled burrows; numerous planar birdseyes in micrite

936'3" 936'10" Limestone, argillaceous, shaly; contorted bedding; burrowed; 3 inches. Shale greenish-gray, bentonitic (biotite $<1$ $\mathrm{mm}$ in diameter); 4 inches. Marker bed

936'10" 948'8'"

Limestone, light- to medium-gray and light- to medium-brownish-gray; laminated micrite; minor amount pelsparite and intrasparite; sparse to numerous planar and nonplanar birdseyes; sparse to numerous vertical shrinkage cracks; sparse to numerous partings and laminations of fine-grained medium-gray dolomitic limestone

948'8' 954'2"
Limestone, light- to medium-gray; mottled dark-gray in part; laminated micrite; numerous argillaceous dark-gray and dark-greenish-gray dolomitic limestone laminations and partings; sparand pellet-filled vertical burrows (concentrated from 949 feet 10 inches to 
950 feet 3 inches) deforming color laminations in micrite and dolomitic limestone

954'2" 954'9" Limestone, fine- to medium-grained, argillaceous; interbedded minor amount dark-green bentonitic shale (biotite $<1$ $\mathrm{mm}$ in diameter); beds of $1 / 4,1 / 4$, and 1 inch. Marker bed $b$

954'9" 959'0" Limestone, light to medium-brownishgray; sparse dark-gray mottling; laminated micrite; sparse planar birdseyes; moderate number to numerous lamina tions and interbeds of fine-grained laminated medium- to dark-brown dolomitic limestone; mudcracks

959'0" 967'0" Limestone, light-gray and light- to medium-brownish-gray; sparse to abundant dark-gray mottling; micrite; sparse faint laminations; sparse planar birdseyes; sparse laminations of fine-grained brown dolomitic limestone; crossbedded in part; sparse horizontal partings of carbonaceous limestone; mudcracked in part

967'0" 968'0" Limestone, light-gray; micrite and pelsparite; sparse burrows filled with argillaceous green dolomitic limestone

968'0" 977'6" Limestone, light- to medium-brownishgray; mottled dark-gray in part; biomicrite and Tetradium biopelsparite; sparse to numerous in terbeds and horizontal burrows of fine-grained mediumto dark-brown dolomitic limestone; bio pelsparite concentrated in beds with biomicrite, cut by burrows and interbeds in other beds

977'6" 995'0" Limestone, light-gray; sparse dark-gray mottling; laminated dolomitic micrite with minor amount micrite and biopelmicrite; sparse planar birdseyes in micrite; increasingly dolomitic in lowermost 9 inches. Top of Oregon Forma tion correlative

995'0" 1005'2" Limestone, light- to medium-brownishgray; mottled dark-gray; biopelsparite, biomicrite, and micrite; in terbedded laminated medium- to dark-brown dolo mitic limestone; minor number horizontal burrows filled with dolomitic limestone; scarce planar birdseyes in micrite. Interlaminated dolomite and micrite with desiccation features mainly in upper and lower one-third; biomicrite, biopelsparite, and horizontal burrows mainly in middle one-third

1005'2" 1006'8" Limestone, light-gray, sparsely burrowed; diffuse dark-gray mottling; micrite and biomicrite (Tetradium); fossils and burrows filled with sparry calcite

1006'8" 1008'3" Limestone, medium-brown; biomicrite and biopelsparite; sparry-calcite-filled Tetradium; moderate number irregular layers of fine-grained medium-brown dolomitic limestone

1008'3" 1015'6" Limestone, light- to medium-brownishgray; mottled dark-gray; biopelsparite, biomicrite, and micrite; numerous in terbeds and horizontal burrows of finegrained light- to medium-brownish-gray dolomitic limestone; dolomitic limestone predominant in lower half

1015'6" 1019'6" Limestone, light-gray and light-brownishgray, dolomitic, fine-grained, laminated; minor amount of laminated micrite. Base of Oregon Formation correlative

1019'6" 1026'5" Limestone, medium-brownish-gray and light- to medium-gray; mottled darkgray in part; laminated micrite, biom: crite, intrasparite, and biopelsparite; interbeds and burrows of fine-grained
$1026{ }^{\prime} 5^{\prime \prime}$

1033'2"

1033'2"

\section{$1035^{\prime} 0$ '”}

$1035^{\prime} 0$ "

1036 '"

$1036^{\prime} 4$

$1064^{\prime} 7$

1072'5"

1076'6"

1080'8"

1083'3"

1091'10"

1100 '"

$1102 ' 0 "$

1107'0'

1113'7"

$1115^{\prime} 7 "$

$1121^{\prime} 6$ '

1123'1" $1113^{\prime} 7^{\prime \prime}$

$1115^{\prime} 7^{\prime \prime}$

1121 '6"

1123'1"

1076'6"

1080'8"

1083'3"

1091 '10"

1100 '4"

1102 '0"

$1107^{\prime} 0$ '”

11240

1124 '0" medium-gray and medium-brown dolomitic limestone; sparse to numerous dark-gray carbonaceous partings; mainly interbedded micrite and dolomite with numerous horizontal burrows from 1019 feet 6 inches to 1020 feet 6 inches; mainly laminated micrite with planar birdseyes from 1020 feet 6 inches to 1021 feet 6 inches; mainly intrasparite and biomicrite interbedded and burrowed with dolomitic limestone from 1021 feet 6 inches to 1026 feet 5 inches

Limestone, medium- to dark-gray and medium-brownish-gray, argillaceous mottled dark-gray in part; micrite and biomicrite; numerous interbeds and horizontal burrows of fine-grained dark-gray and dark-brown dolomitic limestone; sparse dark-gray carbona ceous partings. Marker bed I

Limestone, medium- to dark-brown; biomicrite and micrite; numerous sparrycalcite-filled Tetradium tubes

Limestone, light- to medium-gray, medium-brown; mottled dark-gray in part; biomicrite and micrite; sparry-calcitefilled Tetradium; sparse irregular beds of fine-grained brown dolomitic limestone

Limestone, light- to medium-gray and medium-brown; mottled dark-gray in part; micrite and biomicrite; minor amount pelsparite; numerous horizontal burrows and minor number interbeds of fine-grained medium- to dark-brownish-gray dolomitic limestone

Limestone, light-tan and light-gray; micrite, pelsparite, and biopelsparite; minor number dolomite rhombs; numerous horizontal burrows and interbeds of sucrosic fine-grained light- to medium-gray dolomitic limestone

Limestone as in sample from 1036 feet 4 inches to 1064 feet 7 inches

Limestone as in sample from 1064 feet 7 inches to 1072 feet 5 inches

Limestone as in sample from 1036 feet 4 inches to 1064 feet 7 inches

Limestone as in sample from 1064 feet 7 inches to 1072 feet 5 inches, but light to medium brownish gray

Limestone as above; intrasparite in part Limestone, medium-brownish-gray; micrite and pelsparite; interbedded finegrained dark-gray dolomitic limestone

Limestone, medium-gray and mediumbrownish-gray, dolomitic, fine-grained, sucrosic, laminated; 2-inch bed of pelsparite at base

Limestone as in sample from 1064 feet 7 inches to 1072 feet 5 inches; 4 -inch bed of pelsparite at base

Limestone, light-gray and light-brownishgray; micrite; numerous sparry-calcitereplaced Tetradium

Limestone, light-gray and light- to medium-brown; micrite, pelsparite, and biopelsparite; featureless except for minor number sparry-calcite-filled vertical shrinkage cracks; minor number interbeds and sparse burrows of partially dolomitized medium- to dark-brown limestone

Limestone, light-gray and light-brownishgray, dolomitic; minor amount micrite and intrasparite; sparse planar birdseyes in micrite; dolomite faintly laminated Limestone, light-gray and light-brownishgray; biomicrite; minor amount biopel- 
1124'0" 1129'7" $\quad \begin{gathered}\text { sparite; numerous Tetradium } \\ \text { Limestone, medium- to dark-brownish- }\end{gathered}$ gray; biopelsparite, bioin trasparite, and micrite; sparse to numerous interbeds and horizontal burrows of fine-grained light- to dark-gray dolomitic limestone. Top of marker bed II

1129'7" 1131'51/2" Limestone, light-gray; diffuse dark-gray mottling; biomicrite, micrite, and biopelsparite; horizontally laminated $\mathrm{mi}$ crite; faint horizontal laminations in biopelsparite; scarce dolomite zones

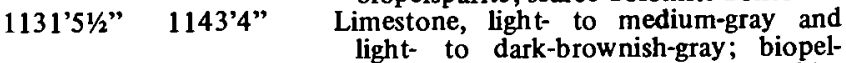
light- to dark-brownish-gray; biopel-
sparite (argillaceous in part) and biomicrite; minor amount micrite; sparse to numerous interbeds and sparse horizontal burrows of fine-grained argillaceous medium- to dark-brownish-gray dolomitic limestone; several $1 / 4-$ to $1 / 2-$ inch zones of shaly dark-gray limestone. Base of marker bed II

1143'4" 1148'0" Limestone, light-tan, light-gray, and light-brownish-gray; minor amount dark-gray mottling; ostracod biomicrite and micrite; slightly dolomitized in part; sparse horizontal and moderate number vertical sparry-calcite-filled and pelsparite-filled burrows; sparse thin interbeds of fine-grained light- to medium-brownish-gray dolomitic limestone

1148'0" 1152'11" Limestone, light-tan and light-brownishgray; micrite, pelsparite, and biopelsparite; moderate number in terbeds and horizontal burrows of fine-grained medium-brown dolomitic limestone

1152'11" 1158'5" Limestone, medium-gray and mediumbrownish-gray; biopelsparite and bio micrite; numerous irregular partings and horizontal burrows of fine-grained lightto dark-gray dolomitic limestone. Zone of medium-grained medium- to darkgray limestone and bentonitic black and dark-greenish-gray shale; biotite up to $2 \mathrm{~mm}$ in diameter sparse in limestone, abundant in shale; $5 \frac{1 / 2}{2}$ inches at 1156 feet 7 inches

1158'5" 1161'4" Limestone, light-tan and light-gray; micrite and pelsparite; sparsely fossiliferous (Tetradium, ostracods, gastropods, bryozoans); sparry-calcite-replaced fossils; minor number thin in terbeds and horizontal burrows of fine-grained lightto medium-brownish-gray dolomitic limestone; sparse dolomite rhombs in micrite

1161'4" 1164'9" Limestone, medium-gray and mediumbrownish-gray; biopelsparite, intrapelsparite, and biomicrite; numerous irregular to nodular partings of finegrained light- to dark-gray dolomitic limestone

1164'9" 1166'9" Limestone, light- to medium-brownishgray; biomicrite and biopelsparite; numerous horizontal burrows filled with biopelsparite; minor number burrows filled with fine-grained light- to darkgray dolomitic limestone

1166'9" 1169'2" Limestone, light- to medium-brownishgray; biomicrite and biointrasparite; numerous Tetradium fragments (some in grow th position?)

1169'2" 1170'8" Limestone, light- to medium-brownishgray; micrite and pelsparite; minor amount large-scale chuming (burrowing?); faint laminations in pelsparite at top; minor number regular $y_{8}$-inch beds of fine-grained dark-brownish-gray dolomitic limestone

1170'8" 1175'8" Limestone, light-tan and light-gray; bio- $1175^{\prime} 8^{\prime \prime} \quad 1188^{\prime} 4^{\prime \prime}$

$1188^{\prime} 4 " \quad 1190{ }^{\prime}$ "

1190'9" 1197'11"

$1197^{\prime} 11^{\prime \prime} \quad 1211^{\prime} 4^{\prime \prime}$

1211'4" 1217'0"

1217'0" 1219'8'

1219'8" 1222'4"

1222'4" 1223'8"

1223'8" 1224'6" pelsparite, biomicrite, and micrite; sparsely dolomitized; in terbeds and horizontal burrows of fine-grained light- to dark-brownish-gray dolomitic limestone

Limestone, medium- to dark-brownishgray and medium- to dark-gray; biopelsparite, pelsparite, and micrite; sparsely dolomitized in part; pelsparite faintly laminated in part; numerous nodular partings, regular in terbeds, and horizontal burrow fillings of fine-grained medium- to dark-brownish-gray and medium- to dark-gray dolomitic limestone. Several $1 / 4-$ to $1 / 2$-inch zones of shaly carbonaceous dark-gray to black limestone from 1180 feet 7 inches to 1182 feet 1 inch

Limestone, medium-brown; mottled dark-gray; biopelsparite, pelsparite, and biomicrite; sparse to moderate number horizontal burrows and thin irregular partings of fine-grained carbonaceous dark-gray and dark-brownish-gray dolomitic limestone

Limestone, medium- to dark-brownishgray and medium- to dark-gray; pelsparite (crossbedded in part), biomicrite, and micrite; irregular to nodular partings and interbeds of shaly darkgray to black limestone and fine-grained dolomitic limestone; gradational with limestone below. Top of upper argillaceous unit

Limestone, medium- to dark-gray and medium-brownish-gray; biomicrite and fossiliferous intrasparite; interbedded with and grading into very argillaceous fine- to medium-grained limestone; laminated in part (color, argillaceous laminae, fossil-hash alignment); mainly laminations and irregular partings of shaly black limestone from 1198 feet $91 / 2$ inches to 1199 feet $7 \frac{1}{2}$ inches

Limestone, medium-brown and mediumbrownish-gray; biomicrite and micrite; Tetradium; sparry-calcite-filled fossils; minor number sparry-calcite-filled burrows; sparse faint laminations and planar birdseyes; sparse wavy to nodular interbeds and partings of fine-grained dark-brown and dark-brownish-gray dolomitic limestone; sparse irregular partings of shaly dark-brownish-gray limestone; moderate number shrinkage cracks in micrite adjacent to finegrained interbeds

Limestone, light-gray to white; micrite; sparse to moderate number dolomite rhombs; sparse to moderate number ostracods; faint lamination (color, grain size, and dolomite layers); sparse birdseyes

Limestone, medium- to dark-brownishgray; interbedded micrite/biomicrite, biopelsparite/biopelmicrite, and intrasparite; faint lamination in some micrite and finer grained pelsparite; sparse to numerous nodular layers of fine-grained dark-brown dolomitic limestone, primarily in lowermost 6 inches

Limestone, light- to medium-gray; mottled dark-gray in part; ostracod biomicrite; pelletal in part; interbedded pelletal to fine-grained laminated dolomite; pelletal areas in biomicrite vaguely burrowed and churned

Limestone, medium-brownish-gray; micrite and pelsparite; sparry-calcite-filled vertical burrows in thickest micrite bed; interbedded fine-grained laminated 


1224'6" 1226'4" $\quad \begin{aligned} & \text { Limestone, light- to medium-gray; ostra- } \\ & \text { cod biomicrite; large churned areas and } \\ & \text { burrows filled with biopelsparite; sparse } \\ & \text { burrows filled with light-green argilla- } \\ & \text { ceous material; } 2 \text {-inch bed of laminated } \\ & \text { biopelsparite (horizontal geopetal struc- } \\ & \text { tures) from 1225 feet } 2 \text { inches to 1225 } \\ & \text { feet 3 inches }\end{aligned}$

1226'4" 1227'5" Limestone, medium- to dark-gray, churned and burrowed; biomicrite and biopelmicrite; several channellike partings of black shale; 1 -inch bed of calcareous fossiliferous dark-greenishgray shale at base (no visible biotite)

1227'5" 1229'1" Limestone, light-gray; minor amount churned and burrowed to pelsparite 1229'1" 1234'1/2" $\begin{gathered}\text { Limestone, medium-grayish-brown and } \\ \text { medium-brown; diffuse dark-gray mot- }\end{gathered}$ tling; laminated micrite; sparse to moderate number planar birdseyes; numerous laminations of fine-grained medium- to dark-brown dolomitic limestone

1234 $7 / 2$ " 1237'5" Limestone, medium- to dark-gray and medium- to dark-brownish-gray, dolomitic, fine-grained, argillaceous; interbedded biopelsparite; minor amount micrite; bedding laminated and nodular/brecciated

1237'5" 1240'8" Limestone, light-gray and light-brownishgray; laminated micrite; moderate number planar birdseyes; sparse laminations of fine-grained medium- to dark-brownish-gray dolomitic limestone

1240'8" 1241'9" Limestone, medium-gray and mediumgreenish-gray; micrite; faint color laminations in part; laminated with finegrained medium- to dark-gray dolomitic limestone; sparse vertical burrows in micrite

1241'9" 1244'2" Limestone, light- to medium-gray; ostracod biomicrite and biopelsparite; fossiliferous churned intrasparite; moderate number wavy laminations of finegrained argillaceous dark-gray dolomitic limestone; minor amount light-green argillaceous material

1244'2" 1244'11/1/2" Limestone, medium- to dark-gray; mi crite. Limestone, dark-brownish-gray, very argillaceous, dolomitic; nodular bedding

1244'111/2" 1245'10" Limestone, medium-brownish-gray; mi crite and pelsparite; prominent 3-inchhigh mudcrack; in terbedded argillaceous dark-gray dolomitic limestone; nodular bedding

1245'10" 1247'10" Limestone, medium-gray and mediumbrownish-gray; laminated micrite; numerous planar birdseyes; laminated with fine-grained dark-brown and darkbrownish-gray dolomitic limestone

1247'10" 1249'3" Limestone, light-gray; diffuse dark-gray mottling; micrite; fossiliferous in part; chumed to pelsparite in part; moderate number sparry-calcite-filled vertical burrows

1249'3" 1256'5" Limestone, light-gray and light-greenishgray; light-brownish-gray toward base; micrite; laminated in part; numerous planar and nonplanar birdseyes; moderate number paper-thin to $3 / 4$-inch regular beds of shaly dark-greenish-gray and dark-brown limestone. Base of upper argillaceous unit

1256'5" 1263'7" Limestone, medium-gray and mediumbrownish-gray; micrite and biomicrite; minor amount pelsparite; Tetradium fragments; sparse burrowlike areas of $12637^{\prime \prime}$

$1270^{\prime} 7 "$

$1270^{\prime \prime}$

$1283^{\prime} 8 "$

$1283^{\prime} 8^{\prime \prime}$

1293'3"

1293'3"

\section{$1295^{\prime} 11^{\prime \prime}$}

$1295^{\prime} 11^{\prime \prime} 1297 ' 6 "$

1297 '6"

1309'8"

1309'8'

$1318^{\prime} 0^{\prime \prime}$

1318'0" 1336'0"

1336 '0" $1337^{\prime} 2$ "'

1337'2" 1338'3"' pelsparite in micrite; moderate number to numerous sparry-calcite-filled vertical burrows; moderate number irregular beds and partings of fine-grained darkgray and dark-brownish-gray dolomitic limestone; sparse shaly dark-gray limestone partings; micrite with vertical burrows concentrated toward top; pelsparite and biomicrite concentrated toward base. Top of Carntown unit

Limestone, light- to medium-brownishgray and medium-gray; biomicrite, biopelsparite, and micrite; numerous irregular partings and horizontal burrow fillings of fine-grained light- to medi um-brownish-gray dolomitic limestone

Limestone, light-tan; biomicrite, biopelsparite, and fossiliferous intrasparite; slightly dolomitized in part; numerous irregular partings and horizontal burrows of fine-grained light- to mediumbrownish-gray dolomitic limestone

Limestone, light- to medium-brownishgray and light- to medium-gray; biomi crite and micrite; numerous irregular partings and horizontal burrow fillings of fine-grained medium- to dark-brownish-gray dolomitic limestone

Limestone, light-gray; sparse diffuse dark-gray mottling; faintly laminated micrite; sparse to moderate number small planar birdseyes

Limestone, medium-brown; laminated mi crite; moderate number planar birdseyes; numerous laminations of finegrained dark-brown dolomitic limestone; featureless micrite in lowermost 3 inches

Limestone, light-gray; sparse diffuse dark-gray mottling; micrite; faintly laminated to laminated; minor amount featureless; sparse to numerous planar birdseyes; sparse nonplanar birdseyes; sligh tly dolomitic in part; sparse laminations of fine-grained medium-brown dolomitic limestone. Dolomite, medium-brownish-gray, laminated; 2 inches at 1299 feet $7 \frac{1}{2}$ inches. Dolomite, medium-brownish-gray, laminated; 1 inch at 1304 feet. Limestone, mediumgray, dolomitic, dense to fine-grained; laminated dark-gray; from 1305 feet 6 inches to 1306 feet 3 inches

Limestone, light- to medium-brown and medium-brownish-gray; dark brown in lowest 6 inches; biomicrite and micrite; Tetradium; micrite slightly dolomitic in part; sparse to moderate number irregular partings and horizontal burrow fill ings of fine-grained medium- to darkbrownish-gray dolomitic limestone. Base of Carntown unit

Limestone, medium- to dark-brownishgray and medium- to dark-gray, fine- to medium-grained; mottled dark-gray and greenish-gray; argillaceous in part; burrowed in part; interbedded minor amount partially laminated light- to dark-brownish-gray micrite, biomicrite (Tetradium), and pelsparite; burrowed in part; argillaceous in part; laminations of dark-brown and dark-gray dolomite. Top of lower argillaceous unit

Limestone, medium-brown; laminated mi crite; numerous planar and nonplanar birdseyes (nonplanar birdseyes grading into pelsparite at base); moderate number laminations of fine-grained mediumto dark-brown dolomitic limestone

Limestone, medium-brown; micrite; mod- 
erate number sparry-calcite-filled vertical cracks or burrows; minor number laminations of fine-grained dark-brown dolomitic limestone

\begin{tabular}{|c|c|c|}
\hline & & \\
\hline 1338'3" & 1339 '0" & $\begin{array}{l}\text { Limestone, light-gray; micrite; moderate } \\
\text { number sparry-calcite-filled vertical and } \\
\text { horizontal burrows }\end{array}$ \\
\hline $1339^{\prime} 0^{\prime \prime}$ & $1342 ' 5 "$ & $\begin{array}{l}\text { Limestone, light-gray and light- to medi- } \\
\text { um-brownish-gray; micrite; sparse } \\
\text { sparry-calcite-filled vertical burrows; } \\
\text { sparse } 1 / 4-\text { to } 1 / 2-\text {-inch zones of fine- } \\
\text { grained medium- to dark-brown dolo- } \\
\text { mitic limestone }\end{array}$ \\
\hline 1342 '5" & 1342'9"' & $\begin{array}{l}\text { Limestone, medium- to dark-brownish- } \\
\text { gray and medium- to dark-greenish- } \\
\text { gray, dense to fine-grained, burrowed; } \\
\text { argillaceous in part; nodular bedding }\end{array}$ \\
\hline 1342'9"' & 1346'5" & $\begin{array}{l}\text { Limestone, light- to medium-brownish- } \\
\text { gray and medium-brown; mottled dark- } \\
\text { gray in part; laminated micrite; minor } \\
\text { amount featureless micrite; moderate } \\
\text { number planar and nonplanar birdseyes; } \\
\text { sparse to moderate number laminations } \\
\text { of fine-grained dolomitic limestone; } \\
\text { grading into limestone below }\end{array}$ \\
\hline 1346 '5" & $1347 ' 5 "$ & $\begin{array}{l}\text { Limestone, medium-gray and dark- } \\
\text { greenish-gray, shaly, fine- to medium- } \\
\text { grained }\end{array}$ \\
\hline 1347 '5" & 1349'5" & $\begin{array}{l}\text { Limestone; grading from light gray at top } \\
\text { to medium brown at base; laminated } \\
\text { micrite; sparse to numerous planar and } \\
\text { nonplanar birdseyes (particularly in } \\
\text { upper part); sparse to numerous lamina- } \\
\text { tions of fine-grained dark-brown dolo- } \\
\text { mitic limestone (particularly in lower } \\
\text { part) }\end{array}$ \\
\hline $1349^{\prime} 5$ " & $1353^{\prime} 0^{\prime \prime \prime}$ & $\begin{array}{l}\text { Limestone as in sample from } 1346 \text { feet } 5 \\
\text { inches to } 1347 \text { feet } 5 \text { inches; some dark } \\
\text { gray }\end{array}$ \\
\hline $1353^{\prime} 0^{\prime \prime}$ & $1359^{\prime} 2^{\prime \prime}$ & $\begin{array}{l}\text { Limestone, medium- to dark-gray and } \\
\text { medium-brownish-gray; mottled dark- } \\
\text { gray in part; laminated micrite; sparse } \\
\text { planar birdseyes; sparse to numerous } \\
\text { laminations of dolomitic limestone. } \\
\text { Base of lower argillaceous unit }\end{array}$ \\
\hline
\end{tabular}

\section{WELLS CREEK FORMATION}

1359'2" 1360'3" Limestone, light-gray to light-greenishgray, dense to fine-grained, argillaceous, dolomitic; sparse diffuse dark-gray mottling; grading into shale below

1360'3" 1361'6"' $\quad \begin{aligned} & \text { Shale, dark-greenish-gray, subfissile } \\ & \text { Dolomite, light-gray, very fine-grained, }\end{aligned}$ argillaceous, porous

1361'10" 1370'0" Dolomite as above; some green shale, 2 to 4 inches thick

Brown County Jackson Township Ash Ridge quadrangle
$8960^{\prime \prime}$ "Depth $926^{\prime}+$
Limestone, medium-gray to medium- brownish-gray, dense- to medium- grained, fossiliferous, medium-bedded; wavy shale interbeddings; some 4- to 10 -inch beds of dark-greenish-gray shale and hard shaly limestone. Chert nodule, reddish; 1 inch at 923 feet

\section{BLACK RIVER GROUP}

\begin{abstract}
Property Owner: Herbert Rockey
Permit No. 5

Sample No. 2507

Elevation (G) 990.3 feet
\end{abstract}

$\begin{array}{ccc}926 & 928^{\prime}+ & \begin{array}{l}\text { Limestone, medium-gray to medium- } \\ \text { b rownish-gray; biopelsparite; minor } \\ \text { amount biomicrite (Tetradium) near } \\ \text { base }\end{array} \\ 928^{\prime}+ & 930^{\prime} 0^{\prime \prime} \quad \begin{array}{l}\text { Shale, light- to dark-green, bentonitic; }\end{array}\end{array}$

961'10" 963'6"

930'0" 937'0" $\quad \begin{aligned} & \text { Marker bed } a \\ & \text { Limestone, light- to medium-brown, bio- }\end{aligned}$ turbated; Tetradium biomicrite, biopelsparite, and micrite; sparry-calcitefilled vertical shrinkage cracks in mi crite; nodular bedding; sparse to numerous carbonaceous partings; some irregular $1 / 2$-inch-thick chert nodules

937'0" 947'3" Limestone, light-gray and light- to medi u m-brownish-gray, argillaceous, bioturbated; mottled medium- to darkbrownish-gray and greenish-gray; biomicrite; minor amount micrite and biopelsparite; nodular bedded; numerous $y_{16}-$ to $3_{8}$-inch irregular beds of darkgray and dark-greenish-gray shale; burrow fillings of light-green argillaceous material

947'3" 948'3" Shale, light-greenish-gray to dark-gray, ben tonitic. Marker bed $\beta$

948'3" 949'0" Limestone, light- to medium-brown, burrowed; micrite, biomicrite, and intrasparite; burrows filled with fine- to medium-grained argillaceous dolomitic limestone; silicified in upper half

949'0" 951'6" Limestone, white to light-gray, faintly laminated; minor amount medium-gray mottling; micrite; sparse planar and nonplanar birdseyes; numerous sparrycalcite-filled horizontal and vertical burrows; minor number burrows filled with very fine-grained white limestone. Chert nodule; 4 inches at 950 feet

951'6" 953'11" Limestone, medium-brownish-gray, stylolitic; micrite and Tetradium biomicrite; minor number burrows filled with finegrained medium- to dark-brown dolomitic limestone; sparry-calcite-filled vertical shrinkage cracks in featureless micrite; lowermost 5 inches grading from intrasparite at top to pelsparite at base

953'11" 955'7" Limestone, tan and light-gray; micrite; laminated in upper part; numerous pla nar and nonplanar birdseyes; sparse lami nations of fine-grained medium- to dark-brownish-gray dolomitic limestone

955'7" 961'10" Limestone, light-brown and light- to medium-brownish-gray; mottled medium- to dark-gray in part; micrite and laminated micrite; sparse to moderate number laminations and interbeds of fine-grained argillaceous medium- to dark-brownish-gray dolomitic limestone; moderate number very small planar birdseyes in laminated micrite; sparse planar birdseyes in thinner beds of nonlaminated micrite; moderate number sparry-calcite-filled vertical burrows in thicker beds of nonlaminated micrite

Limestone, medium- to dark-gray, laminated; argillaceous micrite; sparse to numerous laminations and partings of shaly medium- to dark-greenish-gray limestone; moderate number small planar birdseyes in micrite; numerous sparry-calcite-filled bubblelike voids. Shale, dark-greenish-gray, ex foliated; $1 \frac{112}{2}$ inches at base. Marker bed $\gamma$

963'6" 965'6" Limestone, light-brownish-gray and lightgray, very thin-bedded; micrite; laminated by dark-brown carbonaceous films; mudcrack; very sparse planar birdseyes

965'6" 967'5" Limestone, light- to medium-brownishgray and light-gray; micrite; laminated in part; sparse to numerous nonplanar 
birdseyes; sparse planar birdseyes

Limestone, light- to medium-brownishgray and medium-gray; Tetradium biomicrite; interbedded micrite and pelmicrite; moderate number burrows in lower part

970'4" 976'0" Limestone, medium- to dark-gray and light- to medium-brownish-gray; mottled in part; micrite and pelsparite; fossiliferous in part; moderate number to numerous burrows and nodular interbeds of argillaceous fine-grained darkgray and light- to medium-greenish-gray dolomitic limestone

976'0" 977'7" Limestone, medium-brownish-gray; micrite and pelsparite; numerous horizontal burrows of fine-grained mediumbrownish-gray dolomitic limestone

977'7" 988'6" Limestone, medium-gray, mediumbrownish-gray, and medium-greenishgray; argillaceous bryozoan biomicrite; minor amount micrite and pelsparite; numerous nodular interbeds and minor number horizontal burrows of argillaceous fine-grained dark-gray and darkgreenish-gray dolomitic limestone. Marker bed $\triangle$

988'6" 991'6" Limestone, medium-gray and light- to medium-brownish-gray; micrite and pelsparite; moderate number nodular in terbeds and horizontal burrows of finegrained light- to dark-greenish-gray dolomitic limestone

991'6" 1000'6" Limestone, light-gray and light-brownishgray; sparse dark-gray mottling; micrite; moderate amount intrasparite; minor amount crossbedded pelsparite; moderate number vertical burrows, some filled with sparry calcite, some filled with light-green argillaceous material; moderate number vertical shrinkage cracks (mudcracks?); sparse planar birdseyes; birdseye zones faintly laminated; sparse laminations and interbeds of fine-grained dark-brown dolomitic limestone

1000'6" 1004'6" Limestone, light-brownish-gray and lightto medium-greenish-gray; micrite; minor amount laminated micrite; argillaceous in large part; numerous planar birdseyes; numerous bubblelike birdseyes; minor number burrows; numerous laminations and interbeds of mediumto dark-green shale. Shale, bentonitic, 3 inches at 1003 feet. Marker bed a

1004'6" 1019'6" Limestone, light-gray, light-brown, and light- to medium-brownish-gray; mottled dark-gray in part; laminated $\mathrm{mi}$ crite, intrasparite, pelsparite, and $\mathrm{mr}$ crite; interbedded and laminated with fine-grained medium- to dark-brownish-gray laminated dolomite, concentrated at 1006 feet to 1007 feet 6 inches and 1010 feet 8 inches to 1015 feet; sparse to numerous planar birdseyes and sparse bubblelike birdseyes, mainly in laminated micrite, sparse in pelsparite; moderate number sparrycalcite-filled vertical burrows; minor number pelsparite-filled vertical burrows, mainly in pelsparite and nonlaminated micrite, sparse in laminated $\mathrm{mi}$ crite

1019'6" 1024'10" Limestone, light- to medium-gray and light- to medium-greenish-gray; mottled dark-gray; laminated micrite with minor amount intrasparite; very argillaceous, grading to shale; sparse to moderate number small planar birdseyes; moderate number to numerous vertical bur-
1024'10" 1025'4" Shale, dark-greenish-gray, bentonitic, exfoliated; trace biotite ( $<1 \mathrm{~mm}$ diameter). Marker bed $b$

1025'4" 1026'0" Limestone, medium-gray; micrite; sparse sparry-calcite-filled vertical burrows

1026'0" 1029'5" Dolomite, light- to dark-brownish-gray, fine-grained, laminated; mottled darkgray; interbedded and laminated with light- to medium-brownish-gray limestone; micrite, laminated micrite, and minor amount intrasparite; sparse pla nar birdseyes

1029'5" 1035'3" Limestone, light- to medium-gray and medium-brownish-gray; micrite; minor amount pelsparite and intrasparite; sparse sparry-calcite-filled vertical burrows; sparse faint laminations; sparse small planar birdseyes; sparse thin nodular interbeds and laminations of finegrained medium- to dark-brownish-gray dolomite. Limestone; biointrasparite; 2 -inch bed 2 inches above base

1035'3" 1037'7'"

Limestone, medium- to dark-brownishgray and medium- to dark-brown; mi crite and Tetradium biomicrite; interbedded fine-grained dark-brown and dark-brownish-gray dolomite; nodular bedded in part

1037'7" 1039'4" Limestone, light-brownish-gray; Tetradium biosparite and Tetradium biopelsparite

1039'4" 1043'9" Limestone, light- to medium-brownishgray; mottled dark-gray; Tetradium biosparite, biopelsparite, biomicrite, intra sparite, and micrite; dolomitized in part; in part burrowed and nodular interbedded fine-grained light-brown and medium- to dark-brownish-gray dolomite

1043'9" 1053'0" Limestone, light- to medium-gray and light- to dark-brownish-gray; mottled dark-gray; micrite; moderate amount biomicrite; minor amount pelsparite, biopelsparite, and intrasparite; sparsely to highly dolomitized; faint to definite laminations of color, dolomite rhombs, and pellets, approximately $50 \%$; sparse sparry-calcite-filled vertical burrows. Top of Oregon Formation correlative

1053'0" 1056'0" Limestone and dolomite, light-brownishgray; mottled dark-gray; in terlaminated dolomite and micrite; minor amount intrasparite

1056'0" 1058'0" Limestone, light-brownish-gray, thinbedded; mottled dark-gray; laminated micrite; moderate number to numerous flat to nodular laminations of finegrained light-brown dolomite

1058'0" 1061'0" Limestone, light-gray; sparse dark-gray mottling; 11 inches biomicrite and $\mathrm{mi-}$ crite (Tetradium fragments at top); sparse vertical to horizontal burrows filled with sparry calcite and finegrained dolomite; grading into laminated micrite. 7 inches laminated micrite; moderate number very small planar birdseyes; moderate number bubblelike birdseyes; sparse dolomite rhombs. 3 inches dark-brown and dark-gray laminated dolomite, minor amount faintly laminated micrite. Micrite and biomicrite, nodular bedded in part, faint laminations in part; sparse dolomite rhombs; grading into limestone and dolomite below 
1061'0" 1068'0" Limestone and dolomite, light-gray and light-brownish-gray; mottled dark-gray; laminated dolomite; interlaminated dolomite and micrite; laminated micrite; minor amount micrite and intrasparite; sparse to moderate number planar birdseyes in laminated micrite

1068'0' 1071'2" Limestone, light- to dark-brownish-gray; biomicrite and micrite; minor amount pelsparite and biointrasparite; Tetradium fragments; most fossils replaced by sparry calcite

1071'2" 1078'7" Dolomite and limestone, light- to medium-gray and light- to medium-brownish-gray; dolomite; laminated dolomite; dolomitic micrite; minor amount interlaminated dolomite and micrite; minor amount pelsparite and intrasparite. Base of Oregon Formation correlative

1078'7" 1079'1" Limestone, light- to medium-brownishgray; mottled dark-gray and darkbrownish-gray; Tetradium biomicrite at base; micrite at top; sparse (base) to numerous (top) horizontal burrows filled with fine-grained dolomitic limestone

1079'1" 1080'8" Limestone, light-brownish-gray; micrite; top 4 inches faintly laminated; moderate number nonplanar birdseyes; sparse very small planar birdseyes; middle 9 inches moderate number nodular brown dolomite laminations; basal 6 inches some irregular "disturbed" areas of nonplanar birdseyes (burrowed areas?)

1080'8" 1089'5" Limestone, light- to medium-gray and light- to medium-greenish-gray; biomicrite and micrite; large fauna including Tetradium; argillaceous in part; chumed and burrowed in part; burrows filled with argillaceous light-green and medium- to dark-greenish-gray dolomite; concentrations of regular to nodular bedded and laminated carbonaceous dark-gray shale and shaly limestone at 1081 feet 1 inch to 1081 feet 5 inches, 1084 feet 1 inch to 1084 feet 7 inches (including $\approx 2$-inch black shale bed), 1085 feet 1 inch to 1085 feet 3 inches, and 1088 feet 6 inches to 1089 feet 5 inches. Marker bed I

1089'5" 1097'0" Limestone, light- to medium-brownishgray and light- to medium-gray; Tetradium biomicrite; minor amount Tetradium biopelsparite, Tetradium biosparite, and micrite; uppermost 9 inches micrite and Tetradium biomicrite, very faint laminations, moderate number nonplanar birdseyes; uppermost 1 inch faintly laminated micrite with numerous vertical burrows filled with fine-grained argillaceous dark-brown dolomite

1097'0" 1107'0" Limestone, medium-brownish-gray and medium-gray; micrite, biomicrite, and biopelsparite; minor amount pelsparite; moderate number horizontal burrows and irregular interbeds of fine-grained light- to medium-gray and light-greenish-gray dolomitic limestone

1107'0" 1111'4" Limestone, light-brownish-gray; biopelmicrite and biopelsparite; minor amount biomicrite and intrasparite; sparse to moderate number horizontal burrows and irregular interbeds of finegrained medium- to dark-brown dolomitic limestone

1111'4" 1120'6" Limestone, light- to medium-gray and light- to medium-brownish-gray; pelmicrite, micrite, biopelsparite, and biomicrite; minor amount biopelmicrite; moderate number to numerous horizon- tal burrows and irregular interbeds of fine-grained medium- to dark-gray and medium- to dark-brownish-gray dolomitic limestone

1120'6" 1127'6" Limestone, light- to medium-brown; micrite; slightly to moderately dolomitic; numerous burrows and irregular interbeds of fine-grained medium-brownishgray dolomitic limestone

1127'6" 1156'0" Limestone, light- to medium-gray and light- to medium-brownish-gray; mi crite, pelsparite, biopelsparite, pelmi crite, and biopelmicrite; sparse to moderate number horizontal burrows and irregular interbeds of fine-grained light- to dark-brownish-gray dolomitic limestone

1156'0" 1159'0" Limestone, light- to medium-gray, lami nated, crossbedded; pelmicrite and pelsparite; sparse laminations and thin interbeds (up to $1 / 4$ inch thick) of fine-grained dark-gray dolomitic limestone

1159'0" 1162'0" Limestone, medium-gray, dolomitic; pelmicrite (laminated in part), micrite, and pelsparite; interbedded fine-grained dark-gray dolomite

1162'0" 1167'6" Limestone, tan and light- to mediumbrownish-gray, dolomitic; micrite, pelmicrite, intrasparite, and biopelsparite numerous irregular interbeds and hori zontal burrows of fine-grained medium-brownish-gray dolomitic limestone

1167'6" 1168'11" Limestone, light-gray, dolomitic; micrite, intrasparite, and pelmicrite; sparse irreg ular to nodular laminations of finegrained light- to medium-gray dolomite

1168'11" 1172'6" Limestone, light- to medium-gray and medium-brownish-gray; intrasparite, biointrasparite, and biopelsparite minor amount micrite; sparse to moderate number irregular interbeds of finegrained medium- to dark-brownish-gray and dark-brown dolomite

1172'6" 1175'6" Limestone, light-gray and medium-brownish-gray; biomicrite and biopelsparite; Tetradium fragments; minor amount micrite

1175'6" 1176'4" Cavernous? zone; poor core; probably horizontally burrowed micrite

1176'4" 1181'0" Poor core recovery; ends broken and nonmatching; order uncertain; appears to be medium-gray micrite and dolomitic Tetradium biomicrite; overlain and underlain by biointrasparite, biopelsparite, and in trasparite

1181'0" 1186'10" Limestone, medium- to dark-gray and medium- to dark-brownish-gray; biomicrite, biopelsparite, biointrasparite, and in trasparite; minor amount micrite; argillaceous in part; dolomitic in part; sparse to moderate number irregular in terbeds and sparse horizontal burrows of fine-grained dark-brownish-gray and dark-brown dolomitic limestone. Top of marker bed II

1186'10" 1187'11" Limestone, light-gray and light- to medium-brownish-gray; micrite and biomicrite; chumed and burrowed to pelsparite in part; dolomitic in part; sparse $1 / 4$ - to 1-inch interbeds of dark-brown dolomitic limestone in bottom half

1187'11" 1189'0" Poor core, core loss?; grayish-green and dark-gray shale and shaly limestone

1189'0" 1199'4" Limestone, medium- to dark-gray, medium- to dark-brownish-gray, and darkbrown; biomicrite, biopelsparite, and biointrasparite; argillaceous i large part; dolomitic in part; sparse to numerous irregular interbeds and horizontal 
burrows of fine-grained dark-brownishgray and dark-brown dolomite. Base of marker bed II

1199'4" 1200'10" Limestone, light-brownish-gray; biopelsparite, biointrasparite, and biomicrite; sparse micrite; some dolomitization of sparry matrix

1200'10" 1203'9" Limestone, light-gray; micrite; moderate number vertical and sparse horizontal burrows filled with sparry calcite; sparse to moderate number ostracods

1203'9" 1204'4" Limestone, light-gray and light-brownishgray; Tetradium biomicrite; sparse vertical burrows filled with sparry calcite and pelsparite

1204'4" 1206'2" Limestone, light-gray and light-brownishgray; micrite and pelmicrite; sparse intrasparite; moderate number dolomite rhombs; sparse very faint laminations

1206'2" 1207'9" Limestone, medium-brownish-gray; mi crite; interbedded medium- to darkbrownish-gray dolomite; moderate number sparry-calcite-filled vertical shrinkage cracks in micrite

1207'9" 1216'7" Limestone, medium-gray and light- to medium-brownish-gray; biomicrite, pelmicrite, biopelmicrite, pelsparite, and biopelsparite; minor amount micrite and intrasparite; sparse to moderate number irregular interbeds and horizontal burrows of fine-grained medium- to dark-gray and light- to dark-brownishgray dolomitic limestone

1216'7" 1220'5" Limestone, light- to medium-gray; biointrasparite; sparse irregular partings of argillaceous fine-grained medium- to dark-brownish-gray dolomitic limestone, mainly in lowermost 6 inches 1220'5" 1222'5" $\begin{gathered}\text { Limestone, light-gray; micrite; sparsely } \\ \text { fossiliferous, Tetradium fragments and }\end{gathered}$ ostracods; sparse dolomite rhombs; sparse sparry-calcite-filled vertical and horizontal burrows

1222'5" 1227'0" Limestone, medium-brownish-gray; micrite, biomicrite, biopelmicrite, and biointrasparite; sparse to moderate number Tetradium fragments; Tetradium in growth? position from 1222 feet 11 inches to 1223 feet $4 \frac{1}{2}$ inches; minor number irregular interbeds of finegrained medium- to dark-brownish-gray dolomitic limestone

1227'0" 1230'6" Limestone, light-brownish-gray; micrite, biomicrite, and biointrasparite; dolomitic and chalky in part; numerous irregular interbeds and moderate number horizontal burrows of fine-grained medium- to dark-brown dolomite; numerous sparry-calcite-filled shrinkage cracks in micrite, generally aligned approximately perpendicular to dolomite in terbeds

1230'6" 1249'3" Limestone, medium- to dark-brownishgray, medium- to dark-gray, and lightto dark-brown; biomicrite; moderate amount micrite, pelmicrite, and biopelsparite; minor amount biopelmicrite and pelsparite; sparse to numerous irregular interbeds and horizontal burrows of dark-brown, medium-brownish-gray, and dark-gray dolomitic limestone; moderate number partings and interbeds (up to $1 / 2$ inch thick) of carbonaceous black shale and shaly limestone from 1236 feet to 1238 feet 5 inches; matrix moderately dolomitized from 1241 feet to 1243 feet; sandy biopelsparite, 2 inches at 1243 feet

1249'3" 1256'0" Limestone, medium- to dark-gray, medi-
1256'0" 1261'4" $\begin{gathered}\text { ceous unit } \\ \text { Limestone, medium- to dark-brownish- }\end{gathered}$ gray and medium-greenish-gray, argillaceous; micrite, biopelsparite, and per sparite; regularly interbedded argillaceous fine-grained dark-brownish-gray and dark-greenish-gray dolomite and carbonaceous dark-greenish-gray and dark-gray shale and shaly limestone

1261'4" 1266'8" Limestone, medium-gray and mediumbrownish-gray; biomicrite; argillaceous in part; dolomitic in part; moderate number nodular to feathery interbeds and partings of carbonaceous mediumto dark-greenish-gray and dark-gray shale and shaly limestone; sparse irregular green-clay partings

1266'8" 1268'0" Limestone, light-gray and light-brownishgray; biomicrite; argillaceous in part; bioturbated to biopelsparite in part

1268'0" $\quad 1269^{\prime} 10^{\prime \prime} \quad$ Limestone, light-gray and light-brownishgray; fossiliferous micrite and biomicrite (Tetradium and other corals, ostracods, gastropods); sparry-calcite-filled fossils; sparse sparry-calcite-filled vertical and horizontal burrows; zone of argillaceous biointrasparite from 1269 feet to 1269 feet 4 inches

1269'10" 1270'9" Limestone, medium- to dark-brownishgray; some dark-gray mottling; micrite, biomicrite, biointrasparite, and dolomitic micrite; numerous irregular to nodular partings of carbonaceous black and dark-brownish-gray shale and shaly limestone

1270'9" 1272'3" Limestone, light-brownish-gray; micrite; moderate number sparry-calcitereplaced Tetradium fragments; moderate number sparry-calcite-filled horizontal and vertical burrows, filled with light-green argillaceous material in uppermost 4 inches

1272'3" 1274'0" Limest one, medium-brown; mottled medium- to dark-brownish-gray; mi crite; sparse to moderate number sparry-calcite-filled vertical shrinkage cracks; moderate number nodular partings of fine-grained medium- to darkbrown dolomitic limestone

1274'0" 1278'0" Limestone, medium-brown and mediumto dark-brownish-gray; micrite, biomicrite (Tetradium, ostracods, gastropods), and pelsparite; sparse horizontal burrows of dolomitic limestone; several wavy partings and interbeds (up to $1 / \mathrm{s}$ inch thick) of shaly black and dark-gray limestone from 1276 feet 11 inches to 1277 feet 6 inches

1278'0" 1286'1" Limestone, light- to medium-gray and light- to medium-brownish-gray; minor amount medium- to dark-gray mottling; micrite and pelmicrite; chumed and burrowed to pelsparite in part; slightly fossiliferous in part; minor number sparry-calcite-filled vertical burrows; moderate number swirled burrows; very sparse faint laminations of color or micrite and intrasparite; sparse darkgreen and dark-gray shale interbeds 


$\begin{array}{ll}1286^{\prime} 1 " & 1286^{\prime} 4 " \\ 1286^{\prime} 4 " & 1287^{\prime} 11^{\prime \prime}\end{array}$

1287'11" 1289'4"'

1289'4"

1290'10"

1290'10" 1293'4"

1293 '"'

1297 '0"

1284 feet 6 inches)

Shale, dark-greenish-gray, carbonaceous. Limestone, dark-greenish-gray, shaly

Limestone, dark-brownish-gray; minor amount dark-gray mottling; micrite; minor amount biomicrite (very thin ostracod tests); sparse amount pelsparite; sparse to moderate number horizontal burrows (mainly in uppermost 8 inches) and moderate number irregular to nodular in terbeds of shaly black and dark-gray dolomite

Limestone, light-gray and light-brownishgray; laminated micrite; faint wavy color laminations; very sparse planar birdseyes; moderate number very thin sparry-calcite-filled mudcracks; numerous vertical tubelike striations $(<0.5$ mm wide, $\approx 5 \mathrm{~mm}$ long)

Limestone, light- to medium-brownishgray and medium-brown; micrite; moderate number very faint wavy laminations; numerous very thin sparrycalcite-filled mudcracks; sparse to moderate number vertical tubelike striations Limestone, medium-brownish-gray and medium-brown; micrite; sparse wavy laminations; moderate number to numerous sparry-calcite-filled shrinkage cracks adjacent and perpendicular to partings

Limestone, medium-gray; minor amount dark-gray mottling; micrite; sparse biomicrite and biointrasparite; sparse sparry-calcite-filled shrinkage cracks; moderate number to numerous horizon$\mathrm{tal}$ burrows and irregular interbeds of fine-grained medium- to dark-gray and medium-greenish-gray dolomitic limestone

1297'0" 1299'3" Limestone, medium-brown and mediumbrownish-gray; minor amount dark-gray mottling; micrite, biomicrite, biopelsparite, biointrasparite, and pelmicrite; sparry-calcite-filled vertical shrinkage cracks in micrite; sparse to moderate number vertical to horizontal burrows, some filled with fine-grained light- to dark-gray and light- to mediumgreenish-gray dolomite, some with biopelsparite and biointrasparite 1299'3" 1300'6" $\begin{array}{r}\text { Limestone, medium-brownish-gray, bio- } \\ \text { turbated; minor amount medium- to }\end{array}$ dark-gray mottling; bioin trasparite, bio intrapelsparite, and biomicrite; slightly dolomitic in part; burrows filled with light- to dark-gray dolomite, dolomitic limestone, and biopelsparite

1300'6" 1302'9" Limestone, medium-gray and mediumbrownish-gray; micrite, biomicrite, and biopelsparite; moderate number sparrycalcite-filled vertical shrinkage cracks in micrite; moderate number nodular to regular beds (up to $1 / 2$ inch thick) of fine-grained argillaceous dark-gray dolomite

1302'9" 1307'1" Limestone, medium-brownish-gray; minor amount medium-gray mottling; Tetradium biomicrite and micrite; minor number sparry-calcite-filled vertical shrinkage cracks in micrite; minor number horizontal burrows and irregular interbeds of fine-grained light- to mediumbrown, brownish-gray, and medium- to dark-greenish-gray dolomitic limestone

1307'1" 1310'3" Limestone, medium-brownish-gray; micrite; moderate amount biomicrite; minor amount biointrasparite; minor number sparry-calcite-filled vertical

1310'3" 1313'6"

shrinkage cracks; minor number horizontal and inclined burrows, some filled with medium-grained light-gray dolomite, some with dolomitic pelsparite; minor number nodular interbeds of argillaceous dark-brown dolomite. Base of upper argillaceous unit

Limestone, light- to medium-brown; dolomitic in part; biomicrite, micrite, in trasparite, and intrapelsparite; moderate number to numerous horizontal burrows and minor number nodular interbeds of fine-grained light- to mediumbrown dolomite. Top of Carntown unit

1313'6" 1316'0" Limestone very similar to sample from 1307 feet 1 inch to 1310 feet 3 inches; core jumbled(?); some ends don't match from 1310 feet to 1316 feet

1316'0" 1337'0" Limestone, light- to medium-brown and medium-brownish-gray; mainly dolomitic; biomicrite, biopelsparite, and pelsparite; minor amount micrite; moderate number to numerous horizontal burrows and nodular interbeds of finegrained light- to medium-brown dolomite; moderate number sparry-calcitefilled shrinkage cracks

1337'0" 1338'1" Limestone, medium-gray and mediumbrownish-gray; pelmicrite and biopelmicrite; sparse to numerous horizontal burrows and irregular in terbeds of finegrained medium-gray dolomite. Limestone, medium- to coarse-grained, bioclastic; 3-inch bed at base

1338'1" 1341'5" Limestone, light-brown and light- to medium-brownish-gray; dolomitic in part; micrite, biomicrite, and biopelsparite; numerous burrows of finegrained light-brown and light- to medium-gray dolomite

1341'5" 1347'6" Limestone, light- to medium-brown and light to medium-brownish-gray; dolomitic in part; micrite and biomicrite; sparse to numerous horizontal burrows and nodular interbeds of fine-grained light- to medium-brown dolomite, some burrows filled with sparry calcite in lowermost 3 inches

1347'6" 1349'11" Limestone, medium-gray; pelmicrite; moderate number to numerous horizontal burrows and nodular interbeds of fine-grained light- to medium-gray dolomite

1349'11" 1350'6" Limestone, light- to medium-gray; mottled medium- to dark-gray; micrite; minor amount biomicrite and intra pelsparite; moderate number nodular interbeds of fine-grained medium- to dark-gray dolomite

1350'6" 1351'5" Limestone, light- to medium-brown and brownish-gray; dolomitic in part; micrite, biomicrite, and biopelsparite; bioturbated in part; moderate number horizontal burrows and nodular in terbeds of fine-grained medium-brownishgray dolomite

1351'5" 1352'3" Limestone, light- to medium-brown; largely dolomitic; pelsparite (laminated in part) and intrasparite

1352'3" 1353'3" Limestone, light-gray to white; micrite; faint laminations in part; minor amount flat-pebble in trasparite; numerous small planar and nonplanar birdseyes

1353'3" 1355'8" Limestone, light- to medium-brown; laminated micrite; minor number pelsparite laminations; numerous laminations of fine-grained medium- to dark-brown dolomite; sparse to numerous very small planar and nonplanar birdseyes

1355'8" 1356'9" Limestone, light-brownish-gray; micrite; 
faintly laminated in part; sparse dolomite laminations and interbeds; sparse to moderate number small planar birdseyes; sparse small nonplanar birdseyes; slightly fossiliferous in part, including Tetradium

$1356^{\prime} 9^{\prime \prime} \quad 1359^{\prime} 0^{\prime \prime}$

Limestone, light-gray; minor amount medium-gray mottling; micrite; largely featureless; sparse nodular laminations and interbeds of fine-grained mediumgray dolomite; sparse sparry-calcitefilled vertical burrows; sparse Tetradium fragments. Tetradium biomicrite, $1 \frac{1 / 2}{2}$ inches at base

1359'0" 1372'4" Limestone, light- to medium-brown; largely dolomitic; micrite, Tetradium biomicrite, and biomicrite; numerous horizontal burrows and irregular in terbeds of fine-grained medium-brown dolomite

1372'4" 1374'8" Limestone, medium-brownish-gray; mi crite and biomicrite; bioturbated in part; slightly argillaceous; moderate number irregular to nodular interbeds of fine-grained medium- to dark-brownish-gray dolomite. Base of Carntown unit

1374'8" 1376'10" Limestone, medium- to dark-brownishgray, argillaceous; biomicrite, biopelsparite, and biointrasparite; very finely recrystallized in part; dolomitic in part; algae-coated fossil fragments in lower part. Top of lower argillaceous unit

1376'10" 1378'8" Limestone, dark-gray, very argillaceous, bioturbated; mottled light- to darkgreenish-gray; biomicrite; moderate number to numerous nodular and feathery interbeds of dark-greenish-gray and light-green shale

1378'8" 1379'8" Limestone, medium- to dark-brownishgray; minor amount dark-gray mottling; micrite; churned(?) and bioturbated(?) to pelsparite; faint laminations in pelsparite in bottom half

1379'8" 1381'10" Limestone, light-gray and light- to medium-brownish-gray; Tetradium biomicrite and micrite; sparse irregular partings and interbeds of dark-greenishgray and dark-brown shale; sparsely fossiliferous micrite, very numerous sparry-calcite-filled shrinkage cracks (randomly oriented) in uppermost 2 inches

1381'10" 1382'8" Limestone, medium-brownish-gray; moderate amount dark-gray mottling; $\mathrm{mi}$ crite; sparse sparry-calcite-filled vertical shrinkage cracks; sparse vertical burrows filled with sucrosic light-gray dolomite; moderate number wavy to nodular partings (up to $4 / 1$ inch thick) of dark-gray and dark-brown shale

1382'8" 1384'6" Limestone similar to sample from 1376 feet 10 inches to 1378 feet 8 inches; but more shale

1384'6" 1386'0" Limestone, mottled dark-brown and dark-brownish-gray; micrite; faintly laminated in part; pelletal in part; dolomitic in part; moderate number wavy to nodular partings and interbeds (up to $1 / 4$ inch thick) of dark-gray and darkbrownish-gray shale

1386'0" 1388'7" Limestone, medium-gray and mediumbrownish-gray; mottled medium-greenish-gray; biomicrite; minor amount mi crite and biointrasparite; all very argillaceous; sparse to moderate number irregular to feathery interbeds of dark-gray and dark-greenish-gray shale

1388'7" 1392'1" Limestone, medium-brownish-gray and inches medium-brown; micrite; minor number intrasparite laminations; numerous (top) to sparse (bottom) pla nar and nonplanar birdseyes; sparse laminations of fine-grained dark-brown dolomite. Limestone, mottled light- to dark-greenish-gray; micrite; numerous nonplanar birdseyes; laminated and interbedded dark-greenish-gray shale; grading into shale below; lowermost 5 inches

1394'11" 1395'41/2" Shale, medium- to dark-green and greenish-gray; nodular fragments of biomi crite

1395'41/2" 1396'2" Limestone, light-gray; micrite; sparse to moderate number sparry-calcite-filled vertical burrows

1396'2" 1398'10" Limestone, medium-brownish-gray; mottled dark-brownish-gray near base; biomicrite (Tetradium fragments) and $\mathrm{mi}$ crite; argillaceous near base

1398'10" 1400'9" Limestone, medium-greenish-gray, argilla ceous; biomicrite and micrite; nodular to feathery interbeds of dark-gray and dark-greenish-gray shale

1400'9" 1402'1" Limestone, medium-brownish-gray, bioturbated; micrite and biomicrite; burrows filled with intrasparite, pelsparite and fine-grained medium- to darkbrownish-gray dolomite. Shale, darkgreenish-gray; nodular to feathery interbeds of biomicrite, biopelsparite, and bioin trasparite; lowermost 4 inches

1402'1" 1402'8" Limestone, dolomite, and shale, light- to medium-gray and light- to mediumgreenish-gray; in terlaminated; mainly thin layers of micrite with numerous shale partings and laminations of dolomite rhombs

1402'8" 1403'8" Limestone, light-gray; moderate amount dark-gray mottling; laminated micrite; numerous small planar and nonplanar birdseyes; small mudcracks; moderate number to numerous laminations of medium-brown dolomite; grading into limestone below

1403'8" 1405'1" Limestone, light-gray and light-brownishgray; micrite; sparse to moderate number faint laminations; very small planar birdseyes; very thin mudcracks; all decreasing in number toward base

1405'1" 1407'9" Shale, light- to dark-greenish-gray, calcareous. Limestone, light- to medium-gray and greenish-gray; micrite and pelsparite; dolomitic in part. Upper one third mainly pelsparite with nodular to feathery interbeds of shale. Middle one-third mainly laminated calcareous shale. Lower one-third mainly interlaminated shale and micrite with numerous mudcracks; small planar birdseyes; dolomite rhombs; gradational with limestone below

1407'9" 1411'8" Limestone, medium-brownish-gray; mottled dark-greenish-gray; laminated mi 
crite; argillaceous in part; sparse to moderate number planar and nonplanar birdseyes, decreasing in number toward base; moderate number thin mudcracks; moderate number to numerous laminations and interbeds of dark-greenishgray shale; moderate number lamina tions of dolomite rhombs, decreasing tow ard base; gradational with limestone below

1411'8" 1412'8" Limestone, mottled medium-brownishgray and dark-brownish-gray; micrite and shale; laminated at top; nodular and contorted bedding at bottom. Sphalerite, pale-yellow; opaque crystals; at 1412 feet 4 inches. Gradational with limestone below

1412'8" 1415'7" Limestone, light- to medium-brownishgray and medium-gray; interbedded intrasparite, micrite, and laminated micrite; sparse to moderate number small planar and nonplanar birdseyes, sparse to moderate number laminations of dark-brown dolomite

1415'7" 1416'6" Limestone and dolomite, medium- to dark-brownish-gray, argillaceous. Shale dark-greenish-gray. Interlaminated $\mathrm{mi}$ crite, dolomite, and shale; gradational with shale below. Base of lower argilla ceous unit

\section{WELLS CREEK FORMATION}

1416'6" 1418'0" Shale, dark-greenish-gray, calcareous;

$1418^{\prime} 0^{\prime \prime} \quad 1421^{\prime}+$ grading in to fissile dark-green shale Dolomite, light-gray, fine-grained, porous, argillaceous; carbonaceous laminae 


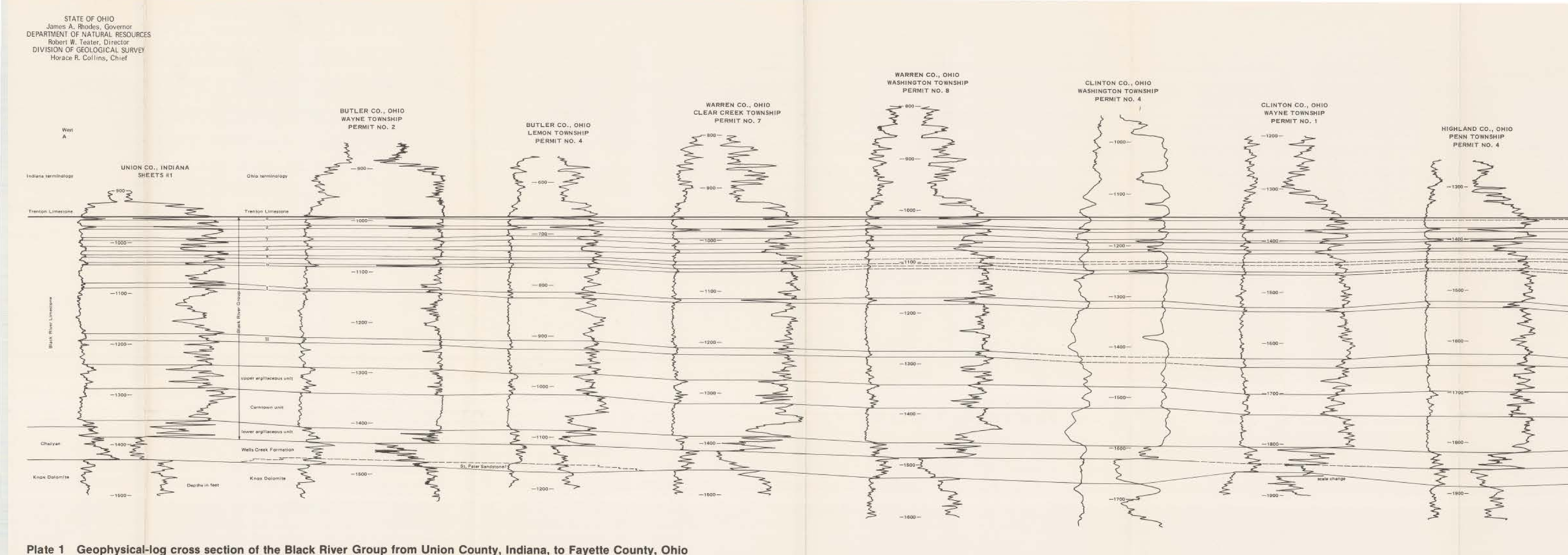


West
$B$

CAMPEELL CO. KENTUCKY
WLLON

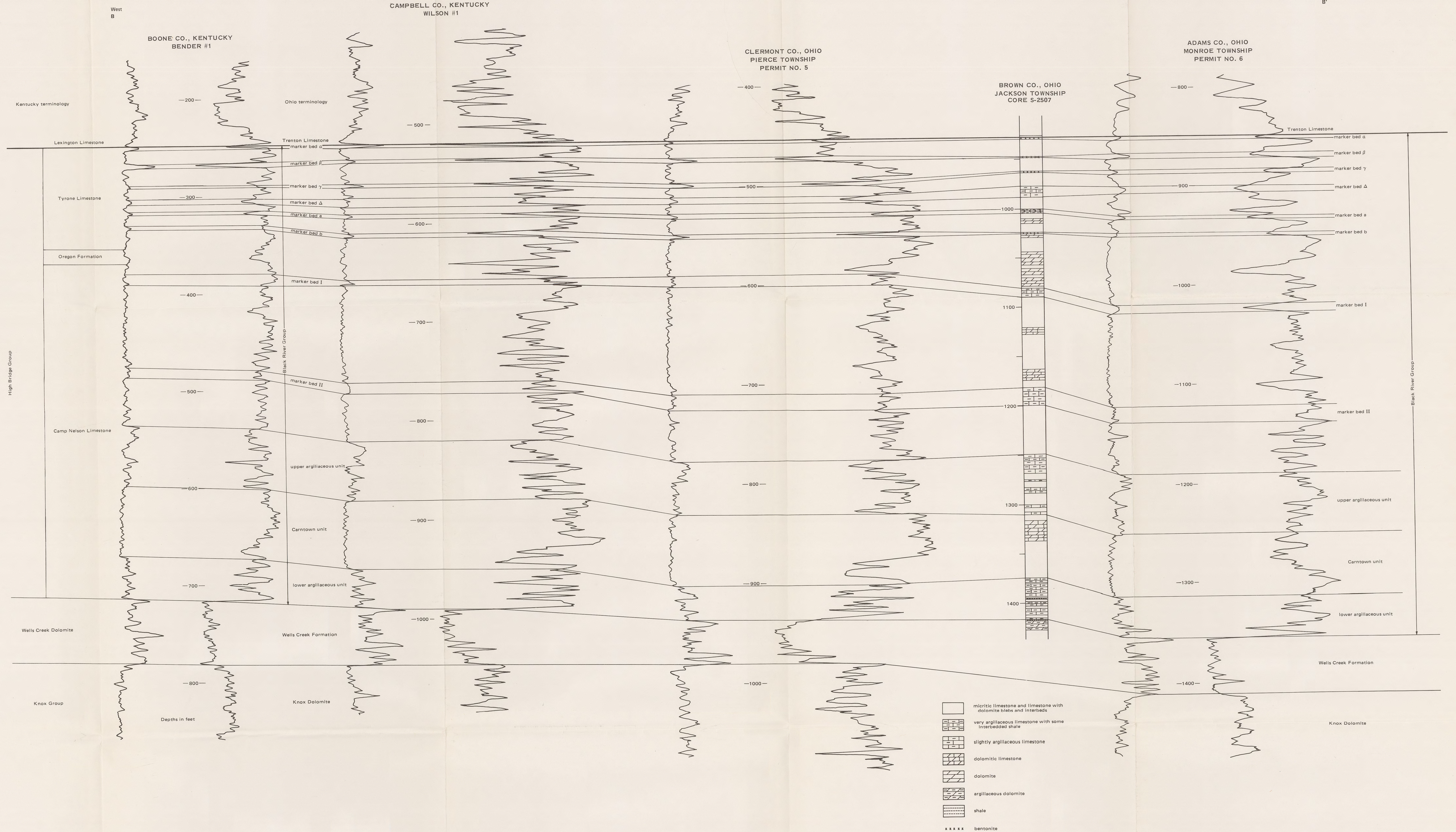


BROWN COUNTY, OHIO
JACKSON TOWNSHIP

$$
\text { S-2507 }
$$

Depth (ft) Find-marker bed $a$
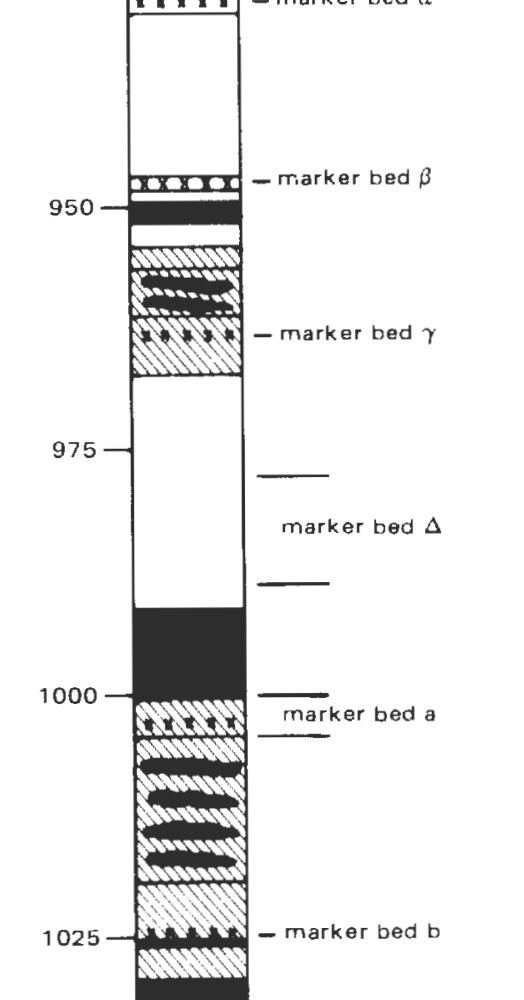

MONROE TOWN, OHIO

MONROE TOWNSHIP
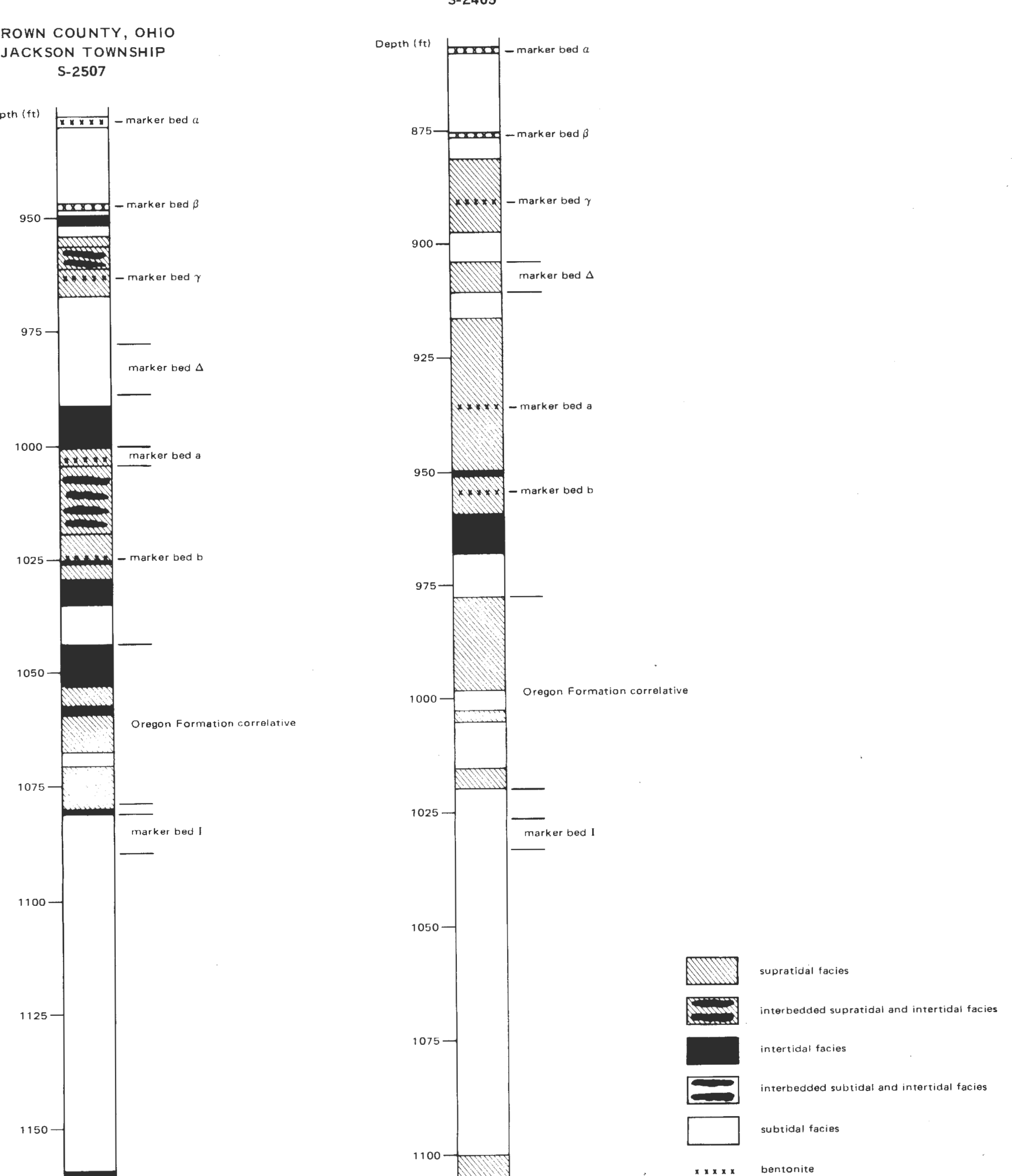

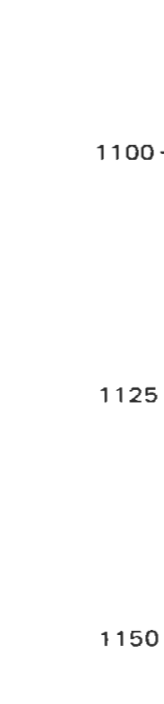
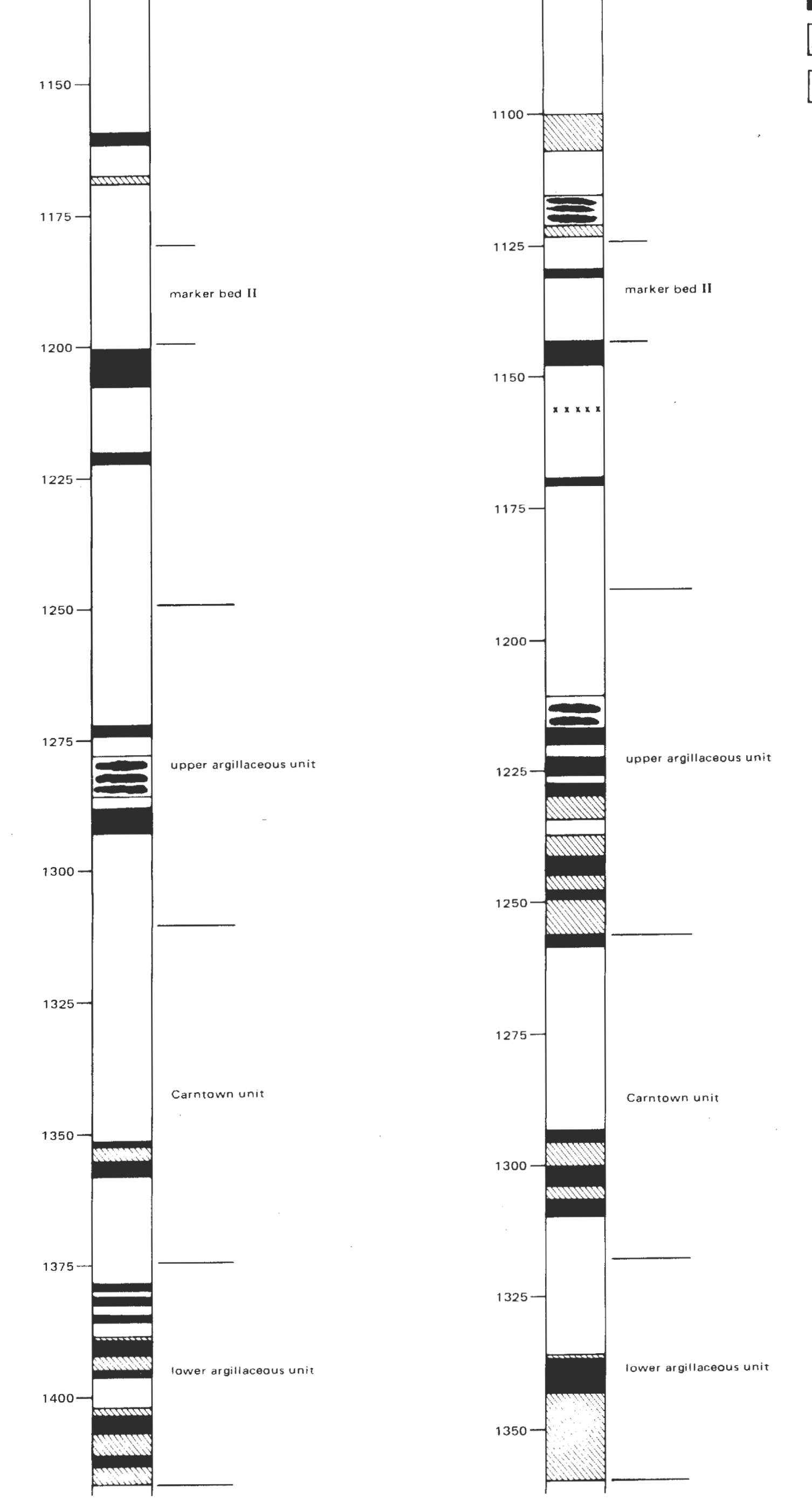

bentonite 